\title{
ANÁLISE DO ARMAZENAMENTO DE MILHO NO BRASIL COM UM MODELO DINÂMICO DE EXPECTATIVAS RACIONAIS
}

\section{VANIA DI ADDARIO GUIMARÃES}

\author{
Tese apresentada à Escola Superior de \\ Agricultura "Luiz de Queiroz", Universidade \\ de São Paulo, para obtenção do título de \\ Doutor em Ciências, Área de Concentração: \\ Economia Aplicada.
}

\section{PIRACICABA}

Estado de São Paulo - Brasil

Junho - 2001 


\title{
ANÁLISE DO ARMAZENAMENTO DE MILHO NO BRASIL COM UM MODELO DINÂMICO DE EXPECTATIVAS RACIONAIS
}

\author{
VANIA DI ADDARIO GUIMARÃES
}

Engenheiro Agrônomo

Orientador: Prof. Dr. GERALDO SANT'ANA DE CAMARGO BARROS

\author{
Tese apresentada à Escola Superior de \\ Agricultura "Luiz de Queiroz", Universidade \\ de São Paulo, para obtenção do título de \\ Doutor em Ciências, Área de Concentração: \\ Economia Aplicada.
}

PIRACICABA

Estado de São Paulo - Brasil

Junho - 2001 
Dados Internacionais de Catalogação na Publicação (CIP)

DIVISÃO DE BIBLIOTECA E DOCUMENTAÇÃO - Campus “Luiz de Queiroz"/USP

\author{
Guimarães, Vania Di Addario \\ Análise do amazenamento de milho no Brasil com um modelo dinâmico de \\ expectativas racionais / Vania Di Addario Guimarães. - - Piracicaba, 2001. \\ $136 \mathrm{p}$. \\ Tese (doutorado) - Escola Superior de Agricultura Luiz de Queiroz, 2001. \\ Bibliografia. \\ 1. Estoque 2. Milho armazenado 3. Política econômica 4. Preço agrícola 5. Produto \\ agrícola I. Título
}

CDD 338.17315 
Para

Francisco, Elisa, Leonilda, Mariana, Juliana e Luciana.

Nosso esforço conjunto

Resultou neste trabalho. 


\section{AGRADECIMENTOS}

Aos colegas do Departamento de Economia Rural e Extensão da Universidade Federal do Paraná, pelo apoio que permitiu meu afastamento para a realização do curso.

Aos professores do Departamento de Economia, Administração e Sociologia da ESALQ pelas oportunidades de aprendizado que me foram oferecidas. Aos funcionários do departamento pela cordialidade de sempre em nos atender. À Capes pelo apoio financeiro.

Ao Professor Geraldo Sant'Ana de Camargo Barros, orientador e parceiro na descoberta de novos conhecimentos, dividindo sempre o entusiasmo pelo tema desta tese. Novamente seu apoio e confiança foram fundamentais em mais um passo de minha vida profissional.

Aos amigos da pós-graduação em Economia Aplicada, agradeço por tudo que aprendi e partilhei com vocês. Aos amigos do CEPEA, pelo apoio e companheirismo.

A Francisco C. Guimarães que, além de todo o apoio como marido e amigo, contribuiu muito na finalização do trabalho. Aos amigos José Roberto Canziani e Judas Tadeu Grassi Mendes pelas muitas parcerias, estímulo e amizade. A todos os que contribuíram direta ou indiretamente, deixo registrada minha gratidão. 


\section{SUMÁRIO}

Página

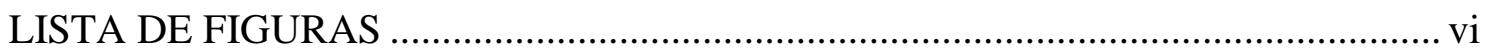

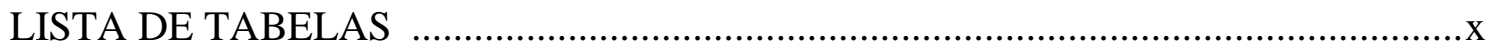

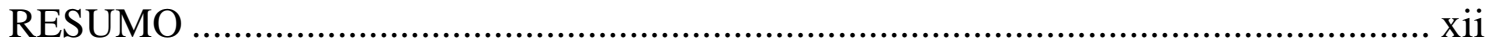

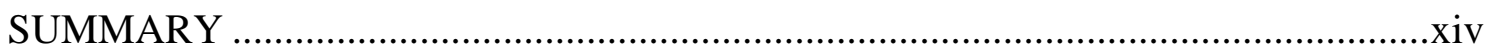

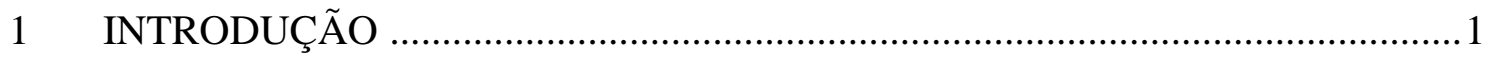

2 POLÍTICA DE GARANTIA DE PREÇOS MÍNIMOS

NO BRASIL E O MERCADO DE MILHO .................................................. 14

2.1 A Política de Garantia de Preços Mínimos ....................................................... 14

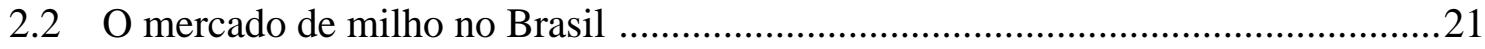

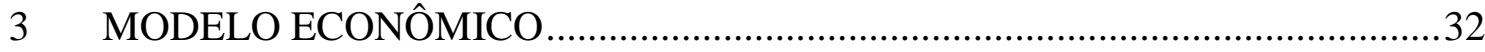

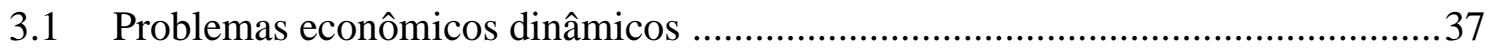

3.2 Armazenamento como problema de controle .............................................. 41

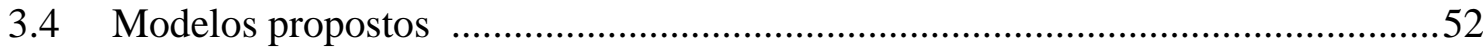

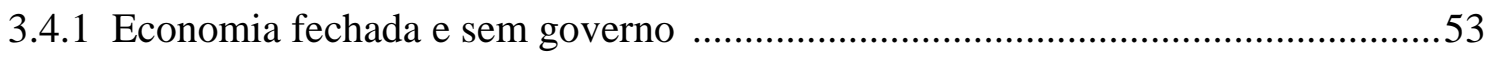

3.4.2 Economia fechada e intervenção via PEP .....................................................57

3.4.3 Economia aberta e sem intervenção .............................................................59

3.4.4 Economia aberta e intervenção via PEP .........................................................62

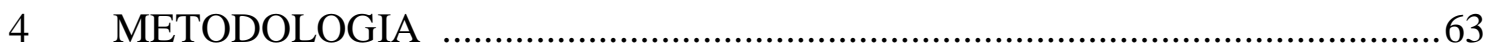

4.1 Programação dinâmica estocástica .....................................................................65

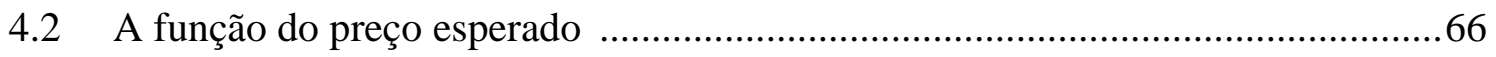

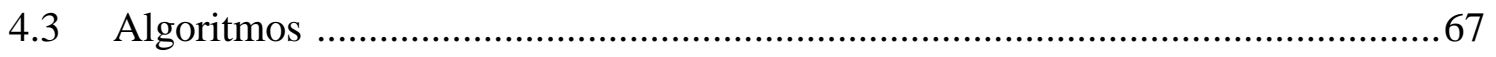

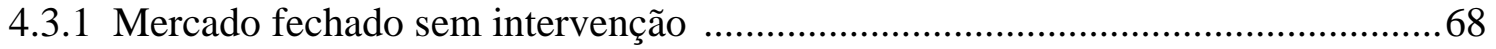

4.3.2 Mercado fechado com intervenção ............................................................... 70 


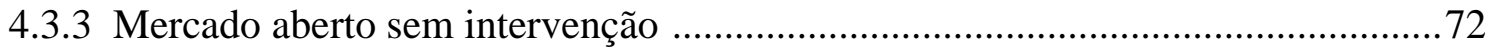

4.3.4 Mercado aberto com intervenção …........................................................ 75

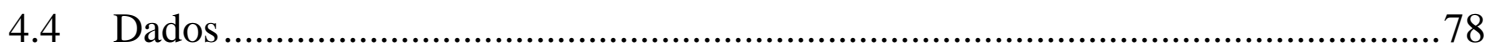

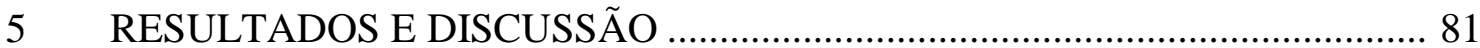

5.1 A política ótima de estoques e as funções de preço esperado

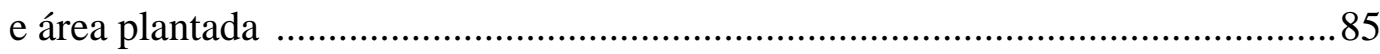

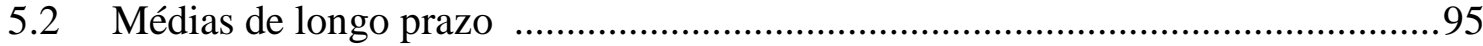

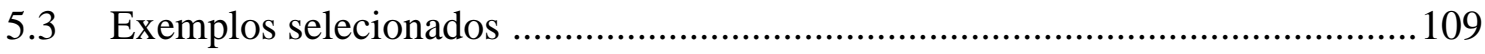

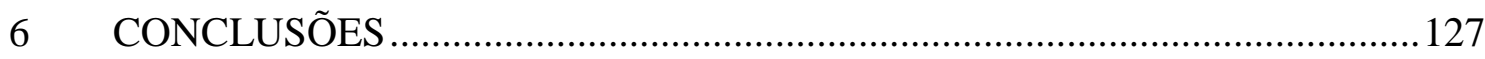

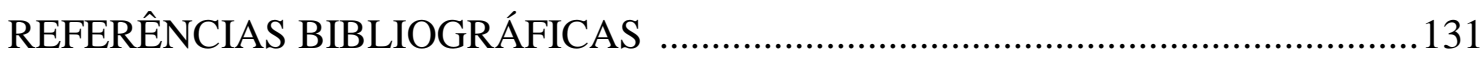




\section{LISTA DE FIGURAS}

Página

1 Fluxograma do Prêmio para Escoamento de Produto (PEP) 18

2 Área plantada com milho no Brasil na safra normal e área total (normal e safrinha), safras 82/83 a 99/00 .26

3 Canais de comercialização do milho .29

4 Equilíbrio de mercado com e sem armazenamento 36

5 Equilíbrio para o modelo de mercado fechado e sem intervenção 57

6 Equilíbrio para o modelo de mercado aberto e sem intervenção 61

7 Disponibilidade inicial e estoque de milho, em milhões de toneladas economia fechada e sem intervenção do governo .86

8 Preço esperado em função do estoque, economia fechada sem PEP 87

9 Área plantada em função do estoque, economia fechada sem PEP 87

10 Disponibilidade inicial e estoque de milho, em milhões de toneladas economia fechada e intervenção via PEP 
11 Preço esperado em função do estoque, economia fechada com PEP

12 Área plantada em função do estoque, economia fechada com PEP 89

13 Disponibilidade inicial e estoque de milho, em milhões de toneladas economia aberta e sem intervenção do governo .91

14 Preço esperado em função do estoque, economia aberta sem PEP 92

15 Área plantada em função do estoque, economia aberta sem PEP 92

16 Disponibilidade inicial e estoque de milho, em milhões de toneladas economia aberta com PEP 93

17 Preço esperado em função do estoque, economia aberta com PEP 94

18 Área plantada em função do estoque, economia aberta com PEP 94

19 Gastos do governo com PEP para o modelo de economia fechada com intervenção

20 Gastos do governo com PEP para o modelo de economia aberta com intervenção

21 Índice da disponibilidade total média de longo prazo de milho $\left(S_{t}\right)$, para os modelos de economia fechada sem intervenção e aberta com intervenção via PEP. 104 
22 Índice do consumo médio de longo prazo de milho $\left(D_{t}\right)$, para os modelos de economia fechada sem intervenção e aberta com intervenção via PEP

23 Índice do estoque médio de longo prazo de milho $\left(I_{t}\right)$, para os modelos de economia fechada sem intervenção e aberta com intervenção via PEP

24 Índice do preço médio de longo prazo de milho $\left(P_{t}\right)$, para os modelos de economia fechada sem intervenção e aberta com intervenção via PEP

25 Índice do preço médio de longo prazo de milho $\left(P_{t}\right)$, para os modelos de economia fechada sem intervenção e aberta com intervenção via PEP 108

26 Índice do preço médio de longo prazo ao produtor de milho $\left(\mathrm{P} P_{t}\right)$, para os modelos de economia fechada sem intervenção e aberta com intervenção via PEP.

27 Índice da disponibilidade anual de milho $\left(S_{t}\right)$, para os modelos de economia fechada sem intervenção e aberta com intervenção via PEP, sequiência 1

28 Índice do consumo anual de milho $\left(D_{t}\right)$, para os modelos de economia fechada sem intervenção e aberta com intervenção via PEP, sequiência 1

29 Índice do preço anual de milho $\left(P_{t}\right)$, para os modelos de economia fechada sem intervenção e aberta com intervenção via PEP, sequiência 1

30 Índice do preço anual esperado de milho $\left(E_{t} P_{t+1}\right)$, para os modelos de economia fechada sem intervenção e aberta com intervenção via PEP, seqüência 1 
31 Índice da disponibilidade total de milho $\left(S_{t}\right)$, para os modelos de economia fechada sem intervenção e aberta com intervenção via PEP, sequiência 2

32 Índice do preço anual de milho $\left(P_{t}\right)$, para os modelos de economia fechada sem intervenção e aberta com intervenção via PEP, sequiência 2 .............125 


\section{LISTA DE TABELAS}

Página

1 Produção e capacidade estática instalada de armazenamento, Brasil, por região, 1998/99

2 Produção, consumo aparente, importações, volume de milho atrelado a AGF, EGF, PEP e Contratos de Opção de milho, 1980/2001

3 Área plantada e produção de milho de primeira safra, média dos últimos 5 anos e safra 00/01, Brasil 24

4 Área plantada e produção de milho de segunda safra, média dos últimos 5 anos, Brasil 25

5 Dados e parâmetros do modelos 81

6 Médias de longo prazo das variáveis endógenas, para o modelo de economia fechada sem intervenção 96

7 Médias de longo prazo das variáveis endógenas, para o modelo de economia fechada com intervenção através de PEP. 98

8 Médias de longo prazo das variáveis endógenas, para o modelo de economia aberta sem intervenção .100 
9 Médias de longo prazo das variáveis endógenas, para o modelo de economia aberta com intervenção através de PEP

10 Choques de demanda e produtividades para duas simulações 110

11 Valores das variáveis endógenas, em mil toneladas, para o modelo de economia fechada sem intervenção, para a sequência 1

12 Valores das variáveis endógenas, em mil toneladas, para o modelo de economia fechada com intervenção, para a sequência 1

13 Valores das variáveis endógenas, em mil toneladas, para o modelo de economia aberta sem intervenção, para a seqüência 1

14 Valores das variáveis endógenas, em mil toneladas, para o modelo de economia aberta com intervenção através de PEP, para a seqüência 1 115

15 Valores das variáveis endógenas, em mil toneladas, para o modelo de economia fechada sem intervenção, para a seqüência 2 120

16 Valores das variáveis endógenas, em mil toneladas, para o modelo de economia fechada com intervenção através de PEP, para a seqüência 2

17 Valores das variáveis endógenas, em mil toneladas, para o modelo de economia aberta sem intervenção, para a seqüência 2

18 Valores das variáveis endógenas, em mil toneladas, para o modelo de economia aberta com intervenção através de PEP, para a seqüência 2 


\title{
ANÁLISE DO ARMAZENAMENTO DE MILHO NO BRASIL COM UM MODELO DINÂMICO DE EXPECTATIVAS RACIONAIS
}

\author{
Autora:VANIA DI ADDARIO GUIMARÃES \\ Orientador: Prof. GERALDO SANT'ANA DE CAMARGO BARROS
}

\section{RESUMO}

O objetivo deste trabalho foi analisar o mercado de milho no Brasil, sob a nova política de preços agrícolas, especificamente através do mecanismo de Prêmio para Escoamento de Produto (PEP) adotada na segunda metade da década de 90. Foram desenvolvidos modelos para representar o mercado brasileiro já que a literatura voltada para estes estudos não continha nenhum modelo adequado à situação brasileira. Os modelos destacam o papel dos estoques entre anos safra sobre o equilíbrio do mercado considerando ainda a possibilidade de importar e exportar. Foram estimadas funções de demanda para consumo e oferta de área plantada para milho no Brasil, obtidos os valores médios históricos, para o período de 1986 a 2000, do custo de armazenamento físico por tonelada, do preço médio do milho no mercado internacional representado pela Bolsa de Chicago, do custo médio de importação/exportação do produto tendo como referência uma distância média de $300 \mathrm{Km}$ até o porto. A taxa de juros utilizada foi de 12\% ao ano. Estas funções e parâmetros serviram de base para a estimação dos modelos dinâmicos de expectativas racionais, através de programação dinâmica estocástica e aproximações das funções de preço esperado e área plantada através de polinômios. Foram também 
desenvolvidos os algoritmos para a estimação dos modelos e todos os cálculos realizados em planilha eletrônica. Foram construídos quatro modelos para o mercado de milho partindo de uma situação de mercado fechado ao comércio exterior sem intervenção do governo; mercado fechado com intervenção através de PEP; mercado aberto ao comércio exterior sem intervenção do governo e mercado aberto com intervenção. Este último modelo representa o mercado de milho no Brasil no final da década de 90. Foram obtidas as políticas ótimas de armazenamento para os quatro modelos e então, realizadas 2500 simulações para uma seqüência de 10 anos para cada modelo. Duas variáveis exógenas aleatórias do modelo são os choques de oferta (produtividade aleatória) e de demanda. O preço de equilíbrio, o volume consumido, o estoque de um ano para o outro e os volumes exportados ou importados são variáveis endógenas, ou seja, resultados da estimação do modelo. A partir dos valores simulados foram calculadas as médias de longo prazo para as variáveis endógenas em cada modelo que foram, então, comparadas entre si. Os resultados mostram que a abertura do mercado transfere para o comércio exterior o papel de amortecedor de choques de oferta e demanda internos que, no caso de mercados fechados, é desempenhado pelos estoques de produtos entre anos safra. Os resultados sugerem que, dependendo dos valores relativos entre o preço mínimo e o preço de paridade de exportação, a política de subsídio pode levar o país à condição de exportador. 


\title{
DINAMYC RATIONAL EXPECTATION STORAGE MODELS APPLIED TO BRAZILIAN CORN MARKET
}

\author{
Author:VANIA DI ADDARIO GUIMARÃES \\ Adviser: Prof. GERALDO SANT'ANA DE CAMARGO BARROS
}

\section{SUMMARY}

Dynamic rational expectation storage models were developed to represent the Brazilian corn market in the late 90's. In theses years the Brazilian agricultural price policy changed from a buffer stock scheme to a producer price subsidy (Prêmio para Escoamento de Produto - PEP) and the Brazilian market was open to international trade. Any model in the existing literature was not able to represent the Brazilian corn market conditions. Acreage supply and consumption demand functions for corn the were estimated, as well as average values from 1986 to 2000 of annual storage cost, export and import prices, based on Chicago Board of Trade quotes. The annual interest rate was $12 \%$. These functions and parameters were used to estimate the dynamic rational expectation models, through stochastic dynamic programming. The expected price and planted area functions were approximated by a fourth degree polynomial. The necessary algorithms were developed and results obtained using worksheets. Four models were estimated beginning with the situation of closed economy with no government intervention; closed economy with intervention through a producer price subsidy; open economy with no government intervention and open economy with intervention through 
a producer price subsidy. The optimal storage policies or storage rules for each model were obtained and used to generate 2.500 simulations of a 10 years path for each model. In these models, equilibrium price, consumption, storage and imports/exports are endogenous variables. Stochastic yields and demand shocks are exogenous variables. The long run means of the endogenous variables were calculated from the simulations and compared among models. The results show that with open markets, exports and imports play the role of shocks absorbers, played by storage in closed economies. Results suggest that the producer price subsidy policy may lead the country to be an exporter, depending on the relative values between minimum price and export price at the cost of ever increasing government expenditures. 


\section{INTRODUÇÃO}

Até meados dos anos 90 a política de preços agrícolas no Brasil consistia na formação de estoques reguladores por parte do governo, retirando o excesso de oferta em anos abundantes e ofertando seus estoques em anos de escassez. O principal formador de estoques entre anos safra era o governo. Com a abertura do mercado brasileiro ao comércio internacional nos anos 90 a política de preços agrícolas mudou para um sistema de subsídio de preço ao produtor sem que o governo forme estoques. Quais as implicações desta nova política num ambiente de mercado aberto para os mercados de produtos agrícolas é uma questão não respondida.

Nos anos 40 e mais especialmente a partir dos anos 60, o tema predominante na literatura envolvendo estoques de produtos agrícolas foi analisar o impacto do armazenamento sobre o bem estar de produtores e consumidores levando em conta a introdução de políticas de estabilização de preços (total ou parcial) através da formação de grandes estoques por parte do governo. Esta análise é feita comparando o desempenho do mercado quando não há possibilidade de armazenar com a situação em que o armazenamento é feito pelo governo através de políticas de estabilização de preços ou outra variável. Em todos estes estudos, o armazenamento privado é totalmente ignorado e todos consideram economia fechada. Os trabalhos fundamentais nesta linha são os de Waugh (1944), Oi (1961) e Massel (1969) que, de forma geral, mostraram que políticas de estabilização de preços (ou outra variável endógena do mercado) tendem a prejudicar os consumidores se objetivarem estabilizar os preços na sua média ou acima dela. Outro exemplo desta linha de pesquisa pode ser encontrado em Reutlinger (1976). 
Turnovsky (1974) destaca que os trabalhos até então haviam se preocupado com a variabilidade dos preços e não com a questão da incerteza. Seu modelo de armazenamento é um sistema recursivo levando em conta pela primeira vez que a tomada de decisão dos produtores por ocasião do plantio é realizada num momento em que os preços que vão vigorar não são ainda conhecidos, corrigindo ao menos esta falha contida em estudos anteriores. Outras limitações permanecem.

Em 1977 Helmberger \& Weaver desenvolveram um modelo de armazenamento de um produto agrícola com produção sazonal levando em conta tanto o armazenamento privado quanto público, através de políticas de estabilização de preços. A decisão econômica da iniciativa privada de armazenar se dá através da possibilidade de arbitragem temporal, onde estoques serão formados desde que o preço esperado, a valor presente, para o próximo período iguale o preço corrente mais o custo de armazenamento. Estes autores, assim como outros da década de 70, passaram a tratar a expectativa de preço contida na arbitragem temporal sob o enfoque de expectativas racionais, levando em conta o trabalho pioneiro de Muth (1961).

Neste ponto é importante ressaltar alguns aspectos relativos à condição de arbitragem temporal e ao efeito da formação de estoques sobre o Bem Estar. A arbitragem temporal tem implicações que só foram percebidas ao longo do tempo e não foram consideradas em toda a literatura das décadas de 40 a 70 . A primeira delas é que existe uma descontinuidade fundamental na formação de estoques proveniente do fato de que é possível armazenar para o futuro, mas não é possível emprestar estoques do futuro. Em outras palavras, o estoque não pode ser negativo o que implica que a atividade econômica de armazenar não seja realizada em um determinado ano.

Outro ponto muito importante é que se há formação de estoque num determinado período em ambiente competitivo e dada uma taxa de juros r, o preço esperado para o período $\mathrm{t}+1$ é $(1+r)$ vezes o preço atual $\left(P_{\mathrm{t}}\right)$ mais o custo de estocagem. Mas isto não significa que o preço esperado no período $\mathrm{t}+2$ seja $(1+r)$ vezes $\mathrm{E} P_{\mathrm{t}+1}$ pois 
existe a possibilidade de que o estoque no período $t+1$ seja zero. Esta segunda implicação está erroneamente contida no modelo de Helmberger \& Weaver que tinha sido até então o modelo mais abrangente e adequado à análise da questão de armazenamento.

Outra limitação importante do modelo de Helmberger \& Weaver e de todos os trabalhos anteriores e diversos posteriores é que, apesar de assumirem que os agentes do mercado formavam expectativas racionais no sentido de Muth, o preço esperado não era estimado como expectativa racional. Ou seja, o preço esperado era exógeno ao modelo e não influenciável por mudanças na política de sustentação de preços do governo o que torna o estudo sujeito à crítica de Lucas (Miranda \& Glauber, 1993). Outros exemplos com a mesma limitação são Reutlinger (1796) e Cochrane \& Danin (1976).

Além disso, a formação de estoques não afeta apenas o equilíbrio no ano em que são formados, mas também o(s) do(s) ano(s) seguinte(s). A partir deste ano $t$, duas coisas acontecem. Primeiro a demanda pela nova produção no período seguinte será reduzida pelo montante equivalente do estoque realizado no período anterior. Segundo que a produção planejada muda de acordo com a nova posição da demanda (para consumo e estoque).

O efeito da introdução do armazenamento sobre o equilíbrio do mercado e o Bem Estar de produtores e consumidores é dinâmico, como será analisado no capítulo 3. O enfoque teórico da análise do efeito do armazenamento (e de quaisquer políticas adotadas para o mercado) deve levar em conta o efeito em diversos anos e não apenas em um só. Em outras palavras, a análise estática comparativa não é o arcabouço teórico apropriado para a análise do armazenamento de produtos agrícolas e sim, a Teoria do Controle. 
Um problema é realmente dinâmico, quando uma decisão tomada num momento qualquer, tem influência sobre outra decisão a ser tomada no futuro, ou que a decisão atual implica em externalidade sobre a(s) decisão(ões) futura(s). Portanto, um problema dinâmico envolve um conjunto de decisões interligadas, ao longo do tempo. Esta é a característica principal que torna um problema de armazenamento um problema dinâmico dado que a decisão de formar ou não estoques para um período futuro afeta os preços, o consumo presente e futuro e as decisões atual e futura. Até início dos anos 80, o armazenamento foi analisado através da estática comparativa, nos estudos citados e numa ampla gama de artigos na área, tais como Newbery \& Stiglitz (1979). Uma revisão bibliográfica abrangente pode ser encontrada em Wright \& Williams (1991).

Foi durante a década de 80 que se buscou solução para as limitações até então encontradas nos modelos teóricos de armazenamento. Wright \& Williams (1982) resgataram o brilhante trabalho de Gustafson (1958) que analisa a economia do armazenamento como um problema econômico dinâmico. Ao enfoque de Gustafson os autores incluíram pela primeira vez a oferta elástica de produtos agrícolas e não perfeitamente inelástica, que era uma condição necessária para se utilizar o modelo de Gustafson. Neste modelo, tanto a produção quanto o armazenamento passam a responder racionalmente a incentivos econômicos. Assim, as decisões de produzir e armazenar são tomadas por agentes que procuram maximizar o lucro num ambiente competitivo e todos formam expectativas racionais, no sentido de Muth (1961), sobre o retorno esperado de suas atividades.

O objetivo do estudo de Wright \& Williams (1982) era analisar o efeito da possibilidade de armazenamento sobre produtores e consumidores e os autores demonstram que este efeito está fortemente ligado à inclinação da curva de demanda e à elasticidade de oferta do produto, já que o armazenamento afeta, de forma assimétrica, os preços e o consumo. Este artigo tem cunho teórico e não foi aplicado a um mercado específico. Uma aplicação do modelo desenvolvido em 1982 é encontrada num trabalho posterior (Wright \& Williams, 1984). Os modelos de Wright \& Williams consideram 
apenas o armazenamento privado e economia fechada.

Todos os estudos até meados da década de 80 se dedicaram à análise do estoque final do ano safra. Lowry et al. (1987) desenvolvem um modelo trimestral que analisa o papel da estocagem dentro do ano e entre anos num mercado livre e com exportação. Os autores destacam o fato de que, nos casos de diversos produtos agrícolas, especialmente os grãos, a demanda por armazenamento tem papel fundamental no período de safra e é a principal fonte de oferta durante a entressafra, um fato que os modelos anuais não conseguem captar. Destacam ainda que nos modelos anuais pressupõe-se que na época do plantio os produtores tomam decisões como se já conhecessem as condições de demanda para todo o ano agrícola seguinte e soubessem o estoque final do ano safra no qual estão plantando. Neste modelo, que considera apenas o armazenamento privado, o volume consumido, exportado e armazenado assim como o preço corrente e o preço esperado para o futuro nos quatro trimestres do ano safra são variáveis endógenas.

O modelo de Lowry et al. envolve uma função de oferta de área plantada e não de produção planejada considerando que a variável de decisão dos produtores é a área que pretendem plantar e não a produção que dependerá do clima. Neste modelo a produtividade é estocástica e outros termos estocásticos aparecem nas equações da oferta de área plantada e na demanda. O preço esperado se torna uma variável endógena enquanto os parâmetros do modelo são estimados econometricamente. São analisados os efeitos sobre o bem estar (através de mudanças no excedente do produtor e do consumidor) de diferentes custos de armazenamento.

O estoque dentro do ano agrícola tem efeito sobre os preços nos diversos períodos do ano mas o estoque final do ano safra afeta não apenas os preços no ano em que são formados mas, também, no ano seguinte. O interesse do presente estudo está na influência dos estoques entre anos e não intra-anos. 
Miranda \& Helmberger (1988) analisam os efeitos dos programas de estabilização de preços de produtos agrícolas nos quais o governo age comprando produto em períodos de oferta abundante e vendendo em períodos de escassez, ou seja, uma política de estoques reguladores semelhante, em tese, à que vigorou no Brasil. Neste modelo, com economia fechada, o objetivo do governo é manter os preços entre um valor mínimo (suporte) e um valor máximo. Este modelo segue a linha desenhada no artigo de 1987 onde ambos foram co-autores e também se aplica ao mercado da soja nos Estados Unidos. A mudança aqui é que o modelo volta a ser anual e o destaque está por conta da intervenção governamental no mercado.

O modelo, de expectativas racionais, mantém as características de que a produtividade é incerta, a área plantada responde aos preços futuros esperados assim como o armazenamento privado, o qual é realizado por agentes que procuram maximizar lucro num ambiente competitivo (arbitragem). A vantagem deste modelo é tornar as decisões privadas relativas à produção e ao armazenamento influenciadas pelas mudanças na política do governo (de estoques reguladores). O modelo é utilizado para analisar a resposta do sistema a diferentes valores para o preço de suporte e de liberação de estoques, através de simulações estocásticas. O modelo também é utilizado para medir os efeitos da política de estoques reguladores do governo sobre o bem estar de produtores e consumidores.

Em 1993, Miranda \& Glauber argumentaram que os modelos de expectativas racionais lineares, utilizados até então na literatura voltada para o tema, são incapazes de compreender de forma correta o processo de armazenamento, o qual tem papel fundamental no mercado de produtos agrícolas armazenáveis. A linearidade a que eles se referem é a que está contida na regra econômica do armazenamento apresentada em (3) onde os preços futuro esperado e atual diferem por um determinado custo de armazenagem. Até então todos os estudos consideravam o custo unitário de armazenamento como constante e não levaram em consideração o fato de que, mesmo 
em períodos de escassez de produto existem estoques, ou seja, o estoque na realidade nunca é zero.

Working (1948) observou que estoques eram formados (pela iniciativa privada) mesmo quando a diferença entre o preço atual e o esperado, usando o mercado futuro como estimativa do preço esperado, era negativa. Brennan (1958) define o custo de armazenar como uma variável composta de outras três variáveis: o custo físico da armazenagem $(k)$, um prêmio pelo risco contido na atividade $(r)$ e inclui o que Kaldor (1939) havia definido como produtividade da conveniência $(c)$. Este último termo representa o valor que as empresas que atuam no mercado de um produto agrícola qualquer, dão ao benefício de possuir um nível mínimo de estoques mesmo quando a expectativa é de que os preços no futuro não sejam suficientes para remunerar estes estoques. É esta função de custo não linear que está incluída no modelo de Miranda \& Glauber (1993).

Segundo os autores, o modelo linear é incapaz de captar os desequilíbrios não lineares causados por compras e vendas maciças do governo através de sua política de estoques reguladores. Os autores apresentam então um modelo similar ao de 1988 mas onde o equilíbrio de expectativa racional é estimado e não parametrizado. É este o modelo desenvolvido ao longo de quase 5 décadas que tem recebido maior aceitação teórica combinando métodos computacionais (numéricos) para encontrar o equilíbrio de expectativa racional do mercado.

Gardner \& López (1996) é outro exemplo de modelo de armazenamento numa economia fechada. O objetivo do estudo foi analisar a possibilidade de estabilização de preços, através de subsídio à taxa de juros para estocagem de grãos nos Estados Unidos.

Makki et al. (1996) ampliam o modelo de Miranda \& Glauber (1993) para uma economia aberta, se aproximando ainda mais da situação real de mercado para 
diversos produtos. $\mathrm{O}$ modelo, representando o mercado de trigo, é composto por dois exportadores (Estados Unidos e União Européia) e o Resto do Mundo como importador e é usado para analisar o efeito da redução no subsídio à exportação existente nas duas regiões exportadoras. Este modelo não inclui política de sustentação de preços internos mas considera a política de subsídio à exportação.

Lance \& Hayes (2000) formularam um modelo complexo e interessante para avaliar a mudança na política agrícola americana (FAIR Act) na década de 90. Os autores elaboram um modelo para as três principais commodities americanas: soja, milho e trigo e procuram analisar os efeitos sobre a área plantada, produção e estoques dos três produtos com a mudança na política comparando a situação pré e pós-mudança. Este modelo é o que mais se assemelha à situação brasileira atual mas com diferença significativa. A semelhança é que a política americana também contém subsídio de preço ao produtor mas, com a diferença de que o governo americano controla a área plantada. A análise dos autores considera a economia fechada.

Nenhum dos modelos desenvolvidos até o momento contém todos os elementos necessários para representar a situação brasileira para o mercado de milho na década de 90. Isto ocorre por dois motivos principais: a) o mercado brasileiro de milho não é fechado mas o país toma a posição de importador ou exportador dependendo dos preços relativos e, b) nesta década os instrumentos tradicionais da Política de Garantia de Preços Mínimos foram alterados. As operações de aquisição de estoques pelo governo hoje são mínimas e os instrumentos de Prêmio para Escoamento de Produto (PEP) e Contratos de Opção de Venda agem no sentido de assegurar um preço mínimo aos produtores garantindo o preço de equilíbrio de mercado aos compradores.

Como pode se observar, a maior parte dos estudos que incluem o governo, o fazem através de uma política de estoques reguladores. Durante os anos 60, 70 e 80, esta era a política mais utilizada pelos países produtores de grãos. Nos anos 60, os Estados Unidos, por exemplo, chegaram a possuir estoques equivalentes a metade da 
sua produção de milho e uma safra inteira de trigo (Estados Unidos, 2000). A política brasileira seguiu, em parte, a mesma linha até meados dos anos 90. O principal instrumento de intervenção governamental nos mercados agrícolas brasileiros é a Política de Garantia de Preços Mínimos - PGPM - que foi criada para, como o próprio nome indica, dar sustentação aos preços ao produtor nos períodos de maior oferta. A PGPM foi desenhada como uma política de estoques reguladores sujeita a uma série de fatores que podem levar ao insucesso da política. Entre estes fatores, estão, a falta de recursos para adquirir a quantidade necessária de produto para estabilizar os preços no patamar desejado, a dificuldade em realizar as compras no tempo necessário, a própria determinação do preço mínimo que deve vigorar em cada safra para cada produto e cada região do país (Barros \& Guimarães, 1998).

Até meados da década de 90, os instrumentos da Política de Garantia de Preços Mínimos foram as Aquisições do Governo Federal (AGF) e os Empréstimos do Governo Federal (EGF). Com a crescente exaustão de recursos da União, tais instrumentos foram sendo substituídos. A estabilização de preços através de estoques reguladores vem sendo substituída pela política de subsídio ao estoque privado. A linha mestra dos novos instrumentos é sustentar preços sem que o governo tenha de adquirir a produção. O quanto esta mudança contribuiu para a maior eficácia da política é ainda uma questão a ser respondida.

As mudanças no Brasil acompanham a tendência de outros países que enfrentaram problemas semelhantes. Townsend (1997), citado em Gardner (1979) e Wright \& Williams (1984), já havia provado que uma política de estabilização de preços através de estoques reguladores é incapaz de estabilizar preços. $\mathrm{O}$ autor prova que os estoques serão esgotados e incapazes de conter a alta nos preços após uma seqüência de frustrações de safra - a probabilidade disto ocorrer é igual a um.

Além disso, Wright \& Williams (1991) analisam políticas diferentes e concluem que a formação de estoques reguladores pelo governo gera o pior efeito sobre 
o Bem Estar de produtores e consumidores. A análise desta política exige admitir que, uma vez adotada esta política, o governo comprará toda a quantidade que quiserem lhe vender (ao preço mínimo), ou seja, o modelo considera a execução perfeita da política por parte do governo. Barros \& Guimarães (1998) comprovaram que isto não aconteceu no Brasil com falhas freqüentes em manter o preço de mercado acima do mínimo. A abertura de mercado dificulta a adoção da política de estoques reguladores pois o preço máximo será dado pela paridade de importação e o preço mínimo pela paridade de exportação. Manter preço mínimo formando estoques com mercado aberto leva ao risco de o país subsidiar não apenas o produtor nacional mas o produtor dos países exportadores. Uma situação muito próxima desta ocorreu no Brasil para o arroz na safra 98/99 quando o preço mínimo ficou acima da paridade de importação com os demais países do Mercosul. O aumento da produção nacional foi acompanhado por aumento das importações fazendo dobrar o estoque final da safra.

A Tabela 1 apresenta a capacidade instalada de armazenamento no Brasil para o ano de 1996 quando a Companhia Nacional de Abastecimento (CONAB) realizou um cadastramento nacional de armazéns. O objetivo da tabela é destacar que o Brasil não apresenta problemas graves de déficit de armazenagem e estoques finais de safra podem ser formados. Os problemas nesta área atualmente são maiores nas regiões norte e nordeste do país onde os investimentos públicos e privados ainda não foram suficientes para atender as necessidades da região.

Todos os anos, a decisão de quanto armazenar é um problema tanto para produtores quanto para os segmentos consumidores de produtos agrícolas. Pressupondo que não há mais deficiência relevante na capacidade de armazenamento, a decisão econômica de quanto armazenar dentro do ano safra e entre anos-safra permanece um problema econômico a ser encarado pelos agentes do mercado. Um dos diversos componentes desta decisão é a atuação do governo no mercado do produto através de algum tipo de política, em geral, de sustentação de preços ao produtor acima de um determinado patamar, no Brasil denominado de Preço Mínimo. Como e quando o 
governo vai agir interfere nas decisões da iniciativa privada e esta ação deve ser levada em conta nas tomadas de decisão.

Tabela 1. Produção e capacidade estática instalada de armazenamento, Brasil, por região, 1998/99.

Em mil toneladas

\begin{tabular}{l|c|c|c}
\hline Região & Produção $^{1}$ & Capacidade instalada $^{2}$ & Capacidade/produção \% $^{\text {Norte }}$ \\
Nordeste & 2.376 & 1.692 & 71,2 \\
Centro-Oeste & 22.474 & 4.811 & 73,6 \\
Sudeste & 12.125 & 25.851 & 115,0 \\
Sul & 37.042 & 16.014 & 132,1 \\
\hline Brasil & 80.556 & 40.389 & 109,0 \\
\hline
\end{tabular}

Fonte: Brasil (1996)

${ }^{1}$ Produção de milho, soja, arroz, feijão, algodão e trigo na safra 98/99

${ }^{2}$ Capacidade total de armazéns convencionais, silos e graneis em 1996

A possibilidade de importar ou exportar e, portanto, a influência do mercado externo, se tornou mais um elemento a ser levado em consideração pelos agentes econômicos quando decidem os níveis de estoque que pretendem formar em determinado ano safra. A decisão de armazenar depende da expectativa que os agentes econômicos possuem sobre os preços futuros do produto e dos custos do armazenamento. Se há intervenção governamental nesta economia, as ações do governo também terão influência tanto sobre as expectativas dos agentes econômicos quanto nos resultados finais. Se esta economia for aberta, a possibilidade de exportar e/ou importar passa a ser outro elemento na tomada de decisão por parte dos agentes envolvidos na comercialização do produto.

Para representar o mercado de milho nas condições atuais foram feitas as 
alterações necessárias nos modelos existentes, resultando num novo modelo, capaz de analisar os efeitos da nova política (especificamente o efeito dos leilões de PEP) sobre todo o sistema. A análise é feita em 4 etapas começando por um mercado livre, sem qualquer intervenção e com a economia fechada. O segundo passo é considerar a economia fechada mas o governo agindo através do PEP, que consiste num subsídio ao preço recebido pelo produtor quando o preço de mercado estiver abaixo do preço mínimo. A terceira análise consiste em avaliar os efeitos da abertura de mercado sem a intervenção do governo e por fim, o modelo final que consiste no mercado com economia aberta e com intervenção do governo através do PEP.

Este estudo se concentra no estoque de um ano safra entre anos e não dentro do ano. Por isso o mecanismo a ser analisado é o PEP já que as opções são mecanismos para formação de estoques pelos produtores dentro do ano safra. Para analisar o efeito das opções é necessário um modelo trimestral ou semestral que não será usado nesta pesquisa.

\section{Objetivo}

O objetivo geral do trabalho é desenvolver um modelo econômico de expectativas racionais para armazenamento de produtos agrícolas, numa economia aberta onde o governo intervém através de uma política de subsídio de preço do

produtor. Desta forma o mecanismo da tomada de decisão quanto à formação de estoques poderia ser conhecido e permitir análises prévias de intervenções pretendidas pelo governo.

\section{Pressupostos}

A pressuposição básica é de que a Política de Garantia de Preços Mínimos a partir dos anos 90 tenha o objetivo de sustentar o preço ao produtor igual ou 
acima do preço mínimo de forma que o governo não tenha de formar estoques. Outro pressuposto relevante para os modelos é de que os agentes que armazenam são neutros quanto ao risco.

\section{Hipótese}

A hipótese básica é de que é possível representar o mercado de milho no Brasil através de um modelo dinâmico de expectativas racionais capaz de captar o efeito da abertura para o mercado externo e das políticas de preços do governo.

\section{Organização do estudo}

O capítulo 2 apresenta a Política de Garantia de Preços Mínimos no país e seus instrumentos e as características relevantes do mercado do milho, o produto escolhido para a aplicação do modelo. O terceiro capítulo trata do modelo econômico de armazenamento nas condições pretendidas, enquanto o capítulo 4 discute a metodologia e procedimentos utilizados na estimação do modelo para milho. Os resultados são apresentados no quinto capítulo e as conclusões no capítulo 6 . 


\section{POLÍTICA DE GARANTIA DE PREÇOS MÍNIMOS NO BRASIL E O MERCADO DE MILHO}

\subsection{A Política de Garantia de Preços Mínimos}

A idéia de o governo garantir um determinado preço mínimo para produtos agrícolas no Brasil remonta ao início do século com as políticas de sustentação de preços do café e açúcar. No pós-guerra surge a preocupação de estabelecer uma política específica para produtos agrícolas, sendo criada a Companhia de Financiamento da Produção (CFP), em 1943'.

Algo mais concreto ocorreu em 1945 estabelecendo pela primeira vez valores de preços mínimos para arroz, feijão, milho, amendoim, soja e girassol, mas nenhuma operação foi feita nesta época. Apenas em 1951 a Política é regulamentada por Lei e começa a funcionar efetivamente no ano seguinte com dois instrumentos: Aquisição pelo Governo Federal (AGF) e Empréstimo pelo Governo Federal (EFG).

AGF é a aquisição de produto pelo Governo Federal pelo preço mínimo vigente na safra e se constitui no instrumento para compras diretas. Este é o único instrumento pelo qual o governo forma estoques efetivamente. O EGF é um crédito de comercialização, consistindo num empréstimo do governo ao produtor, cooperativa ou indústria, pelo valor do preço mínimo vigente e que vence no período de entressafra. $\mathrm{O}$

\footnotetext{
${ }^{1}$ Os dados históricos estão baseados em Delgado (1978).
} 
objetivo é evitar que o produtor tenha de vender a produção na safra por falta de recursos para saldar seus compromissos financeiros, inclusive o vencimento do crédito de custeio.

De 1952 até 1962 a política foi usada basicamente para algodão que absorvia de 60 a $88 \%$ dos recursos do programa e beneficiando basicamente as indústrias algodoeiras. A década de 60 foi marcada por crises repetidas de abastecimento levando o governo a transformar a política num instrumento de incentivo à produção agrícola, elevando os níveis dos preços mínimos que até então eram inferiores aos preços de mercado. Os números de AGF e EGF da época mostram que a intenção não se concretizou, e que foram amparados os produtos que mais precisaram em cada ano e não uma ação generalizada de incentivo.

De 1952 até 1966, quem efetivamente captou recursos da política foram intermediários, indústrias e beneficiadores mas não os produtores. Apenas em 1965 um decreto Lei determina que só teriam direito ao crédito aqueles intermediários que pagassem ao menos o preço mínimo ao produtor. Durante todo este período e mesmo até a década de 70 os beneficiários principais da PGPM foram intermediários (Oliveira \& Albuquerque, 1985).

Havia duas modalidades de EGF: Com Opção de Venda (COV) e Sem Opção de Venda (SOV). A opção de venda significa que, na época de vencimento do EGF o produtor poderia optar por entregar o produto ao governo liquidando a dívida. Em outras palavras, o EGF/COV pode se tornar um AGF segundo o desejo do produtor enquanto o EGF/SOV só pode ser liquidado pelo pagamento do empréstimo.

O preço mínimo é o preço de suporte que a política pretende garantir e forma estoques através dos AGF. Mas uma política de estoques reguladores deve conter um critério para liberação destes estoques. Quando e como o governo deveria colocar no mercado os estoques formados em períodos de safras abundantes? 
O critério para estas liberações no Brasil é o Preço de Liberação de Estoques (PLE), calculado nas principais praças de comercialização de cada produto. Quando o PLE é atingido, o governo começa a desovar seus estoques e deveria suspender as vendas quando o preço de mercado voltasse a ficar abaixo do PLE. É importante ressaltar que estas regras mais claras da intervenção do governo foram efetivamente aplicadas a partir da safra 87/88 (CFP, 1989). Eram comuns vendas desordenadas de estoques ou em momento inadequado, gerando insatisfação no mercado tanto para produtores quanto para consumidores de produtos agrícolas in natura. Durante os anos 80, arroz e milho (e feijão em alguns anos) foram os maiores demandantes dos recursos da PGPM, absorvendo entre 60 e $80 \%$ dos recursos. Milho e arroz sempre predominaram em quantidades adquiridas e financiadas.

Os problemas operacionais da PGPM se tornaram notórios na década de 80 e início dos anos 90, ressaltando-se as dificuldades em administrar o volume de estoques em mãos do governo tanto no aspecto de garantir sua existência efetiva quanto na questão da qualidade dos estoques. Outro problema era a demora da realização das vendas do governo quando o PLE era atingido e, em outras ocasiões, a continuidade das vendas quando o preço de mercado já estava abaixo do PLE.

Desde os últimos anos da década de 80 , reduziram-se significativamente as aplicações públicas fiscais e financeiras no setor agrícola (Barros et al., 1993). O maior corte de aplicações públicas teria ocorrido entre os anos de 1988 e 1989, quando os gastos federais (inclusive das empresas públicas) reduziram cerca de $43 \%$, em decorrência da redução de recursos para crédito rural, abastecimento e para produtos específicos como trigo, cacau, café, açúcar e álcool. Com isso, os dois principais instrumentos de política agrícola - crédito rural e política de preços mínimos - foram severamente sacrificados. Neste cenário cresce a dificuldade do governo em realizar AGF's e o volume de EGF passa a predominar. Os EGF's passam a ser concedidos aos 
produtores que haviam captado crédito de custeio tornando bastante difícil obter EGF para produto não atrelado ao custeio.

A redução de recursos, os problemas na administração dos estoques e a abertura do mercado brasileiro ao comércio internacional através da redução ou eliminação do imposto de importação, levaram à criação de novos instrumentos para a Política de Garantia de Preços Mínimos no Brasil nos anos 90. A importância maior destes novos instrumentos é que eles representam também uma nova política na qual o governo evita formar estoques, preferindo mecanismos que transfiram para a iniciativa privada o carregamento de estoques dentro do ano e entre anos safra.

Ao mesmo tempo, permanece o preço mínimo de garantia mantendo o objetivo original da PGPM neste sentido. A abertura do mercado às importações tornou o PLE questionável, pois uma economia aberta não condiz com uma política de estabilização de preços numa determinada faixa, a não ser que o PLE seja equivalente ao preço do produto internalizado.

\section{NOVOS INSTRUMENTOS}

\section{Prêmio para Escoamento do Produto (PEP)}

O Prêmio para Escoamento de Produto (PEP), lançado em 1996, é um destes novos instrumentos da PGPM e tem por objetivo permitir que a iniciativa privada adquira a produção no período de safra garantindo ao produtor o preço mínimo, subsidiando os produtores. Uma determinada quantidade de lotes de produto (cujos proprietários são identificados) é colocada em leilão com um prêmio máximo que o governo se dispõe a aceitar. Leva o produto aquele comprador que ofertar o menor prêmio, ou seja, o menor subsídio pelo qual ele aceita adquirir o produto. Considerando um ambiente competitivo, o prêmio de arremate dos leilões corresponde à diferença entre o preço mínimo e o preço de equilíbrio de mercado. 
Feito o leilão, produtor e comprador comparecem ao Banco do Brasil onde o produtor recebe o valor correspondente ao preço mínimo e o comprador paga a diferença entre o preço mínimo e o prêmio pelo qual arrematou o produto. Este prêmio é o subsídio, bancado pelo governo. A operacionalização deste instrumento, baseada em CONAB (2000a) é apresentada na Figura 1.

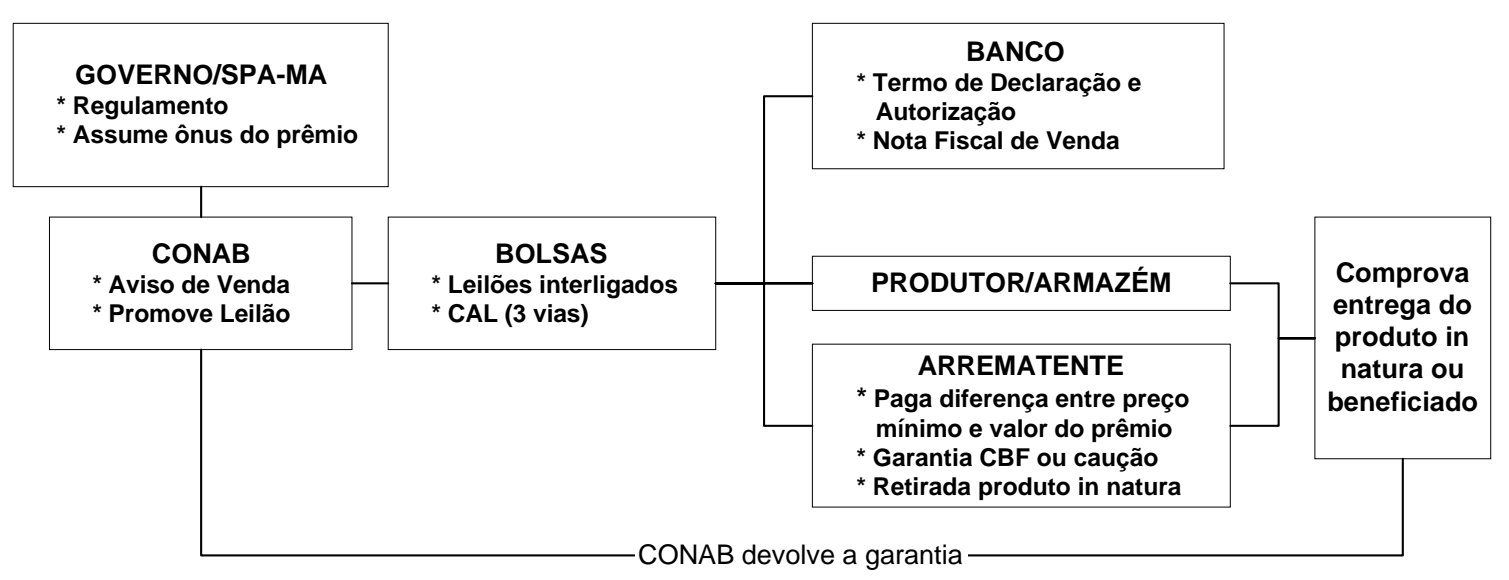

Figura 1 - Fluxograma do Prêmio para Escoamento de Produto (PEP)

Um ponto de fundamental importância no PEP é deixar claro que o produto sendo leiloado não pertence ao governo, mas ao produtor e/ou cooperativa. A mesma lógica do PEP é utilizada para escoar outros produtos mas neste caso, recebe a denominação de VEP (Valor para Escoamento do Produto).

O VEP segue a mesma lógica do PEP, mas se refere a produto pertencente ao governo e se destina a permitir o escoamento deste produto para determinada região onde se identifica escassez de produto. Para um estoque existente em determinado local o governo se dispõe a conceder um subsídio para que este produto seja adquirido pela iniciativa privada para ser levado ao destino definido pelo governo. $\mathrm{O}$ adquirente deve comprovar que o estoque foi para o destino pretendido. 


\section{Contrato de Opção}

O outro instrumento lançado em 1997 é o Contrato de Opção de Venda que segue as mesmas regras e lógicas de uma opção de venda qualquer como as existentes em bolsas de mercadorias (CONAB, 2000b). A diferença é que o lançador é sempre o governo e o preço de exercício da opção é o valor do preço mínimo acrescido dos custos de armazenamento entre o período de lançamento da opção (safra) até seu vencimento (entressafra). Assim, o contrato de opção é, antes de tudo, um instrumento a ser usado para o armazenamento dento do ano e não entre anos e se mostra como substituto ao EGF. O produtor que estiver interessado em garantir a venda de seu produto ao governo nestas condições, adquire a opção de venda pagando um prêmio por isto (como ocorre em qualquer tipo de opção).

Note que aqui o governo não gasta nada até este ponto, pelo contrário, pois recebe o prêmio que o produtor pagou. No vencimento da opção, o produtor decide se vai exercê-la ou não, o que será resultado da diferença entre o preço de exercício e o preço de mercado na ocasião. Se o preço de mercado estiver acima do preço de exercício

o produtor não exerce a opção e vende no mercado. Se, por outro lado, o preço de mercado for inferior ao preço de exercício, o produtor exerce a opção vendendo ao governo que se obriga a comprar. Neste momento o governo tem duas alternativas: ou ficar o produto se tiver interesse em manter um determinado nível de estoque de produto ou promove leilões de PEP para transferir este volume para a iniciativa privada. Inicialmente, apenas arroz longo fino (agulhinha) em casca, milho em grãos, trigo em grãos e algodão em pluma foram amparados por esse mecanismo.

\section{Recompra de Contratos de Opção}

A recompra dos contratos de opção consiste em o governo comprar dos produtores o contrato de opção que lhe foi vendido. Esta estratégia é adotada quando o 
governo percebe que o preço de mercado, na data de vencimento da opção, será inferior ao preço de exercício e os produtores exercerão a sua opção. Se o governo não quer adquirir o produto, ele pode se oferecer para comprar de volta o contrato pagando, naturalmente, para isto.

O valor que o governo terá de desembolsar na recompra destes contratos terá de ser de tal magnitude que cubra a diferença entre o preço de exercício e o preço de mercado e do prêmio que o produtor já pagou. A recompra tem efeito muito semelhante (se não o mesmo) do PEP, mas operacionalizado de outra forma. Quando as opções vencem, o produtor pode optar por exercê-las, como foi analisado em item anterior. Diante deste exercício o governo (se não recomprou o contrato) tem basicamente duas alternativas: ou adquire o produto pagando o valor integral ao produtor ou procura escoar este volume para o mercado. O mecanismo para este escoamento é semelhante aos anteriores mas o preço referência deste leilão não é o preço mínimo, mas o preço de exercício da opção.

Um ponto merece ser destacado. Em princípio, o preço de exercício de uma opção é o preço mínimo mais o custo de carregamento deste estoque entre a data de contratação e a data de vencimento. Mas não há uma imposição de que seja assim, depende do interesse do governo em estimular ou desestimular o uso dos mecanismos por parte dos produtores e dos seus recursos para o ano.

O PEP foi lançado em 1996 e utilizado inicialmente para trigo. Naquele ano, 1,07 milhão de toneladas ou o equivalente a um terço da safra nacional foram comercializadas através deste mecanismo. No ano seguinte, 566 mil toneladas de trigo foram comercializadas através dos leilões de PEP, equivalente a $26 \%$ da produção nacional. $\mathrm{O}$ volume foi menor neste ano porque os preços de mercado estiveram acima do preço mínimo na maioria das regiões produtoras. Em 1998 o volume de trigo negociado através do PEP sobe para 1,3 milhão de toneladas equivalente a $55 \%$ da produção brasileira no ano. 
A Tabela 2 mostra um histórico dos volumes realizados de AGF e EGF de milho no Brasil, deixando clara a importância da atuação do governo neste mercado. Observe a redução expressiva dos AGF e EGF do produto, substituídos por Opções e PEP. Para milho os primeiros leilões de PEP foram realizados em 1997 totalizando 1.076,7 mil toneladas. Os leilões se concentraram no Centro-Oeste, Tocantins e Bahia a exemplo do que já ocorria nos anos anteriores com os instrumentos tradicionais. No mesmo ano, foram negociados pouco mais de 38 mil contratos de opção, correspondendo a um volume de 1.021,2 mil toneladas ${ }^{2}$.

Em 1999 tiveram início os leilões de PEP e Opções para arroz e algodão em pluma. O estoque do governo, após 4 anos de implementação da política reduziu para todos os produtos especialmente trigo, algodão, arroz e milho. No caso do milho, o estoque do governo ao final da safra 99/00 era de 300 mil toneladas e este volume já chegou a quase 6 milhões de toneladas (CONAB, 1992-2001).

\subsection{O mercado de milho no Brasil}

O objetivo desta seção não é apresentar um diagnóstico completo do mercado de milho no Brasil, mas ressaltar os aspectos relevantes para este estudo que são a distribuição geográfica da produção, as características do consumo. A importância a PGPM neste mercado já ficou evidente na seção anterior. Até início dos anos 90 a produção brasileira de milho era constituída de uma única safra, plantada no outono e colhida no verão com uma diferença de calendário agrícola da região nordeste em relação à região Centro-Sul. A produção nordestina é plantada entre março e maio e colhida entre outubro e dezembro enquanto na região centro sul o plantio se concentra entre setembro e novembro e a colheita se estende de fevereiro a junho (CONAB, 19922001).

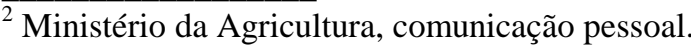


Tabela 2. Produção, consumo aparente, importações, volume de milho atrelado a AGF, EGF, PEP e contratos de opção de milho, 1980/2001.

\begin{tabular}{|c|c|c|c|c|c|c|c|c|}
\hline Ano & $\begin{array}{c}\text { Produção } \\
(\text { mil t })\end{array}$ & $\begin{array}{c}\text { Consumo } \\
(\text { mil t })\end{array}$ & $\begin{array}{c}\text { Importações } \\
\text { (mil t) }\end{array}$ & $\begin{array}{l}\text { Estoque } \\
\text { Final } \\
\text { (Mil t) }\end{array}$ & $\begin{array}{l}\text { AGF } \\
(\text { mil t })\end{array}$ & $\begin{array}{l}\text { EGF } \\
(\text { mil t) }\end{array}$ & $\begin{array}{l}\text { PEP } \\
(\text { mil } t)\end{array}$ & $\begin{array}{l}\text { Opções } \\
\text { (mil t) }\end{array}$ \\
\hline 1980 & 19.485 & 20.600 & -- & $1.180,0$ & 1 & 1.536 & & \\
\hline 1981 & 21.282 & 21.995 & 902 & $136^{\prime}$ & 64 & 3.471 & & \\
\hline 1982 & 21.603 & 20.609 & 9 & 18234 & 3.531 & 3.073 & & \\
\hline 1983 & 19.014 & 19.461 & 213 & 8235 & 1377 & 2.297 & & \\
\hline 1984 & 21.177 & 19.955 & 254 & 21210 & 470 & 1.807 & & \\
\hline 1985 & 21.174 & 22.957 & 262 & 6000 & 3.227 & 1.668 & & \\
\hline 1986 & 20.264 & 21.688 & 2.424 & 16001 & 4.272 & 1.708 & & \\
\hline 1987 & 26.758 & 26.350 & 871 & 2879 & 7.885 & 1.840 & & \\
\hline 1988 & 25.224 & 25.320 & 15 & 2798 & 1.659 & 3.926 & & \\
\hline 1989 & 26.267 & 26.140 & 155 & 30797 & 1.001 & 3.690 & & \\
\hline 1990 & 22.257 & 24.800 & 700 & 1237.1 & 455 & 483 & & \\
\hline 1991 & 24.096 & 25.288 & 832 & 8774 & 0 & 861 & & \\
\hline 1992 & 30.771 & 28.500 & 340 & 348 & 365 & 7.320 & & \\
\hline 1993 & 29.605 & 31.172 & 1.498 & 3418 & 434 & 5.288 & & \\
\hline 1994 & 33.174 & 32.732 & 1.569 & 542 & 33 & 3.216 & & \\
\hline 1995 & 37.222 & 34.640 & 984 & 89951 & 705 & 5.370 & & \\
\hline 1996 & 32.401 & 35.204 & 377 & 59614 & 504 & 365 & & \\
\hline 1997 & 35.303 & 35.513 & 500 & 61695 & 2.819 & 481 & 1.077 & 1.021 \\
\hline 1998 & 31.145 & 35.957 & 1.765 & 31225 & 1.105 & 75 & 65 & 0 \\
\hline 1999 & 32.710 & 35.317 & 900 & $1.415,7$ & 154 & 0 & 227 & 355 \\
\hline 2000 & 31.963 & 34.802 & 2.100 & 676,6 & & & 0 & 152 \\
\hline $2001^{1}$ & 38.500 & 36.236 & 200 & $2.141,1$ & 914 & & 184 & 1.638 \\
\hline
\end{tabular}

Fonte: Barros \& Guimarães (1998) e CONAB (2001).

${ }^{1}$ Projeção para produção, consumo e importações e dados até abril/01 para PEP e Opções. 
Nos anos 90 com a decadência da triticultura, o milho passou a ser uma alternativa interessante para os produtores do Centro-Sul como cultivo de inverno. A chamada "safrinha" plantada no verão e colhida no inverno começou timidamente em 1991 com uma produção de 923 mil toneladas. Desde então a área plantada com a cultura tem crescido a uma taxa média de 21,5\% ao ano. Na safra 97/98 a produção chegou a 6,1 milhões de toneladas, ou 19,6\% da produção total nacional. Apesar de ser uma cultura de risco na região sul em função dos perigos das geadas, a área tem crescido pelo baixo custo atribuído a este cultivo, estimado em pouco mais da metade do custo por hectare da lavoura de verão segundo estudo do Departamento de Economia Rural (DERAL, 1999). Isto se deve ao fato de que no cultivo da safrinha os produtores aproveitam a adubação residual da lavoura de verão e a incidência de pragas e doenças nesta época é menor.

O plantio de verão, que ainda é a maior produção brasileira, se concentra fortemente na região Centro-Sul responsável por $70 \%$ da área cultivada no país e por $88 \%$ da produção, na média dos últimos 5 anos safra. O cultivo da safrinha é quase exclusivo da região Centro-Sul com uma pequena participação da região nordeste representada pelo Sul da Bahia. O Paraná é o maior produtor de milho do Brasil, com $21,7 \%$ da safra normal, $39,4 \%$ da safrinha e $24,2 \%$ da produção total do ano, levando em conta os valores médios dos últimos 5 anos. Os dados de área produção e produtividade das duas safras de milho para períodos selecionados são apresentados nas Tabelas 3 e 4.

A região Sudeste é a segunda maior produtora seguida pela região CentroOeste. Como se verá a seguir, apesar do grande volume produzido no Sudeste esta região é importadora líquida de milho (no mercado doméstico), pois seu consumo supera a produção regional. 
Tabela 3. Área plantada e produção de milho de primeira safra, média dos últimos 5 anos e safra 00/01, Brasil.

\begin{tabular}{|c|c|c|c|c|c|c|}
\hline \multirow{2}{*}{$\begin{array}{l}\text { Estado } \\
\text { Região }\end{array}$} & \multicolumn{3}{|c|}{ Área (Mil ha) } & \multicolumn{3}{|c|}{ Produção (Mil t) } \\
\hline & Média & $00 / 01$ & Part \% & Média & $00 / 01$ & Part \% \\
\hline Paraná & 1.641 & 1.845 & 15,6 & 6.062 & 8.941 & 21,7 \\
\hline Santa Catarina & 900 & 893 & 8,6 & 3.163 & 3.929 & 11,3 \\
\hline Rio Grande do Sul & 1.583 & 1.617 & 15,0 & 3.767 & 5.660 & 13,5 \\
\hline SUL & 4.124 & 4.355 & 39,2 & 12.992 & 18.529 & 46,5 \\
\hline Minas Gerais & 1.307 & 1.330 & 12,4 & 4.050 & 4.035 & 14,5 \\
\hline São Paulo & 786 & 881 & 7,5 & 2.803 & 3.034 & 10,0 \\
\hline SUDESTE & 2.172 & 2.275 & 20,6 & 7.039 & 7.280 & 25,2 \\
\hline Goiás & 644 & 759 & 6,1 & 2.844 & 3.149 & 10,2 \\
\hline Mato Grosso & 227 & 241 & 2,2 & 808 & 1.053 & 2,9 \\
\hline Mato Grosso do Sul & 214 & 230 & 2,0 & 923 & 1.033 & 3,3 \\
\hline CENTRO-OESTE & 1.110 & 1.254 & 10,5 & 4.693 & 5.335 & 16,8 \\
\hline Pará & 332 & 410 & 3,2 & 512 & 621 & 1,8 \\
\hline Rondônia & 165 & 132 & 1,6 & 296 & 240 & 1,1 \\
\hline NORTE & 609 & 662 & 5,8 & 997 & 1.062 & 3,6 \\
\hline Ceará & 579 & 619 & 5,5 & 407 & 636 & 1,5 \\
\hline Maranhão & 435 & 320 & 4,1 & 327 & 314 & 1,2 \\
\hline Bahia & 343 & 350 & 3,3 & 769 & 1.051 & 2,7 \\
\hline Piauí & 339 & 283 & 3,2 & 228 & 231 & 0,8 \\
\hline NORDESTE & 2.511 & 2.283 & 23,9 & 2.239 & 2.699 & 8,0 \\
\hline $\mathrm{N} / \mathrm{NE}$ & 3.120 & 2.945 & 29,6 & 3.236 & 3.760 & 11,6 \\
\hline C-SUL & 7.406 & 7.884 & 70,4 & 24.723 & 31.145 & 88,4 \\
\hline BRASIL & 10.526 & 10.830 & 100,0 & 27.959 & 34.905 & 100,0 \\
\hline
\end{tabular}

Fonte: CONAB (1992-2001) e PARANÁ (1984-2001) 
Tabela 4. Área plantada e produção de milho de segunda safra, média dos últimos 5 anos, Brasil.

\begin{tabular}{l|r|r|r|r|r}
\hline \multirow{2}{*}{ Estado } & \multicolumn{2}{|c|}{ Área (Mil ha) } & \multicolumn{2}{c|}{ Produção (Mil t) } & Kg/ha \\
\cline { 2 - 6 } Região & Média & Part \% & \multicolumn{1}{c}{ Média } & Part \% & \multicolumn{1}{c}{ Média } \\
\hline Paraná & 837 & 35,0 & 1.860 & 38,9 & 2.221 \\
SUL & 837 & 35,0 & 1.860 & 38,9 & 2.221 \\
Minas Gerais & 37 & 1,5 & 56 & 1,2 & 1.540 \\
São Paulo & 399 & 16,7 & 781 & 16,3 & 1.955 \\
SUDESTE & 436 & 18,2 & 837 & 17,5 & 1.920 \\
Goiás & 209 & 8,7 & 576 & 12,1 & 2.760 \\
Mato Grosso & 340 & 14,2 & 661 & 13,8 & 1.946 \\
Mato Grosso do Sul & 282 & 11,8 & 615 & 12,9 & 2.177 \\
CENTRO-OESTE & 836 & 34,9 & 1.864 & 39,0 & 2.231 \\
Bahia & 285 & 11,9 & 219 & 4,6 & 766 \\
NORDESTE & 285 & 11,9 & 219 & 4,6 & 766 \\
C-SUL & 2109 & 88,1 & 4.561 & 95,4 & 2.163 \\
\hline BRASIL & 2.394 & 100,0 & 4.780 & 100,0 & 1.996 \\
\hline
\end{tabular}

Fonte: CONAB (1992-2001) e PARANÁ (1984-2001)

As regiões norte e nordeste produzem apenas 11,6\% da produção nacional de milho e são regiões (especialmente o nordeste), que importam milho tanto de outras regiões do país quanto do exterior. É para estas regiões que se destina, preferencialmente, o milho importado pelo Brasil. Já a região Centro-Oeste é exportadora líquida e a principal demandante de recursos da PGPM. O Paraná também é exportador líquido no mercado doméstico, mas demanda poucos recursos da PGPM pois o nível de preços praticado no estado tem superado, via de regra, o preço mínimo estabelecido para a região. 
Apesar do aumento da área cultivada com milho safrinha, a Figura 2 evidencia que, na realidade, parte da área cultivada no verão foi transferida para o inverno. A Figura 2 apresenta a evolução da área plantada com milho no Brasil na safra normal (ou de verão) e a área total, incluindo a área da safrinha. A faixa de variação da área total a partir de 1991 continua muito semelhante à do período anterior mas com parte da área transferida para o plantio de inverno. Sem perda de generalidade este estudo analisa a área total de milho no país.

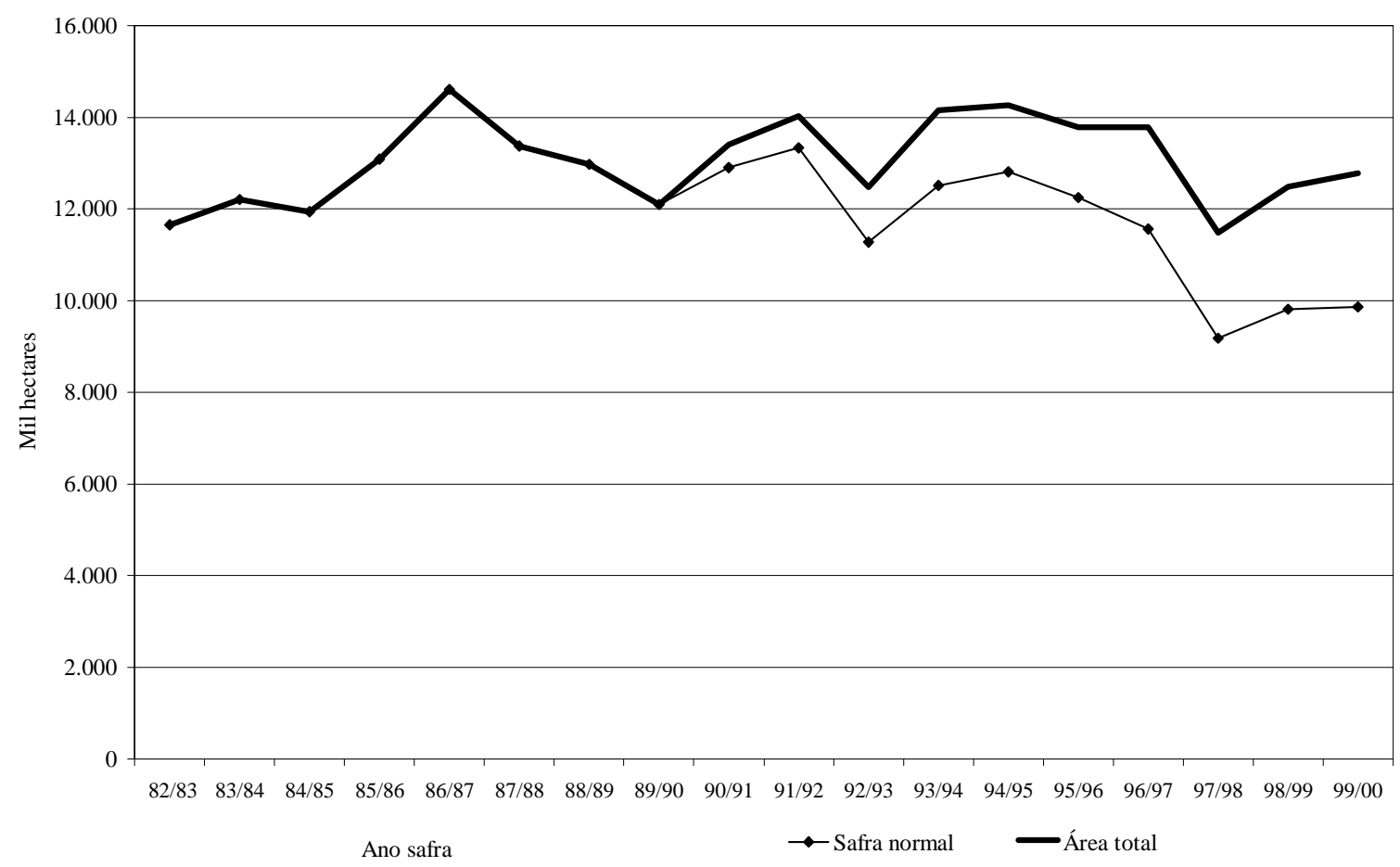

Figura 2 - Área plantada com milho no Brasil na safra normal e área total (normal e safrinha), safras $82 / 83$ a $99 / 00$.

Cabe ressaltar aqui três características importantes do milho no Brasil. Primeiro é o fato de que o milho é a única lavoura cultivada de norte a sul do país em praticamente todas as propriedades rurais. $\mathrm{O}$ autoconsumo de milho nas propriedades 
rurais é significativo,pois em quase todas há algum tipo de criação de animais para a qual o milho é insumo básico na alimentação. A outra característica é que a produção de milho nacional é dividida em duas realidades completamente diferentes. A produção em pequenas propriedades para autoconsumo é realizada com nível tecnológico extremamente baixo, com sementes guardadas de um ano para o outro, sem adubação e em geral consorciada com outra cultura (geralmente feijão). Por outro lado é cada vez maior a produção de milho com alto nível de tecnologia, sementes de alta qualidade e produtividade equiparável à americana. Portanto, quando se analisa a produtividade média nacional ou mesmo regional do milho é importante estar ciente de que estes números são uma mistura de tecnologias absolutamente diversas. Apenas no CentroOeste predomina a produção comercial de milho o que se reflete na produtividade média da região, acima de 4 toneladas/ha.

O terceiro ponto é a relevância da cultura como sustentáculo do crescimento de outras atividades, especialmente a avicultura de corte. A partir dos anos 70 a produção nacional de aves de corte cresceu a taxas impressionantes dada a excelente adaptação do pacote tecnológico da produção de frango de corte no Brasil. Rapidamente o frango se tornou produto de exportação, competitivo no mercado internacional e proporcionou carne mais barata no mercado interno (Guimarães, 1990). Para manter a atividade competitiva é preciso dispor de milho (70\% do peso da ração) e o preço mínimo foi também utilizado como estímulo à lavoura apoiado na PGPM. Não foi sem razão que o milho, ao lado do arroz, foram os produtos que mais utilizaram recursos da PGPM tanto em AGF quanto EGF.

Voltando ao abastecimento do mercado nacional, note que as importações crescem significativamente nos anos 90 mesmo quando a disponibilidade interna não foi pequena. Isto ocorreu porque para a região nordeste é mais barato adquirir milho no mercado externo (especialmente da Argentina) do que no mercado brasileiro devido ao custo de frete e diferencial de impostos. É por isso que em diversos anos, como 1994, 
sobraram estoques enormes de milho na região Centro-Oeste e, mesmo assim, houve importações superiores a 1,5 milhão de toneladas.

Ainda com relação às importações é relevante neste ponto determinar a importância das compras brasileiras no mercado mundial de milho. A análise dos dados contidos na tabela 3 deixa claro que o Brasil não é importante comprador no mercado mundial pois suas aquisições nos últimos 10 anos nunca superaram $4 \%$ do total de importações mundiais. Mesmo levando em conta apenas o mercado Argentino, que fornece em média $70 \%$ das compras externas brasileiras é possível perceber que a participação brasileira nas vendas totais de milho da Argentina não chega a 10\% (Argentina, 2000). Por isso, este estudo considera que o Brasil não é importante no mercado mundial e será considerado como um tomador de preços quando importar.

Durante a década de 80 as importações de milho ocorreram em períodos de escassez de produto. Nas raras vezes em que o Brasil exportou, estas vendas foram consideradas operações de "limpeza de estoques antigos" e não por competitividade da produção nacional. O milho é considerado um produto de mercado externo, mas comercializável externamente (Melo, 2000). Em anos de frustração de safra o Brasil importa volumes maiores como na safra 99/00, cujos valores são apresentados na Tabela 3. No ano 2001 o país está colhendo uma grande safra de verão (perto de 35 milhões de toneladas) e pode colher uma safra recorde dependendo da produção da safra de inverno. Os preços no mercado interno caíram o suficiente para viabilizar as exportações que devem ultrapassar 2 milhões de toneladas.

Portanto, um modelo que pretenda analisar o mercado de milho brasileiro do ponto de vista da formação de estoques privados, deve levar em conta a possibilidade de comércio internacional e a intervenção do governo. O objetivo deste trabalho é desenvolver este modelo. 


\section{Canais de comercialização do milho no Brasil}

A Figura 3 mostra o fluxograma da cadeia do milho no Brasil, resultado de pesquisa realizada a partir de diversos estudos e junto a agentes do mercado. Todos os percentuais se referem à parcela do milho em grão, consumido anualmente, que flui para cada segmento do mercado. O autoconsumo é estimado em $40 \%$ do consumo total ou 14,2 milhões de toneladas na média dos últimos 3 anos safra (FGV, 1998). Este percentual inclui a produção de milho pertencente a produtores integrados de frangos e suínos, ou seja, parcela do milho que é utilizada na fabricação de rações, mas não é comercializada no mercado, apenas entre integradora e produtor. $\mathrm{O}$ autoconsumo inclui ainda a parcela da produção que é utilizada para semente.

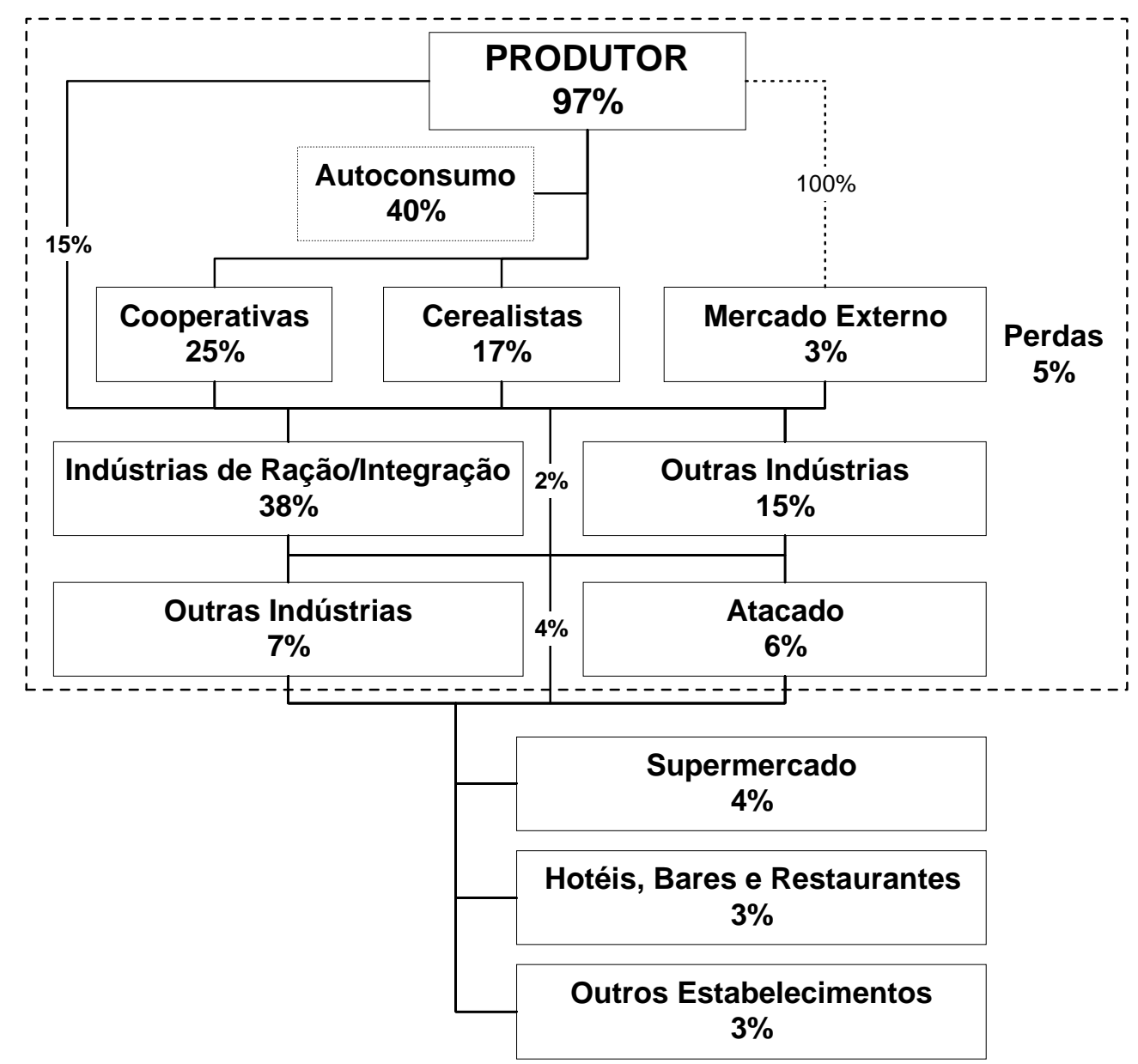

Figura 3 - Canais de comercialização do milho 
Cerca de $25 \%$ do milho produzido no Brasil passa pelas cooperativas, que tanto podem vender o grão no mercado como assumir o papel da indústria (rações ou outras). Estima-se em $17 \%$ a parcela do milho que é entregue a cerealistas, os quais negociam o produto no mercado numa segunda etapa. As empresas recebem direto do produtor cerca de $15 \%$ do milho, os $3 \%$ restantes vêm do mercado externo. A indústria de rações, incluindo a parcela de milho que as integradoras adquirem no mercado, corresponde a $38 \%$ do total. A partir deste ponto, o milho passa a integrar indiretamente as cadeias produtivas da produção animal, incluindo o segmento de rações para pequenos animais.

O conjunto das demais indústrias que utilizam milho e do milho "in natura" absorvem $15 \%$ do volume. Este grupo gera uma grande variedade de produtos a partir do milho, dos quais alguns são insumos para outras empresas enquanto outros são produtos para consumo final. Dois tipos de indústrias se destacam: as indústrias de Moagem Úmida e Moagem a Seco. A moagem úmida produz amido, glicose, corantes, malto dextrina, dextrina, adesivos e ingredientes protéicos para ração animal. Boa parte da produção desta indústria é insumo para outras indústrias. Este segmento é fortemente concentrado em 3 grandes empresas, todas multinacionais.

As indústrias de moagem a seco formam três grupos: a indústria moageira, indústria de "snacks" e indústria de cereais matinais. A indústria moageira produz canjica, fubá, polenta, floculados, pré-cozidos, farinhas, óleo, entre outros produtos. A maior parcela destes produtos é para consumo final, assim como os snacks e cereais matinais. Há um grande número de indústrias moageiras no Brasil, mas seis delas respondem por mais de metade da produção. Neste segmento predominam as empresas de capital nacional. Já na parte de "snacks", predomina uma empresa multinacional, enquanto o segmento de cereais matinais é dominado por 4 empresas também multinacionais. Apesar da concentração em determinados segmentos industriais 
a sua participação no consumo de milho é relativamente pequena não caracterizando um mercado concentrado para o grão em termos gerais.

As conclusões sobre as características da produção e consumo é que são bastante dispersos geograficamente e não concentrados. Não há como eleger uma única região representativa do mercado de milho. A opção deste estudo foi pela produção e consumo nacional, ciente de que a divisão em regiões seria mais adequada mas, para isto são necessários dados confiáveis de estrutura produtiva, consumo e estoques regionais, não disponíveis no país. 


\section{MODELO ECONÔMICO}

Este estudo trata de produtos agrícolas armazenáveis produzidos anualmente tais como grãos, algodão e café. O problema do armazenamento é a questão da alocação de uma dada quantidade de produto disponível entre o consumo corrente e a formação de estoques para o próximo ano. Dada uma determinada disponibilidade de produto, qual a melhor decisão: consumir tudo agora ou guardar uma parte para o ano seguinte? Neste caso, quanto deve ser armazenado? E de que forma este estoque afetará os preços do próximo ano? Como decidir a quantidade a formar de estoques?

Armazenar é uma atividade econômica como qualquer outra, através da qual "produto hoje" se transforma em "produto amanhã" e envolve receita e custo. Considerando um ambiente competitivo, do ponto de vista de cada agente individual, seria economicamente viável armazenar uma unidade a mais de produto de um período para outro enquanto a diferença entre o preço no período atual e o preço esperado para o próximo período fosse maior ou igual ao custo de armazenar esta unidade. Em outras palavras, a condição de maximização de lucro no armazenamento em condições competitivas se dá no ponto em que o custo marginal de armazenar é igual à receita marginal esperada.

Para um agente individual $i$ (produtor, indústria, cerealista, etc) o lucro esperado por cada agente é dado por:

$$
E \Pi_{t}^{i}=\delta E_{t} P_{t+1} I_{t}^{i}-P_{t} I_{t}^{i}+\mathrm{k} I_{t}^{i}
$$


onde $I_{t}^{i}$ é o volume a ser armazenado por um agente no período $t, E_{t} P_{t+1}$ é a sua expectativa em $t$ para o preço no período seguinte $(t+1), P_{t}$ é o preço corrente, k é o custo médio unitário (constante) do armazenamento físico e $\delta$ é a taxa de desconto dada por $[1 /(1+r)]$ onde $r$ é a taxa de juros. A condição de primeira ordem para maximização do lucro por cada agente individual em relação ao volume a ser estocado é dada por:

$$
\frac{\partial E \prod_{t}^{i}}{\partial I_{t}^{i}}=\delta E_{t} P_{t+1}+\delta \frac{\partial E_{t} P_{t+1}}{\partial I_{t}^{i}} I_{t}^{i}+P_{t}+\frac{\partial P_{t}}{\partial I_{t}^{i}} I_{t}^{i}+\mathbf{k}=0
$$

O segundo termo da equação é zero para cada indivíduo, assim como o quarto termo, dado que cada agente é tomador de preços e uma unidade a mais que cada indivíduo decide estocar não deve alterar o preço de mercado. Re-escrevendo a expressão acima, chega-se à famosa regra de arbitragem temporal, adicionando-se a condição de que, se o preço esperado (a valor presente) for menor do que o preço corrente mais o custo de armazenamento, o indivíduo não formará estoques

$$
\begin{array}{ll}
\delta E P_{\mathrm{t}+1}-P_{\mathrm{t}}-\mathrm{k} \geq 0 & I_{\mathrm{t}}^{i}>0 \\
\delta E P_{\mathrm{t}+1}-P_{\mathrm{t}}-\mathrm{k}<0 & I_{\mathrm{t}}^{i}=0
\end{array}
$$

Assim, o equilíbrio do mercado em ambiente competitivo é assegurado pela arbitragem de tempo. Quando a valorização esperada no preço do produto excede o custo da estocagem, os agentes do mercado procuram se apropriar desta oportunidade de lucro aumentando seus estoques até que o equilíbrio se estabeleça. Quando a valorização esperada é inferior ao custo da estocagem, o prejuízo previsto leva os agentes a reduzir seus estoques até que o equilíbrio seja atingido.

A análise do armazenamento do ponto de vista individual num ambiente competitivo não nos leva mais longe do que compreender o papel da arbitragem 
temporal sobre os preços em dois períodos e não fornece elementos suficientes para avançar no problema. Apesar da aparente simplicidade da formulação teórica do problema econômico do armazenamento, há implicações importantes por trás desta relação de arbitragem temporal dada por (3). Como se forma a expectativa do preço para o período seguinte? Qual a influência do volume a ser armazenado sobre os preços corrente e futuro? Qual o papel do estoque sobre o mercado de um produto agrícola? Ou seja, qual o resultado agregado das decisões individuais quanto à formação de estoques de um ano safra para outro?

A análise começa por compreender o papel dos estoques de produtos agrícolas e pode ser encontrada em Wright \& Williams (1984). Admita que a Figura 4 representa o mercado de um produto agrícola armazenável com produção sazonal (uma produção por ano). A função de oferta deste produto agrícola, onde a quantidade ofertada corresponde à produção planejada, é dada por:

$$
\hat{H}_{\mathrm{t}}=\omega\left(P_{t}\right)
$$

São apresentadas duas curvas de demanda, a primeira, mais à esquerda, é a demanda para consumo no período $(D c)$, uma função negativamente inclinada do preço corrente e a única demanda do mercado quando não é possível armazenar:

$$
D c=D\left(P_{t}\right)
$$

O equilíbrio do mercado no ano $t$ corresponde ao preço $P$ e quantidade $H$. $\mathrm{O}$ valor do Bem Estar, para produtores e consumidores, de se produzir e utilizar a quantidade $X$ de produto pode ser mensurado pela área abaixo da curva de demanda até o preço de equilíbrio e acima da curva de oferta até o preço de equilíbrio. Prova-se que o ponto de equilíbrio equivale ao ponto de Bem Estar máximo naquele ano.

Se as curvas de demanda e oferta são as mesmas em todos os anos 
(estacionárias) e determinísticas, o Bem Estar não poderia ser aumentado abrindo mão do consumo corrente e transferindo estoques para o ano seguinte. No entanto, no caso de produtos agrícolas, a oferta não é determinística, ao contrário, é estocástica, pois a produção agrícola depende de fatores incontroláveis e imprevisíveis (clima). A oferta, portanto, é de uma produção planejada, mas a produção obtida freqüentemente difere da planejada. Nestes casos, pode ser vantajoso formar estoques de um ano $t$ para o ano seguinte, pois não se sabe qual será a quantidade de produto disponível para consumo no próximo período (Kennedy, 1986).

Considere que, num primeiro momento, não é possível armazenar. A produção obtida $X$ apresenta um desvio $\eta$ em relação à produção planejada $(X)$, onde cada $\eta$ tem probabilidade $=0,5$. Assim, a produção num ano qualquer será a produção planejada mais ou menos o desvio $(X \pm \eta)$, ou seja, a produção será $X-\eta(X a)$ ou $X+\eta$ $(X b)$, pontos A e B, respectivamente. A produção é planejada no ano anterior, portanto, a curva de oferta que aparece na figura é defasada de um ano e é função do preço esperado pelo produtor $\left(\mathrm{P}^{\mathrm{r}}\right)$ que não é o preço médio e por isso o ponto de equilíbrio não está sobre a função de demanda (Wright \& Williams, 1982 e Gardner, 1979). O Bem Estar muda, a cada ano, de acordo com o ponto de equilíbrio do ano. Quando a produção for $X a$, o preço será $P a$ penalizando os consumidores. Quando a produção for $X b$ o preço será $P b$, penalizando os produtores.

Considere agora que se tornou possível armazenar o produto. A curva de demanda relevante passa a ser a demanda de mercado $(D m)$ que inclui a demanda para consumo mais a demanda para armazenamento (que segue a arbitragem temporal dada em (3.3)), que começa a existir a partir de um determinado nível de preços, marcado como ponto U na figura.

A nova produção planejada passa a ser $X^{\prime}$ e o preço equivalente $P^{\prime}$. A produção efetivamente obtida será ou $X^{\prime}-\eta(X c)$ ou $H^{\prime}+\eta(X d)$, pontos $\mathrm{C}$ e $\mathrm{D}$, respectivamente. Quando a produção for $X d$, o preço será $P d$, maior do que no caso 
anterior porque agora a demanda de mercado é maior. Ao preço $P d$, a demanda para consumo será $X e$ e a quantidade a ser estocada no período 1 será $(X d-X e)$.

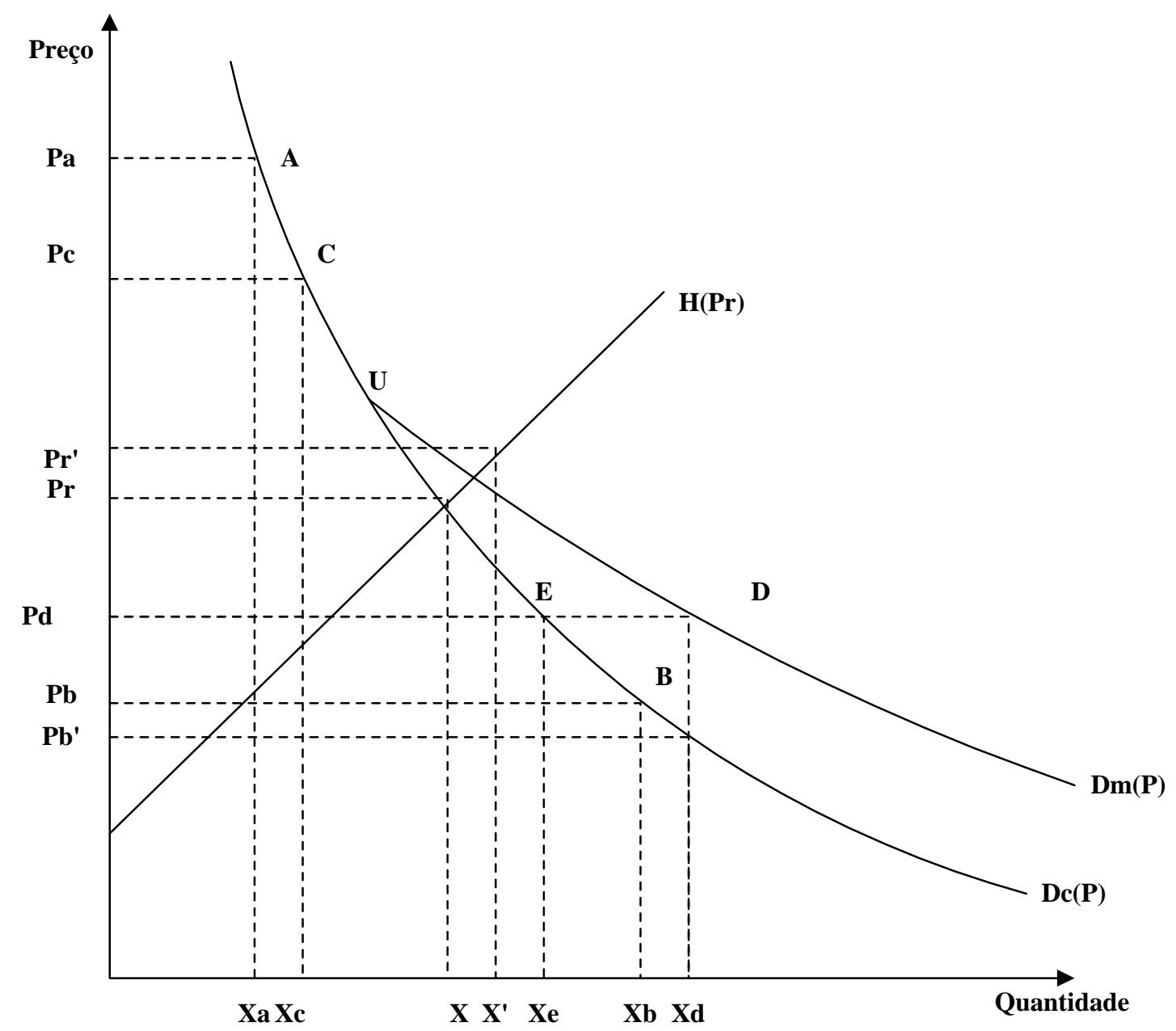

Figura 4 - Equilíbrio de mercado com e sem armazenamento

Mas o efeito do armazenamento sobre o mercado é dinâmico afetando não apenas os preços e quantidade consumida no ano em que são formados mas também o preço e a quantidade disponível para consumo no(s) ano(s) seguinte(s). Em suma, o efeito do armazenamento é dinâmico e não estático e deve ser analisado através da teoria do controle. 


\subsection{Problemas econômicos dinâmicos}

Esta seção aborda o armazenamento como um problema econômico de natureza dinâmica e emprega a Teoria do Controle que é a base teórica de análise destes problemas. Além da fundamentação teórica, esta seção prepara as bases para o método de solução do modelo, que é a programação dinâmica estocástica. A abordagem da teoria do controle utilizada nesta seção é baseada em Silberberg (1990).

Os temas mais comuns que se encaixam nos problemas dinâmicos são aqueles relacionados à utilização de um determinado recurso, envolvendo a taxa de utilização deste recurso no tempo. Há um estoque inicial do recurso, receitas e custos resultantes de sua utilização, e o efeito do uso do recurso sobre o estoque ao longo do tempo.

Seja $x_{0}$ o estoque inicial do recurso, $x(t)$ o estoque do recurso em qualquer instante $t, u(t)$ a taxa de utilização do recurso, $p$ o preço de venda e $c=c(x, u, w)$ a função de custo de utilização do recurso onde $w$ é um vetor com os preços dos fatores. Considere que o horizonte de planejamento é infinito.

O problema consiste em maximizar o valor presente líquido do recurso:

$$
\max _{u(t)} \int_{t 0}^{t 1}[p u(t)-c(u(t), x(t), w)] e^{-r t} d t
$$

Note que o tempo $t$ está explícito na formulação acima o que significa que é importante quando aquela atividade acontece. $\mathrm{O}$ armazenamento se enquadra na categoria de problemas autônomos, ou seja, a decisão não depende de qual período se está mas apenas da variável estado. Em outras palavras, o armazenamento é um processo markoviano em que a decisão depende apenas da variável estado naquele período. 
Nestes casos o tempo entra na formulação apenas na taxa de desconto $\left(e^{-r t}\right)$. Reformulando:

$$
\max _{u} \int_{t 0}^{t 1}[p u-c(u, x, w)] e^{-r t} d t
$$

É preciso também definir de que forma o estoque muda. Seja $g(x)$ a taxa de crescimento do estoque do recurso e $x^{\prime}$ a taxa de mudança no estoque:

$$
x^{\prime}=g(x)-u
$$

É possível impor restrições à variável $u$ como por exemplo $u \geq 0$, como é necessário no problema de armazenamento, onde o estoque $I$ não pode ser negativo. $\mathrm{O}$ uso do recurso $(u)$ é a variável controle e $x$ é a variável estado, dois elementos característicos da teoria do controle. No problema do armazenamento a variável estado é a disponibilidade inicial e a variável controle o estoque formado a cada período. É preciso ainda determinar um valor inicial para $x: x\left(t_{0}\right)=x_{0}$. Um valor final não é necessário $\left(x\left(t_{1}\right)\right.$ livre). Outra exigência é que $u$ pertença a um determinado conjunto controle U.

A forma geral dos problemas de controle pode ser apresentada como:

$$
\max _{u} \int_{t 0}^{t 1} f(x, u) e^{-r t} d t
$$

sujeito a: $x^{\prime}=g(x, u)$

com condição de ponto inicial $x\left(t_{0}\right)=x_{0}$, um ponto final que pode ser livre e um conjunto controle $U \in \mathrm{U}$. 
Observe que, na estática comparativa, a solução consiste em encontrar o valor máximo de uma função, mas nos modelos dinâmicos, a solução é encontrar a própria função que fornece uma série de valores das variáveis, de forma a maximizar (ou minimizar) um valor da função, especificado num intervalo de tempo. Por isso, a expressão a integrar ( $f$ na eq. (8)) é chamada de funcional, sendo uma função de funções $\left(x\right.$ e $u$ ). A solução do modelo é encontrar a seqüência de decisões ótimas $u^{*}, x^{*}$ para cada ano. O conjunto destas decisões é a política ótima.

De forma simples, o Princípio de Bellman diz que "uma política ótima tem a propriedade de, independente de qual a situação inicial e de qual seja a primeira decisão ótima, as decisões restantes se constituem numa política ótima com respeito à situação resultante da primeira decisão”. É com base neste princípio que a solução do modelo é feita de forma recursiva.

O benefício líquido do uso do recurso a uma determinada taxa $u$ é a soma dos benefícios no presente $f(x, u)$ mais a mudança no valor máximo do estoque causada por tomar esta decisão no presente. A mudança no valor futuro esperado no estoque, a valor presente, é analisada da seguinte maneira. Admita que o problema apresentado até o momento tem uma solução interna finita $\left(u^{*}, x^{*}\right)$ onde $u^{*}$ e $x^{*}$ representam as trajetórias ótimas das variáveis controle e estado. Tanto $u^{*}$ quanto $x^{*}$ dependem dos parâmetros $x_{0}$ e $t_{0}$. O valor da funcional objetivo $V\left(x_{0}, t_{0}\right)$ é:

$$
V\left(x_{o}, t_{o}\right) \equiv \int_{t_{o}}^{t_{1}} f\left(x^{*}, u^{*}\right) e^{-r t} d t
$$

Esta função é análoga à função objetivo indireta da estática comparativa e é denominada "função do valor ótimo". O valor marginal de um aumento no estoque inicial $x_{0}$ é dado pela derivada da eq. (10) com relação à $x_{0}$. De forma geral, $V(x, t)$ representa o valor marginal do recurso no tempo $t$ se a variável estado $(x)$ é aumentada 
exogenamente no tempo $t$. Dado $x_{0}$ há um valor marginal do estoque para qualquer instante $t$ entre $t_{0}$ e $t_{1}$ (início e final). Seja $\lambda=V\left(x^{*}, t\right)$ este valor imputado, normalmente chamado de variável adjunta.

A mudança no valor do estoque causada pela sua utilização é dada por:

$$
d[\lambda(t) x(t)] / d t=\lambda x^{\prime}+x \lambda^{\prime}
$$

A trajetória ótima ou seqüência ótima de decisões que maximiza o valor presente do recurso é obtida igualando a zero, a cada instante $t$, o benefício marginal líquido (atual + futuro).

$$
\max \quad f(x, u)+\lambda g(x, u)+x \lambda
$$

Diferenciando em relação a $u$ e $x$ obtém-se as condições necessárias para um caminho ótimo $\left(u^{*}, x^{*}\right)$ das variáveis controle e estado ao longo do horizonte. Determina-se também a trajetória ótima dos valores marginais do estoque $(\lambda)$ :

$$
\begin{aligned}
& e^{-r t} f_{u}+\lambda g_{u}=0 \\
& e^{-r t} f_{x}+\lambda g_{x}+\lambda '=0
\end{aligned}
$$

A eq. (12) é chamada de princípio de máximo e (13) de equação adjunta. Um ponto importante é que a solução dos problemas de controle envolve a solução de equações diferenciais de segunda ordem (ou, de forma equivalente, equações simultâneas de primeira ordem) onde aparecem constantes arbitrárias de integração as quais, só podem ser avaliadas, fazendo pressupostos adicionais sobre o caminho ótimo ou sobre o ponto inicial e final.

Se o problema é modelado definindo o estoque em termos de um valor 
inicial e outro final, o problema está resolvido. Senão, é preciso uma suposição a mais, especialmente sobre o ponto final. Se houver algum estoque no ponto final, necessariamente seu valor marginal tem que ser zero. As condições sobre o ponto inicial e final são denominadas condições de transversalidade. A condição de ponto final é particularmente essencial, pois a solução do modelo é feita recursivamente, de trás para frente. No caso dos problemas de armazenamento, de horizonte infinito, o ponto final é determinado pelo estoque igual a zero. As condições de segunda ordem são as seguintes: que as funções $f(x, u)$ e $\mathrm{g}(x, u)$ sejam ambas côncavas em $x$ e $u$ para todo $t$; que $\mathrm{g}(x, u)$ seja não linear em $x$ ou $u$ e que $\lambda \geq 0$.

\subsection{Armazenamento como problema de controle}

A modelagem do problema de armazenamento como um problema de controle (otimização dinâmica) se deve a Gustafson (1958). Dado que a oferta é estocástica pode haver aumento no Bem Estar abrindo mão do consumo presente formando estoque para o período futuro. Considere novamente o mercado de um produto agrícola com produção anual e armazenável numa economia fechada e sem governo admitindo que a área plantada é sempre a mesma (perfeitamente inelástica) de forma que a produção H é uma variável estocástica em função da produtividade. O Bem Estar dos consumidores será medido pelo excedente de demanda do consumidor, correspondente à área sob a curva de demanda para consumo até o preço de equilíbrio. O Bem Estar dos produtores será medido pelo excedente do produtor, correspondente à área acima da curva de oferta até o preço de equilíbrio.

Neste exemplo, sem perda de generalidade, o interesse se concentra apenas no excedente do consumidor. O objetivo, pela proposta de Gustafson é maximizar o ganho esperado de armazenar parte do produto disponível no ano $t\left(S_{t}\right)$ para o ano $t+1$ dado que $H_{t}$ é estocástica. $\mathrm{O}$ ganho num ano $t$ qualquer $\left(W_{t}\right)$ é dado pelo valor total do grão utilizado no ano $\left(Z_{t}\right)$ menos o custo de armazenamento do estoque formado no ano (k) para ser utilizado no ano seguinte. O valor total é a integral sob a curva 
inversa da demanda representada pela seguinte função:

$$
Z_{t}=\phi\left(D_{t}\right)
$$

ou

$$
Z_{t}=\phi\left(S_{t}-I_{t}\right)
$$

O valor marginal, isto é, a derivada de (14) com relação a $D_{t}$ que é a própria função inversa da demanda. $\mathrm{O}$ ganho no ano $t$, como definido acima é dado por:

$$
\mathrm{W}_{\mathrm{t}}=\mathrm{Z}_{\mathrm{t}}-\mathrm{k}\left(\mathrm{I}_{\mathrm{t}}\right)
$$

ou

$$
\mathrm{W}_{\mathrm{t}}=\phi\left(\mathrm{D}_{\mathrm{t}}\right)-\mathrm{k}_{\mathrm{t}}\left(\mathrm{I}_{\mathrm{t}}\right)
$$

ou

$$
\mathrm{W}_{\mathrm{t}}=\phi\left(\mathrm{S}_{\mathrm{t}}-\mathrm{I}_{\mathrm{t}}\right)-\mathrm{k}_{\mathrm{t}}\left(\mathrm{I}_{\mathrm{t}}\right)
$$

A regra do armazenamento, ou política ótima, que é a solução do modelo, é uma função $\varphi_{t}$ que mostra a dependência de $I_{t}$ com relação a $S_{t}$ (que é o mesmo que $I_{t-1}$ e $H_{t}$ que definem $S_{t}$ ). Ou seja, a "regra do armazenamento" é uma função que mostra quanto de estoque será formado para cada quantidade de produto disponível num dado período:

$$
I_{t}=\varphi_{t}\left(I_{t-1}, H_{t}\right)
$$

Dado um período $n(t=1, \ldots, \mathrm{n})$ é possível obter uma função $\varphi$ para cada ano $\left(\varphi_{1}, \varphi_{2}, \ldots, \varphi_{\mathrm{n}}\right)$. Dado o caráter dinâmico, o objetivo passa a ser maximizar a soma, $a$ valor presente (descontados para o ano t), dos ganhos futuros esperados em função do armazenamento no período 1 a $\mathrm{n}$. Para obter o valor presente é necessário definir uma taxa anual de desconto $(\delta=1 /(1+r))$, onde $r$ é a taxa anual de juros. 
Seja $V_{1, n}$ a soma dos ganhos anuais esperados do ano 1 ao $n$, descontados para o ano 1 .

$$
V_{1, n}=W_{1}+\delta E W_{2}+\delta^{2} E W_{3}+\ldots+\delta^{n-1} E W_{n}
$$

onde E é o operador de expectativa. Observe que a eq. (20) é equivalente à eq. (10), transformando o problema de equilíbrio do mercado em um problema de otimização dinâmica. A "política ótima de armazenamento" é o conjunto das regras ótimas anuais de armazenamento $\varphi^{*}, \varphi^{*}{ }_{t+1}, \ldots, \varphi^{*}$, como definida pelo Princípio de Bellman.

Sejam $\mathrm{F}_{2}, \ldots, \mathrm{F}_{n}$ as funções de distribuição de probabilidade das produções estocásticas $\left(H_{2}, \ldots, H_{n}\right)$. Para dados $\mathrm{F}_{2}, \ldots, \mathrm{F}_{n}, V_{1, n}$ é uma função de $S_{1}$ e $\varphi_{1}, \ldots$, $\varphi_{n}$. No ano $n$ ou período final, o estoque $I_{\mathrm{n}}$ deve ser pré determinado (condição de transversalidade) e tanto pode ser igual a zero quanto a qualquer outro valor que se julgue relevante. No exemplo, $I_{\mathrm{n}}=0$. O valor do ganho no ano $n$ será:

$$
V_{n, n}=W_{n}=\phi_{n}\left(S_{n}-I_{n}\right)-\mathrm{k}\left(I_{n}\right)
$$

Seja $V^{*}{ }_{n, n}$ o valor máximo alcançável de $V_{n, n}$ :

$$
\begin{aligned}
V_{n, n}= & \operatorname{Max}\left[\phi_{n}\left(S_{n}-I_{n}\right)-\mathrm{k}\left(I_{n}\right)\right]=\phi_{n}\left(S_{n}\right) \\
0 \leq \mathrm{In} \leq \mathrm{Sn} &
\end{aligned}
$$

Dado que o estoque ótimo no ano $n$ é igual a zero $\left(I_{n}=0\right)$, o valor do ganho no ano n é função apenas de $S_{n}$. Como o ganho é o Bem Estar da quantidade consumida e não será formado estoque neste ano, o ganho será função da quantidade de produto que estiver disponível neste ano $\left(\mathrm{S}_{n}\right)$.

Para o ano $n$-1, o ganho total será o ganho do ano mais o ganho esperado (porque a produção é estocástica) para o ano n: 


$$
V_{n-1, n}=W_{n-1}+\delta W_{n}=\phi_{n-1}\left(S_{n-1}-I_{n-1}\right)-\mathrm{k}\left(I_{n-1}\right)+\delta E \phi_{n}\left(S_{n}\right)
$$

E lembrando (3)

$$
V_{n-1, n}=W_{n-1}+\delta W_{n}=\phi_{n-1}\left(S_{n-1}-I_{n-1}\right)-\mathrm{k}\left(I_{n-1}\right)+\delta E \phi_{n}\left(I_{n-1}+H_{n}\right)
$$

Maximizando (23) com respeito a $I_{n-1}$ :

$$
V_{n-1, n}^{*}=\underset{0 \leq I n-1 \leq S n-1}{\operatorname{Max}}\left[\phi_{n-1}\left(S_{n-1}-I_{n-1}\right)-\mathrm{k}\left(I_{n-1}\right)\right]+\delta E\left[\phi_{n}\left(I_{n-1}+H_{n}\right)\right.
$$

condição de primeira ordem:

$$
\frac{\partial V_{n-1, n}}{\partial I_{n-1}}=-\frac{\partial \phi_{n-1}}{\partial I_{n-1}}-k+\delta E \frac{\partial \phi_{n}}{\partial I_{n-1}}=0
$$

como a derivada de $\phi$ é o valor marginal do ganho, ou a própria função de demanda:

$$
-P_{n-1}\left(S_{n-1}-I_{n-1}\right)-\mathrm{k}+\delta \mathrm{E} P_{n}\left(I_{n-1}+H_{n}\right)=0
$$

A condição de primeira ordem para maximizar a soma dos ganhos líquidos em dois períodos é de que o ganho adicional de transferir uma unidade de produto do período n-1 (que é uma unidade a mais de estoque $I_{n-1}$ ) para o período $n$ $\left(\delta \mathrm{E} P_{n}\right)$ iguale a perda líquida marginal de uma unidade a menos para ser consumida no período n-1 $\left(P_{n-1}-\mathrm{k}\right)$. Esta condição é o princípio de otimização aplicado ao problema do armazenamento. O volume ótimo de estoque é o que iguala o ganho marginal à perda marginal de Bem Estar, que é exatamente a condição de otimização do armazenamento privado (arbitragem temporal).

Em termos gerais, a solução do problema é encontrar a sequiência de 
estoques a serem formados ao longo dos períodos de forma que esta seqüência seja ótima (princípio de Bellman ${ }^{3}$ ) a partir de um dado estoque inicial.

$\mathrm{O}$ que difere as abordagens (equilíbrio do mercado competitivo e otimização dinâmica) é quem toma a decisão. Quando o enfoque é no mercado competitivo como no início deste capítulo, a decisão de armazenar é tomada pelo conjunto dos participantes do mercado. Quando a modelagem é pela teoria do controle (otimização dinâmica) quem decide é um planejador central, o governo, no caso.

Samuelson (1971) demonstrou que, numa sociedade sem distorções, com uma função de bem estar social individualista, a condição de arbitragem privada dada por (3) é exatamente a condição de Kuhn-Tucker para um armazenamento socialmente ótimo. Essa demonstração permite admitir que as ações dos armazenadores privados (demanda pelo produto ao invés de função do Bem Estar marginal; preço do grão como valor marginal do grão; maximização do excedente do produtor e do consumidor ao invés de maximização da função de Bem Estar, taxa de desconto privada ao invés de taxa de desconto social) sejam consideradas como ótimas também socialmente (Gardner, 1979). Portanto, as duas abordagens são equivalentes, levando aos mesmos resultados. Um planejador central procurando maximizar o Bem Estar da sociedade quanto ao armazenamento deste produto não fará melhor do que o conjunto de agentes do mercado em condições competitivas.

A grande diferença é que a transformação do problema de equilíbrio competitivo de mercado com expectativa racional em um problema de otimização dinâmica é que nesta última formulação é possível obter a solução.

Observe agora a condição de segunda ordem para máximo, dada por:

$\overline{{ }^{3} \text { Ver Silberberg, } 1990}$ 


$$
\frac{\partial^{2} V_{n-1, n}}{\partial I_{n-1}^{2}}=\frac{\partial P\left(S_{n-1}-I_{n-1}\right)}{\partial I_{n-1}}+\delta E \frac{\partial P\left(I_{n-1}+H_{n}\right)}{\partial I_{n-1}}<0
$$

A expressão certamente é negativa porque a demanda é negativamente inclinada. Para o período n-2 o objetivo é maximizar a soma dos ganhos líquidos dos períodos $n$-2 a $n$, dado que $V^{*}{ }_{n-1, n}$ já é máximo:

$$
\begin{gathered}
V_{n-2, n}=W_{n-2}+\delta E V^{*}{ }_{n-1, n}=\phi_{n-2}\left(S_{n-2}-I_{n-2}\right)-\mathrm{k}\left(I_{n-2}\right)+\delta E V^{*}{ }_{n-1, n}\left(S_{n-1}\right) \\
V_{n-2, n}=\phi_{n-2}\left(S_{n-2}-I_{n-2}\right)-\mathrm{k}\left(I_{n-2}\right)+\delta E V^{*}{ }_{n-1, n}\left(I_{n-2+} H_{n-1}\right) \\
V_{n-2, n}^{*}=\operatorname{Max}_{0 \leq I n-2 \leq S n-2}\left[\phi_{n-2}\left(S_{n-2}-I_{n-2}\right)-\mathrm{k}\left(I_{n-2}\right)\right]+\delta E\left[V_{n-1, n}^{*}\left(I_{n-2}+H_{n-1}\right)\right.
\end{gathered}
$$

O mesmo procedimento é realizado até o ano 1, quanto então:

$$
\begin{aligned}
& V_{1, n}=W_{1}+\delta E V_{2, n}^{*_{2, n}}=\phi_{1}\left(S_{1}-I_{1}\right)-\mathrm{k}\left(I_{1}\right)+\delta E V^{*}{ }_{2, n}\left(S_{1}\right) \\
& V_{1, n}=\phi_{1}\left(S_{1}-I_{1}\right)-\mathrm{k}\left(I_{1}\right)+\delta E V^{*, n}\left(I_{1+} H_{2}\right) \\
& V^{*}{ }_{1, n}=\operatorname{Max}_{0 \leq I_{1} \leq S_{l}}\left[\phi_{1}\left(S_{1}-I_{1}\right)-\mathrm{k}\left(I_{1}\right)+\delta E V^{*}{ }_{2, n}\left(I_{1}+H_{2}\right)\right]
\end{aligned}
$$

A expressão (29) é a equação de Bellman do problema de armazenamento, deixando claro porque $V_{l, n}$ é função de $S_{1}$. O valor máximo de $\mathrm{V}$ num período $t$ qualquer é resultado da implementação da regra ótima de armazenamento $\varphi^{*}{ }_{t}$.

\section{Horizonte infinito}

Não é necessário analisar o problema do armazenamento para um 
horizonte finito $(5,1020$ ou 50 anos, por exemplo). O mesmo pode ser feito para um horizonte infinito já que a variável a ser maximizada é a soma, a valor presente, dos ganhos líquidos atual e futuros. Mesmo numa seqüência infinita, a soma é finita. Para que isto seja verdadeiro ${ }^{4}$, a função de valor total (integral sob a curva de demanda ou soma dos excedentes do produtor e do consumidor para o caso de oferta elástica), seja delimitada acima e abaixo. Para isto, basta que a função de demanda tenha pontos limites tanto no eixo do preço quanto da quantidade. A segunda condição é que o fator de desconto $(\delta=1 /(1+r))$ esteja entre 0 e $1(0 \leq \delta \leq 1)$ o que não apresenta problemas, pois o fator de desconto jamais estará fora deste intervalo.

\section{Estacionariedade}

Se as funções de oferta e demanda e os parâmetros do modelo (custo de armazenamento, taxa de juros, etc) forem os mesmos todos os anos, o processo passa a ser estacionário e, novamente, a solução do problema será uma única função $\varphi^{*}$ t. Neste estudo será analisado o problema do armazenamento estacionário e de horizonte infinito.

Nestes casos, o que se procura não é uma seqüência de regras ótimas $\left(\varphi^{*}{ }_{1}, \ldots, \varphi^{*}{ }_{n}\right)$ a serem aplicadas nos anos 1 a $\mathrm{n}$, mas uma única regra ótima (função que relaciona $I_{t}$ e $S_{t}$ ) a ser aplicada a cada ano. Isto não significa que o estoque será o mesmo todos os anos. Significa apenas que, a mesma regra será aplicada todas as vezes que a variável estado assumir o mesmo valor (o que é praticamente impossível, diga-se de passagem, pois, raramente, em anos diferentes, a soma do estoque do ano anterior mais a produção será a mesma).

\section{Abordagem pela função de valor marginal}

Gustafson (1958) demonstrou que o problema do armazenamento pode

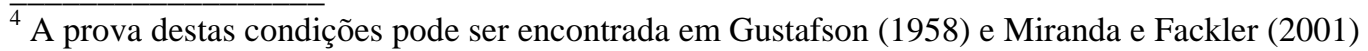


ser abordado pela função de valor total (equação de Bellman), que foi o enfoque usado nesta seção, como através da função de valor marginal (no caso, a própria função de demanda pelo produto).

A abordagem pela função de valor marginal é o mesmo que aplicar as condições de equilíbrio de Euler para um processo dinâmico (Miranda \& Fackler, 2001; Silberberg, 1990, Judd, 1999). Para o ano $n$ o estoque ótimo ainda é zero $\left(I_{n}=0\right)$. Permitindo que o custo marginal não seja constante (mas crescente), a maximização para o ano n-1 é obtida pela condição de primeira ordem, cuja solução consiste em encontrar, para cada valor possível de $S$, o valor de I >0 que satisfaz:

$$
\begin{aligned}
-P_{n-1}\left(S_{n-1}-I_{n-1}\right)-\mathrm{k}^{\prime}\left(I_{n-1}\right)+\delta E_{n-1} P_{n}\left(I_{n-1}+H_{n}\right) & =0 \\
& \text { se } I_{n-1}>0 \\
<0 & \text { se } I_{n-1}=0
\end{aligned}
$$

isto resultará em $I_{n-1}^{*}$ como função de $S_{n}$ :

$$
\begin{aligned}
& I_{n-1}^{*}=\varphi_{n-1}^{*}\left(S_{n}\right) \\
& I_{n-1}^{*}=\varphi_{n-1}^{*}\left(I_{n-1}+H_{n}\right) \quad \text { para } I_{n-1}>0 \\
& \text { ou } \quad \varphi^{*}{ }_{n-1}\left(S_{n}\right)=0 \quad \text { para } I_{n-1}=0
\end{aligned}
$$

Para o ano n-2:

$$
-P_{n-2}\left(S_{n-2}-I_{n-2}\right)-\mathrm{k}^{\prime}\left(I_{n-2}\right)+\delta E_{n-2} P_{n-1}\left[I_{n-2}+H_{n-1}-\varphi^{*}{ }_{n-1}\left(I_{n-2}+H_{n-1}\right)\right]=0
$$

cuja solução resulta em

$$
I_{n-2}=\varphi_{n-2}^{*}\left(S_{n-1}\right)
$$

$\mathrm{E}$, de forma geral, para o ano $\mathrm{t}(\mathrm{t}=\mathrm{n}-1, \mathrm{n}-2, \ldots, 1)$ : 


$$
\begin{gathered}
-P_{t}\left(S_{t}-I_{t}\right)-\mathrm{k}^{\prime}\left(I_{t}\right)+\delta E_{t} P_{t+1}\left[I_{t}+H_{t+1}-\varphi^{*}{ }_{t+1}\left(I_{t}+H_{t+1}\right)\right]=0 \\
I_{t}=\varphi^{*}{ }_{t}\left(S_{t}\right)
\end{gathered}
$$

Note que tanto $E_{t} P_{t+1}$ quanto $P_{t}$ são dependentes do estoque atual e do montante de produto disponível. Portanto, a condição de arbitragem contém, de forma implícita, o armazenamento atual $\left(I_{t}\right)$ como função do montante disponível $\left(S_{t}\right)$. Se o horizonte é infinito e, dadas condições apropriadas de regularidade e transversalidade ${ }^{5}$, o armazenamento é uma função estacionária da disponibilidade:

$$
I_{t}=f\left(S_{t}\right) \quad 0 \leq f \leq 1, \quad I_{t} \geq 0
$$

Dada esta relação, $P_{t}$ pode ser expresso como uma função apenas do estoque atual. Tomando o modelo mais simples, composto pela função inversa da demanda para consumo, os equilíbrios físicos de que a disponibilidade atual é a soma do estoque anterior mais a produção do período; e do montante disponível, o que não é consumido é armazenado, resulta em:

$$
P_{t}=P\left(f^{-1}\left(I_{t}\right)-I_{t}\right) \equiv \rho\left(I_{t}\right)
$$

Onde $\rho\left(I_{t}\right)$ é a função inversa da demanda por estoques. Dado que o armazenamento privado num ambiente competitivo é também o armazenamento que maximiza o Bem Estar numa economia sem distorções, a área sob a função inversa da demanda por estoques $\rho\left(I_{t}\right)$ pode ser interpretada como o valor presente do Bem Estar futuro esperado, a partir do estoque atual. Qualquer volume estocado agora será usado de forma ótima em algum ponto no futuro e, assim, o seu valor marginal atual reflete de forma correta o seu uso esperado no futuro (Wright \& Williams, 1984). 
Na figura 3, o efeito líquido do estoque sobre o valor presente da soma esperada do excedente do consumidor e do produtor em todos os períodos futuros, líquido do custo do armazenamento, é dado pelo excedente sob a área da curva de demanda derivada para armazenamento:

$$
\int_{0}^{D-E} \rho\left(I_{t}\right) d I-P d(D-E)
$$

a qual é representada, no gráfico, pela área UDE.

Os efeitos totais de Bem Estar para produtor e consumidor devidos à possibilidade de armazenar por mais um período, são os valores presentes dos efeitos esperados no futuro mais os efeitos no período 1. Com esta mesma base de análise é possível avaliar o impacto de políticas de intervenção nos mercados através da formação de estoques públicos.

\subsection{Bem Estar}

O ganho definido a ser maximizado foi definido como "o valor total esperado do grão utilizado menos o custo de armazenamento do montante que será estocado para o período seguinte" (Gustafson, 1958, p. 17). O termo “esperado" é usado no sentido de expectativa racional, o que implica que este depende da distribuição de frequiência da(s) variável(eis) aleatória(s) e que a expectativa é formada endogenamente, a partir das variáveis contidas no modelo, além das condições conhecidas de que os agentes usam toda a informação disponível no momento da decisão e não cometem erros sistematicamente. O "valor total" pode ser visto como a área sob a curva de demanda para a quantidade utilizada naquele ano e acima da curva de oferta para o mesmo

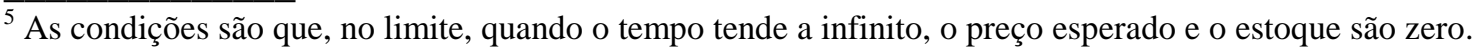


intervalo, ou seja, o Bem Estar.

Nesta análise são feitos os seguintes pressupostos, a exemplo de inúmeros estudos anteriores: que não há distorções neste mercado ou fontes de instabilidade na economia além do mercado em estudo; que o Bem Estar pode ser medido pelas mudanças nos excedentes do produtor e do consumidor - assim, são desconsideradas as questões distributivas que não sejam a comparação dos ganhos agregados de produtores e consumidores; que as medidas relevantes do excedente são aproximadas, de forma adequada, por cálculos feitos com base nas curvas de oferta e demanda de mercado. Talvez seja importante no momento deixar claro que o estudo se concentra na matériaprima agrícola e que se trata do mercado ao produtor e que, portanto, a demanda com a qual ele se defronta é uma demanda derivada dado que as negociações diretas entre produtores e consumidores são desprezíveis. Supõe-se que os ganhos de Bem Estar sejam devidamente repassados aos consumidores finais através da elasticidade de transmissão de preços. Guimarães (1990) estimou a elasticidade cruzada de transmissão de preços do milho para o frango, mas não foram encontradas outras elasticidades para os demais produtos finais derivados do milho.

Medir o Bem Estar através do excedente do consumidor não é consenso na literatura econômica. Silberberg (1990) demonstra claramente as dificuldades que o problema apresenta. Se a demanda de mercado é a curva de demanda compensada, a área a esquerda da curva mede quanto o consumidor está disposto a pagar, mantendo utilidade constante, por uma determinada quantidade de produto. Mas as curvas de demanda utilizadas na análise do armazenamento são curvas de demanda Marshallianas, onde a renda é constante e a utilidade muda - mas não é possível obter valores monetários para a mudança de utilidade.

Wright \& Williams (1982, pg. 609) destacam que, a rigor, a mudança na área sob a curva não compensada da demanda por consumo só é a medida exata da mudança no Bem Estar se a utilidade marginal da renda é constante na faixa de preços 
relevante. De forma geral, a análise dos autores é de que o erro envolvido em usar uma curva de demanda Marshalliana é pequeno se o produto em questão tem uma participação pequena nos gastos do consumidor ou se a elasticidade renda da demanda pelo produto é baixa. No caso do milho a participação nos gastos do consumidor é indireta, através das carnes, dado que a maior parte do grão (em torno de $80 \%$ ) é usada na alimentação animal especialmente frango e suíno. A participação das carnes em geral e ovos nos gastos dos consumidores brasileiros, medida pela POF de 1996 é de apenas $3 \%$. A participação na renda será um pouco menor do que isto e a participação da parcela do milho contida na carne será ainda menor.

\subsection{Modelos propostos}

O modelo completo de economia aberta e intervenção via PEP é apresentado em 4 etapas, que servirão também para análise do modelo final. $\mathrm{O}$ primeiro modelo representa o mercado fechado ao comércio exterior e sem intervenção do governo; o segundo mantém o mercado fechado, mas o governo intervém através de uma política de subsídio cujo instrumento é o PEP; o terceiro modelo representa o mercado aberto e sem intervenção e no quarto e último modelo o mercado é aberto e com política de PEP.

Os modelos propostos são resultado da combinação de modelos encontrados na literatura e de propostas originais. A utilização da função da área plantada como variável de decisão é encontrada em Lowry et al., (1987), Miranda \& Helmberger (1988), Glauber et al. (1989), Miranda \& Glauber (1993), Makki et al., (1996) e Lence \& Hayes (2000). A maximização de lucro pelo produtor tendo a área como variável de escolha e o custo marginal por hectare foi adaptada de Wright \& Williams (1984) e não está claramente definida nos trabalhos citados acima. A demanda estocástica foi incluída nos modelos seguindo a sugestão de Gustafson (1958). A inclusão de subsídio ao preço do produtor com mercado aberto é original neste tipo de 
análise, embora uma análise de mercado aberto possa ser encontra em Makki et al., (1996) levando em conta apenas subsídio na exportação.

\subsubsection{Economia fechada e sem governo}

Considere inicialmente a economia fechada e o mercado livre e com a possibilidade de armazenar. Cada produtor decide a quantidade de área que está disposto a plantar no ano safra maximizando o lucro esperado que é dado por:

$$
E \Pi_{t}^{i}=\delta E_{t} P_{t+1} * E_{t} \mathrm{Y}_{t+1} * A_{t}^{i}-C_{t}\left(A_{t}^{i}\right)
$$

onde $A_{t}^{i}$ é a área a ser plantada pelo produtor $i$ no período $t, E_{t} P_{t+1}$ é a sua expectativa em $t$ para o preço no período seguinte $(t+1), E_{t} Y_{t+1}$ é a sua expectativa quanto a produtividade no ano $t+1$ e $C_{t}$ é o custo total de produção, em função da área; $\delta$ é a taxa de desconto dada por $[1 /(1+r)]$ onde $r$ é a taxa de juros. A condição de primeira ordem para maximização do lucro do produtor em relação à área a ser plantada é dada por:

$$
\frac{\partial E \prod_{t}^{i}}{\partial A_{t}^{i}}=\delta E_{t} P_{t+1} * E_{t} Y_{t+1}-c_{t}^{i}=0
$$

Em ambiente competitivo o produtor iguala o custo marginal por hectare

$\left(c_{t}^{i}\right)$ à receita marginal esperada por hectare $\left(\delta E_{t} P_{t+1} * E_{t} \mathrm{Y}_{t+1}\right)$. A área a ser plantada atende à condição de equilíbrio dada pela eq. (37) e resulta na área como função do preço esperado:

$$
\begin{aligned}
& A_{\mathrm{t}}=A\left[\left(E_{t} P_{t+1}\right)\right] \\
& \partial A_{t} / \partial E_{t} P_{t+1}>0
\end{aligned}
$$


onde $A_{\mathrm{t}}$ é a área plantada no ano $t, E_{t}\left(P_{t+1}\right)$ é a expectativa (racional no sentido de Muth) dos produtores quanto ao preço para o ano safra seguinte. A área cresce em função do preço esperado porque o custo marginal por hectare é crescente. A produção que será colhida no ano safra $\left(H_{t}\right)$ é o produto da área plantada no ano safra anterior e da produtividade obtida no ano $\left(Y_{t}\right)$ :

$$
H_{t}=A_{t-1} * Y_{\mathrm{t}}
$$

A produtividade é uma variável aleatória com distribuição normal, média $\mu$ e variância $\sigma^{2}\left(Y_{t} \approx \mathrm{N}\left(\mu, \sigma^{2}\right)\right)$. O ano safra começa com uma disponibilidade inicial $S_{t}$ composta dos estoques finais privados do ano safra anterior $\left(I_{t-1}^{i}\right)$ e da nova produção $\left(H_{\mathrm{t}}\right)$ :

$$
S_{\mathrm{t}}=I_{\mathrm{t}-1}+H_{\mathrm{t}}
$$

Este volume de produto disponível ou será utilizado para consumo ou será armazenado pela iniciativa privada, implicando na equação de equilíbrio quantitativo do mercado:

$$
S_{\mathrm{t}}=D_{\mathrm{t}}+I_{\mathrm{t}}
$$

Rearranjando os termos

$$
D_{t}=S_{t}-I_{t}
$$

substituindo a eq. (3.4.1.5) em (3.4.1.6b)

$$
D_{t}=I_{t-1}+H_{t}-I_{t}
$$


A função inversa da demanda para consumo é uma função negativamente inclinada dos preços correntes de mercado e de um choque aleatório $u_{t}$ :

$$
\begin{gathered}
P_{\mathrm{t}}=\mathrm{P}\left(D_{\mathrm{t}}, u_{\mathrm{t}}\right) \\
\partial P_{\mathrm{t}} / \partial D_{\mathrm{t}}<0
\end{gathered}
$$

Admite-se que as funções de oferta de área e de demanda para consumo são as mesmas em todos os anos. O nível de estoque privado de equilíbrio que será formado, segue a condição de arbitragem temporal:

$$
\begin{array}{ll}
\delta \mathrm{E}_{\mathrm{t}} P_{\mathrm{t}+1} \geq P_{\mathrm{t}}+\mathrm{k} & I_{\mathrm{t}} \geq 0 \\
\delta \mathrm{E}_{\mathrm{t}} P_{\mathrm{t}+1}<P_{\mathrm{t}}+\mathrm{k} & I_{\mathrm{t}}=0
\end{array}
$$

A eq. (45) implica em que, se o preço esperado (a valor presente) for menor do que o preço corrente mais o custo de armazenamento, não se formam estoques $\left(I_{\mathrm{t}}=0\right)$. A solução deste sistema de equações é o estoque de equilíbrio. Observe que o preço esperado (expectativa racional) para o período $t+1$ é função do estoque a ser formado no período $t$. De (43) e (44):

$$
E P_{\mathrm{t}+1}=f\left(I_{t}+H_{t+1}-I_{t-1}\right)
$$

Explicitamente o que se procura é o valor de $I_{t}$ que soluciona a seguinte expressão:

$$
E P_{t+1}\left(D_{t+1}\right)-P_{t}\left(D_{t}\right)-k=0
$$

$\mathrm{ou}$

$$
E P_{t+1}\left(S_{t+1}-I_{t+1}\right)-P_{t}\left(S_{t}-I_{t}\right)-k=0
$$


$\mathrm{ou}$

$$
E P_{t+1}\left(I_{t}+A_{t} * Y_{t+1}-I_{t+1}\right)-P_{t}\left(I_{t-1}+A_{t-1} * Y_{t}-I_{t}\right)-k=0
$$

No período $t$ a produtividade $Y_{t}$ é conhecida bem como o estoque do período anterior, mas a produtividade e o estoque do período $t+1$ não são conhecidos e $I_{t}$ é a variável que soluciona o modelo. Note ainda que $Y_{t+1}$ é uma variável estocástica que pode assumir qualquer valor da sua distribuição de freqüência e que a área a ser plantada no período t é determinada junto com o estoque $I_{t}$. A solução dos modelos é discutida no capítulo 4. A Figura 5 representa o equilíbrio deste mercado num ano t qualquer. A função de oferta que aparece no gráfico é resultado da área plantada no período anterior e da produtividade do ano, como expressa na eq. (39). A produção do ano é $H_{t}$, o preço de equilíbrio do mercado é $P_{t}$; a quantidade consumida será $D_{t}$ e o estoque do ano será $I_{t}$ $=H_{t}-D_{t}$. A figura representa o mercado sem estoque inicial $\left(I_{t-1}=0\right)$. 


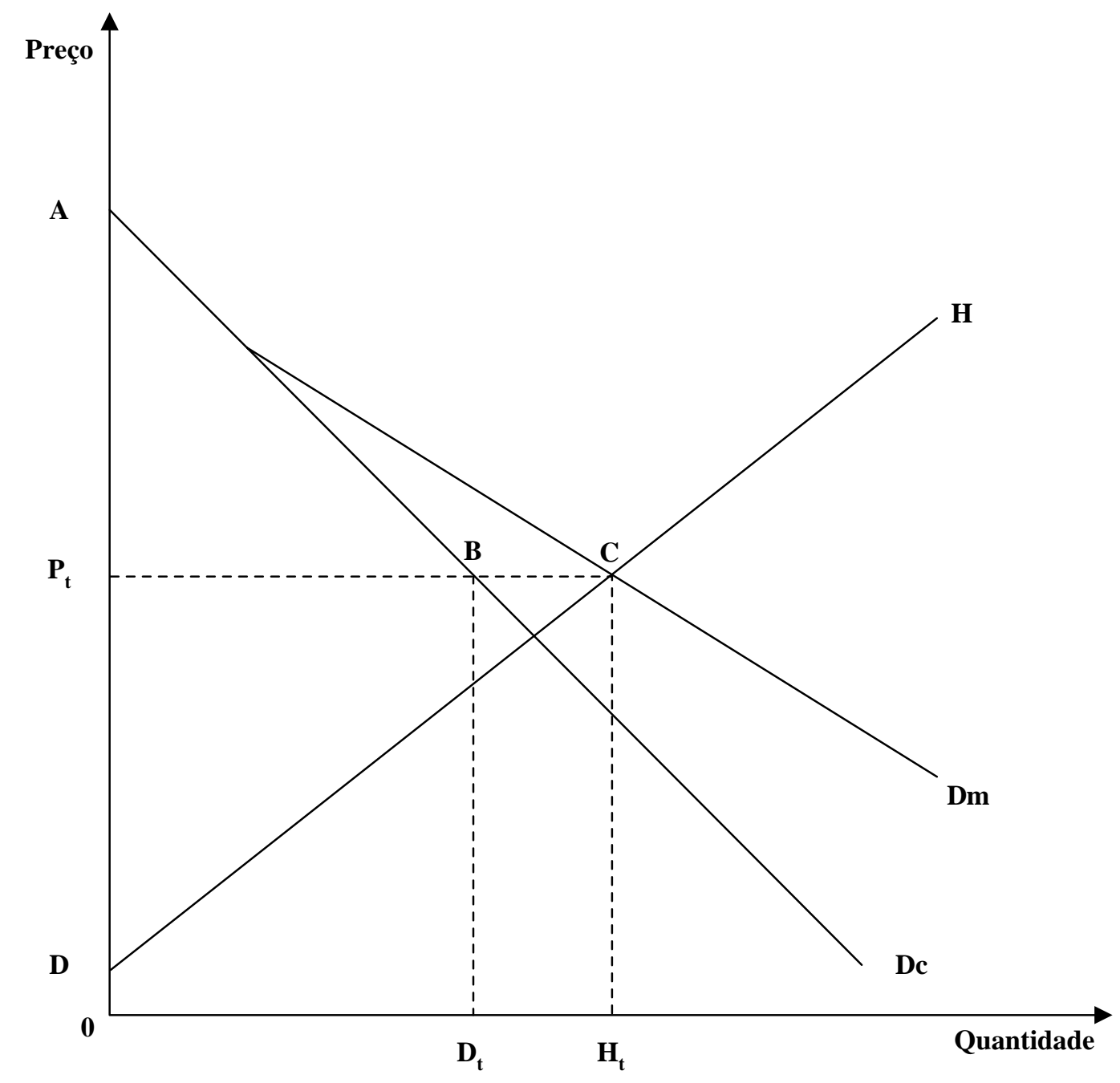

Figura 5 - Equilíbrio para o modelo de mercado fechado sem intervenção

\subsubsection{Economia fechada e intervenção via PEP}

Este modelo contém todos os elementos do modelo anterior com exceção de que a área plantada que passa a levar em conta o preço mínimo da próxima safra. $\mathrm{O}$ pressuposto principal é que o governo anuncia o novo preço mínimo no período de plantio. O governo intervém através do PEP (Prêmio para Escoamento de Produto), instalando um diferencial de preços no mercado - um para o produtor (mínimo) e o preço 
de mercado de equilíbrio. O governo não forma estoque. A área plantada é função do maior de dois valores: preço mínimo e preço de mercado esperado:

$$
\begin{aligned}
& A_{t}=A\left[\max \left(E_{t} P_{t+1}, P_{T+1}^{M}\right)\right] \\
& \partial A_{t} / \partial E_{t} P_{t+1}>0 ; \quad \partial A_{t} / \partial P^{M}{ }_{t+1}>0
\end{aligned}
$$

onde $P^{M}{ }_{t+1}$ é o preço mínimo anunciado no ano safra $t$ para vigorar no ano safra $t+1$. As demais funções e relações permanecem as mesmas do modelo anterior. O prêmio ou subsídio $\left(\theta_{t}\right)$ a ser pago pelo governo por unidade de produto será dado por:

$$
\begin{aligned}
& P_{t}>P^{\mathrm{M}} \quad \Rightarrow \quad \theta_{t}=0 \\
& P_{t}<P^{\mathrm{M}} \quad \Rightarrow \quad \theta_{t}=\left(P^{\mathrm{M}}-P_{t}\right)
\end{aligned}
$$

O subsídio é concedido apenas ao produtor e para a produção colhida no ano safra. Assim, o subsídio total do ano $\left(\Theta_{\mathrm{t}}\right)$ é o produto do subsídio por unidade e da produção do ano. Esta modelagem segue as normas vigentes para o PEP no Brasil (CONAB, 2000a).

As demais funções e relações são iguais ao modelo 3.1.1, ou seja:

$$
\begin{array}{ll} 
& H_{t}=A_{t-1} * Y_{\mathrm{t}} \\
& S_{\mathrm{t}}=I_{\mathrm{t}-1}+H_{\mathrm{t}} \\
& S_{\mathrm{t}}=D_{\mathrm{t}}+I_{\mathrm{t}} \\
& D_{t}=I_{t-1}+H_{t}-I_{t} \\
& P_{\mathrm{t}}=P\left(D_{\mathrm{t}}, u_{\mathrm{t}}\right) \\
& \delta \mathrm{E}_{\mathrm{t}} P_{\mathrm{t}+1} \geq P_{\mathrm{t}}+\mathrm{k} \quad I_{\mathrm{t}} \geq 0 \\
& \\
& \delta \mathrm{E}_{\mathrm{t}} P_{\mathrm{t}+1}<P_{\mathrm{t}}+\mathrm{k} \quad I_{\mathrm{t}}=0
\end{array}
$$




$$
E P_{t+1}\left(I_{t}+A_{t} * Y_{t+1}-I_{t+1}\right)-P_{t}\left(I_{t-1}+A_{t-1} * Y_{t}-I_{t}\right)-k=0
$$

\subsubsection{Economia aberta e sem intervenção}

O milho é um produto de mercado interno, mas comercializável externamente, dependendo dos preços internacional e doméstico. A Figura 5 representa o mercado deste produto num ano $\mathrm{t}$ em que o preço de equilíbrio no mercado interno está entre o preço de exportação e o preço de importação.

A função de oferta que aparece no gráfico é dada pela área plantada no período anterior multiplicada pela produtividade média observada no ano. A demanda Dc é a demanda para consumo no ano e a curva Dm se refere à demanda de mercado, incluindo a demanda por armazenamento.

Neste modelo as funções de oferta de área e demanda para consumo são iguais ao modelo inicial (3.1.1):

$$
\begin{aligned}
& A_{\mathrm{t}}=A\left[\left(E_{t} P_{t+1}\right)\right] \\
& H_{t}=A_{t-1} * Y_{\mathrm{t}} \\
& P_{\mathrm{t}}=P\left(D_{\mathrm{t}}, u_{\mathrm{t}}\right)
\end{aligned}
$$

O comércio internacional é incluído através de uma condição de arbitragem espacial entre o mercado interno e o externo:

$$
\begin{array}{ll}
P_{t}^{R M}-\tau_{t}-P_{t} \geq 0 & M_{t} \geq 0 \\
P_{t}^{R M}-\tau_{t}-P_{t}<0 & M_{t}<0
\end{array}
$$


Onde $\tau_{\mathrm{t}}$ é o custo de transação no mercado internacional, considerado o mesmo tanto para a exportação quanto para a importação. A expressão (60) significa que, quando o preço no mercado externo $\left(P^{R M}\right)$ é maior do que o preço no mercado interno $\left(P_{t}\right)$ mais o custo de Transação, o país exporta $(\mathrm{M}>0)$; quando ocorre o inverso, o país importa. A disponibilidade $(\mathrm{S})$ passa a ser expressa por

$$
\begin{aligned}
S_{t} & =D_{t}+I_{t}+M_{t} \\
\text { ou } \quad D_{t} & =I_{t-1}+H_{t}-I_{t}-M_{t}
\end{aligned}
$$

O volume de produto disponível será utilizado para consumo ou será armazenado e, quanto ao comércio internacional, parte da disponibilidade pode ser alocada para exportação $(\mathrm{M}>0)$ ou então o montante disponível aumenta pelo volume de importações $(M<0)$. Se a relação for de igualdade não há comércio exterior. As demais relações permanecem as mesmas:

$$
\begin{gathered}
S_{\mathrm{t}}=I_{\mathrm{t}-1}+H_{\mathrm{t}} \\
\delta \mathrm{E}_{\mathrm{t}} P_{\mathrm{t}+1} \geq P_{\mathrm{t}}+\mathrm{k} \quad I_{\mathrm{t}} \geq 0 \\
\delta \mathrm{E}_{\mathrm{t}} P_{\mathrm{t}+1}<P_{\mathrm{t}}+\mathrm{k} \quad I_{\mathrm{t}}=0 \\
E P_{t+1}\left(I_{t}+A_{t} * Y_{t+1}-I_{t+1}-M_{t+1}\right)-P_{t}\left(I_{t-1}+A_{t-1} * Y_{t}-I_{t}-M_{t}\right)-k=0
\end{gathered}
$$

A Figura 6 representa o equilíbrio deste mercado num ano t qualquer da mesma forma que na Figura 5, incluindo o preço de paridade de exportação $\left(\mathrm{P}^{\mathrm{OFB}}\right)$ e o preço de paridade de importação $\left(\mathrm{P}^{\mathrm{CIF}}\right)$. O país exportará quando demanda e/ou oferta se deslocarem de forma que o preço de equilíbrio seria inferior ao preço de paridade de exportação, viabilizando as vendas externas e fazendo com que o preço de equilíbrio do mercado no ano iguale o preço de exportação. Se o deslocamento de oferta e/ou demanda levar a um preço de equilíbrio superior ao preço de paridade de importação, o país importa e o preço interno iguala o preço de importação. O mercado brasileiro de 
milho, em geral, se encontra na condição de equilíbrio apresentada no gráfico. Em anos de quebra de safra o preço sobe o suficiente para viabilizar importações e em outros anos, excedentes são destinados ao mercado externo.

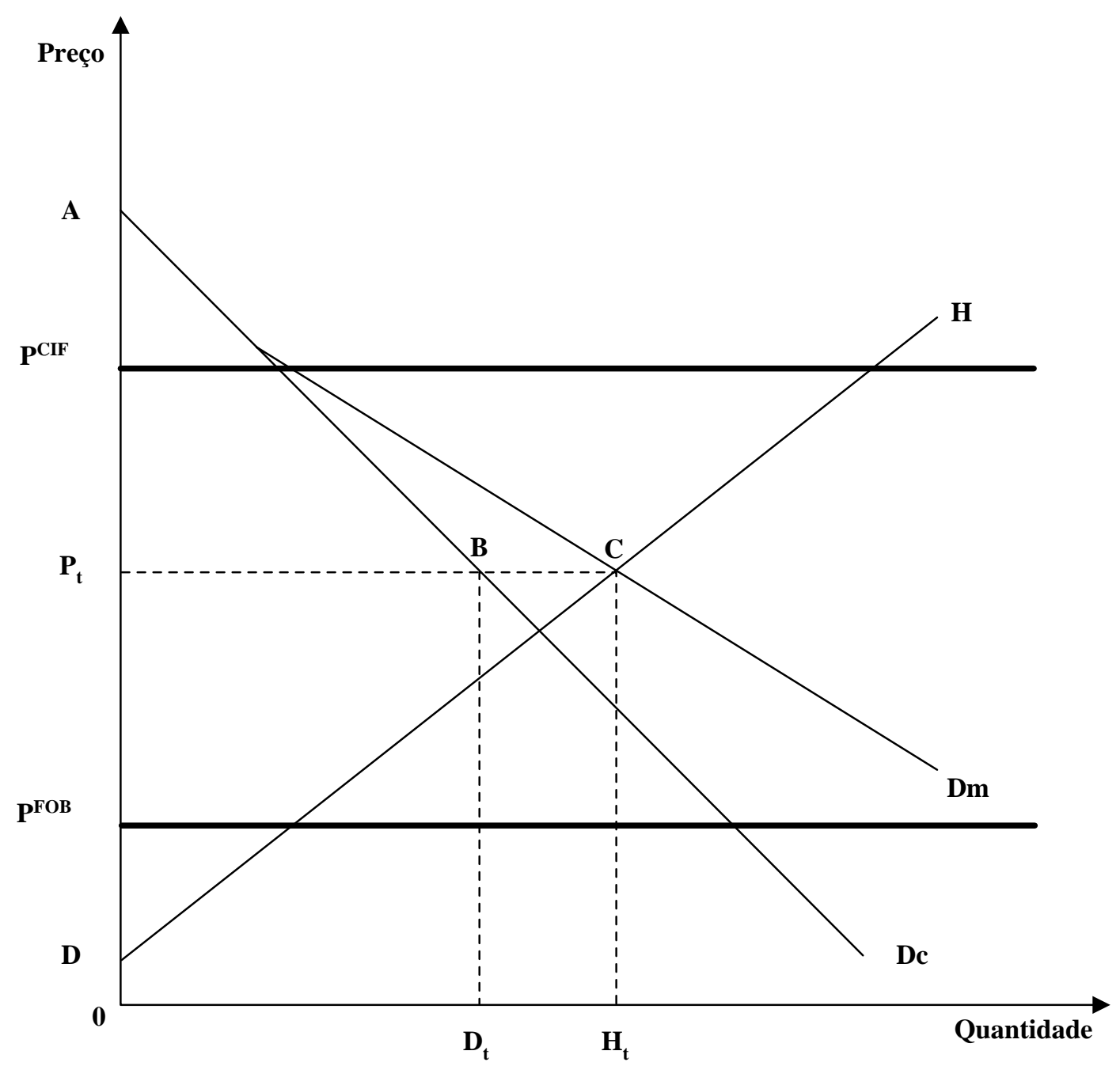

Figura 6 - Equilíbrio para o modelo de mercado aberto sem intervenção 


\subsubsection{Economia aberta e intervenção via PEP}

Este modelo reúne todas as informações anteriores. O mercado deste produto é descrito pelas seguintes relações:

$$
\begin{aligned}
& A_{t}=A\left[\max \left(E_{t} P_{t+1}, P^{M}{ }_{t+1}\right)\right] \\
& H_{t}=A_{t-1} * Y_{t} \\
& P_{t}=P\left(D_{t}, u_{t}\right) \\
& S_{t}=I_{t-1}+H_{t} \\
& S_{t}=D_{t}+I_{t}+M_{t} \\
& D_{t}=I_{t-1}+H_{t}-I_{t}-M_{t} \\
\text { ou } & \\
& \delta E_{t} P_{t+1} \geq P_{t}+\mathrm{k} \quad I_{t} \geq 0 \\
& \delta E_{t} P_{t+1}<P_{t}+\mathrm{k} \quad I_{t}=0 \\
& P_{t}>P^{M} \Rightarrow \quad \theta_{t}=0 \\
& P_{\mathrm{t}}<P^{M} \quad \theta_{t}=\left(P^{\mathrm{M}}-P_{\mathrm{t}}\right) \\
& P^{R M}-\tau_{t}-P_{t}>0 \\
& P_{t}^{R M}{ }_{t}-\tau_{t}-P_{t}<0 \\
& \left.I_{t}+A_{t} * Y_{t+1}-I_{t+1}-M_{t+1}\right)-P_{t}\left(I_{t-1}+A_{t-1} * Y_{t}-I_{t}-M_{t}\right)-k=0
\end{aligned}
$$

Este modelo representa a situação atual brasileira tanto para milho quanto para outros produtos como arroz. O mérito deste tipo de intervenção é a não formação de estoques públicos e permitir que o preço de mercado seja o preço de equilíbrio. 


\section{METODOLOGIA}

O método de estimação do modelo foi desenvolvido de forma pioneira por Gustafson (1958) e continua sendo a base para os modelos de armazenamento. Este capítulo apresenta e discute o método de solução e os dados utilizados na análise. A opção de solução foi pela função de valor marginal.

O problema do armazenamento corresponde a um problema dinâmico de expectativas racionais, onde as variáveis estado e decisão são contínuas e pertencem a um conjunto convexo fechado não nulo, mas o tempo é discreto. Trata-se de um modelo de equilíbrio dinâmico, o qual caracteriza o comportamento de um mercado através de condições de arbitragem intertemporal, as quais são atingidas pela ação individual de inúmeros agentes maximizadores.

Uma das condições para que um problema de equilíbrio dinâmico possa ser apresentado na forma de um problema de otimização dinâmica é que o processo de decisão seja Markoviano, ou seja, num período t um agente do mercado observa o estado do processo econômico $\left(S_{\mathrm{t}}\right)$, toma uma ação $\left(I_{\mathrm{t}}\right)$ e obtém um retorno $f\left(S_{\mathrm{t}}, I_{\mathrm{t}}\right)$ o qual depende apenas do estado do processo e da ação adotada. Esta condição é atendida pelo problema em análise (Miranda \& Fackler, 2001).

O problema pode ser solucionado tanto através da função de valor total quanto pela função de valor marginal (curva de demanda), com vantagens para esta última pois uma função de valor total pode ser difícil de obter enquanto funções de demanda estão mais presentes na literatura. Gustafson (1958) demonstra que maximizar 
a função do valor total é equivalente a encontrar os pares de valores de I e $\mathrm{S}$ (para I >0) que satisfazem a arbitragem temporal.

O método de solução exige que as funções de demanda e oferta de área, o custo unitário de armazenamento e a distribuição de freqüência da variável estocástica sejam conhecidos. Se as funções e os parâmetros forem os mesmos todos os anos o problema se torna estacionário e é possível atingir a regra de armazenamento ótimo para a condição de equilíbrio, ou seja, em algum momento a função $\theta$ tende a convergir. Isto significa que a regra do armazenamento passa a ser a mesma $\left(\theta^{*}\right)$ para todos os anos.

Outra condição necessária para otimização é de que a função objetivo seja separável, obtendo-se otimização em cada período. Isto é atingido quando a função objetivo é aditiva, ou seja, a soma dos valores maximizados em cada período, que é justamente o caso do problema da seqüência de estoques ótimos que maximiza o Bem Estar. A condição suficiente é que a funcional objetivo seja estritamente côncava em $S_{t}$ e $I_{t}$ e que ambos sejam conjuntos convexos fechados não nulos.

De forma mais explícita, as condições suficientes são (Miranda \& Fackler, 2001 e Silberberg, 1999):

- A função inversa da demanda para consumo seja contínua para todo $S$ e estritamente decrescente;

- A função da oferta de área seja crescente e contínua;

- A função do preço esperado seja decrescente em relação ao estoque e área plantada

Todas as condições exigidas para solução do modelo são atendidas pelos 4 modelos apresentados dado que: a função inversa da demanda para consumo é negativamente inclinada e contínua para todo $\mathrm{S}$; a função de oferta de área é crescente e contínua e a função do preço esperado é decrescente para o estoque e área plantada. 


\subsection{Programação Dinâmica Estocástica}

Programação dinâmica estocástica ${ }^{6}$ é o método de solucionar um problema dinâmico a partir do último período e obter os valores de solução para cada valor possível da variável estocástica. O princípio de Bellman é a chave para a utilização do método pois permite a solução recursiva de problemas dinâmicos. O objetivo do problema estacionário de armazenamento é maximizar a soma dos ganhos líquidos esperados num horizonte infinito, descontados para o ano 1 ou a seguinte equação de Bellman, considerando o primeiro modelo de economia fechada e sem governo:

$$
V(S)=\frac{\max }{0 \leq I \leq S}\left[\int_{0}^{S-I} P(S-I)-\int_{0}^{I} k(I)-\int_{0}^{H} C(H)+\delta E V(I+H)\right.
$$

cuja condição de primeira ordem é dada por:

$$
\begin{array}{ll}
-P_{t}\left(S_{t}-I_{t}\right)-\mathrm{k}+\delta E_{t} P_{t+1}\left(I_{t}+H_{t+1}\right)=0 & \mathrm{I} \geq 0 \\
-P_{t}\left(A_{t-1} * Y_{t}-I_{t}\right)-\mathrm{k}+\delta E_{t} P_{t+1}\left(I_{t}+A_{t} * Y_{t+1}\right)=0 & \mathrm{I} \geq 0
\end{array}
$$

A solução do problema é encontrar a "política ótima" ou regra anual de armazenamento $\phi^{*}$ como definida pelo Princípio de Bellman. Observe que a expressão acima implica em obter, para cada valor possível de $Y$, o valor máximo correspondente da expressão e não simplesmente substituir o valor esperado de $Y_{t+1}$. O resultado da implementação da expressão acima é um valor que representa uma média ponderada pela probabilidade de ocorrência de cada valor de $Y$.

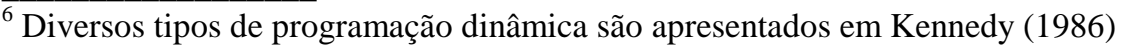


Este modelo de expectativas racionais não pode ser resolvido utilizandose técnicas algébricas usuais. Se a função do preço de equilíbrio do mercado fosse conhecida, a expectativa racional ex-ante do preço poderia ser computada integrando a partir da distribuição de probabilidade da produtividade $Y$. Adicionando esta equação às anteriores, o resultado seria um sistema de equações algébricas não lineares que seria determinado e, em princípio, com solução para todas as incógnitas.

Desde que se conheça a função do preço esperado, a solução não apresenta maiores dificuldades. A distribuição contínua de probabilidade da variável aleatória é transformada em uma distribuição discreta o que permite o cálculo do preço esperado para qualquer disponibilidade inicial. O problema é que a função do preço esperado não é conhecida. O primeiro passo é a escolha de um método de aproximação desta função.

\subsection{A função do preço esperado}

A função do preço esperado pode ser encontrada por aproximações sucessivas. Há vários métodos para aproximação de funções não lineares. Em Judd (1999) se encontra a análise mais completa destes métodos. Outras referências são Miranda \& Fackler (2001) e Cristiano \& Fisher (2000). Este estudo adota procedimento proposto por Wright \& Williams (1991) que consiste em aproximar $\mathrm{E}_{\mathrm{t}} \mathrm{P}_{\mathrm{t}+1}\left(I_{\mathrm{t}}\right)-$ o preço esperado como função do estoque atual - através de um polinômio de quarta ordem em $I_{\mathrm{t}}$ (estoque). A razão desta escolha reside em dois pontos: é um procedimento simples que pode ser realizado até mesmo em planilha eletrônica, é eficaz e análises de autores como Judd (1999) e Cristiano \& Fisher (2000) comprovam que o método é adequado para solucionar o problema de armazenamento.

Outros métodos incluem a aproximação da função do preço esperado (ou mesmo da própria regra do armazenamento) através de outros polinômios como o de Chebychev. Por se tratar de um problema sem solução analítica, o armazenamento 
requer métodos de solução numérica que estão se desenvolvendo com extrema rapidez nos últimos anos. No entanto, ainda há uma certa restrição por parte dos economistas quanto às reais implicações destes métodos (Judd, 1997). Inclusive por esta razão foi adotado um procedimento de solução que permite maior controle por parte do pesquisador quanto aos resultados que obtém de seus modelos.

Assim, a montagem do problema requer a função inversa da demanda para consumo, a função de oferta de área plantada, a distribuição de probabilidade da variável aleatória (produtividade) e dos choques de demanda, custo unitário de armazenamento, taxa anual de juros e, nos casos de economia aberta, o preço internacional e os custos para exportar/importar. Quando há intervenção o outro parâmetro necessário é o preço mínimo.

As distribuições de probabilidade das variáveis aleatórias (choque de oferta e produtividade) são aproximadas por uma distribuição discreta com as respectivas probabilidades associadas o que equivale à utilização da Quadratura de Gauss (Miranda \& Fackler, 2001).

O algoritmo está disponível também em Wright \& Williams (1991). Segundo os autores, na última iteração o polinômio está corretamente estimado até a $6^{\mathrm{a}}$ casa decimal. Este método transforma o problema de equações funcionais de dimensão infinita num problema de encontrar a raiz de uma equação algébrica não linear de dimensão finita. A raiz (para o intervalo em que o estoque existe, ou seja, $0<\mathrm{It}<\mathrm{St}$ ) é obtida pelo método de Newton (Miranda \& Fackler, 2001; Judd, 1999). Os algoritmos utilizados para cada modelo são apresentados a seguir.

\subsection{Algoritmos}

O início do procedimento de estimação é o mesmo para todos os modelos e consiste nas seguintes etapas: 
a) Determine os parâmetros das funções de oferta de área e inversa da demanda para consumo

b) Determine o valor k do custo unitário de armazenamento

c) Determine a taxa de juros e, portanto, o fator de desconto $(\delta)$

d) Quando for o caso determine o valor para o preço mínimo $\left(P^{M}\right)$

e) Quando for o caso, determine os valores para o preço de importação $\left(P^{C I F}\right)$ e o preço de exportação $\left(P^{F O B}\right)$. Calcule a quantidade consumida para cada um destes preços $\left(\mathrm{D}_{\mathrm{c}}^{\mathrm{CIF}}\right)$ e $\left(\mathrm{D}_{\mathrm{c}}^{\mathrm{FOB}}\right)$

f) Construa uma distribuição discreta de $\mathrm{m}(\mathrm{j}=1, \ldots, \mathrm{m})$ valores para a produtividade $Y^{j}$ com com média $\mu$ e variância $\sigma^{2}$ e as respectivas probabilidades $\left(\omega_{\mathrm{j}}\right)$.

g) Construa uma distribuição discreta de $\mathrm{K}(\mathrm{k}=1, \ldots, \mathrm{K})$ valores para os choques de demanda $\left(u^{k}\right)$ com a média zero e variância $\sigma^{2}$ e as respectivas probabilidades $\left(\gamma_{k}\right)$

h) Escolha um polinômio $\psi^{0}$ como a primeira aproximação do preço esperado em função do estoque. Observe que a função é utilizada para representar $E_{t+1}\left(P_{t+2}\right)$.

\subsubsection{Mercado fechado sem intervenção}

\section{LOOP PARA $\psi$}

Passo 1 - Escolha um vetor $I_{t}$ de $N$ valores discretos $\left(I_{t}^{i}\right)$ para o estoque, igualmente espaçados.

Passo 2 - Escolha um vetor de $N$ valores para a área plantada $\left(A_{t}^{i}\right)$; associado a cada $I_{t}^{i}$

\section{LOOP PARA CADA $I_{t}^{i}$}


Passo 3 - Multiplique $A_{t}^{i}$ por cada valor $Y_{t+1}^{j}$ gerando um vetor de produção $H_{t+1}^{i j}$. Some $H_{t+1}^{i j}$ a cada $I_{t}^{i}$ obtendo um vetor de disponibilidade $S_{t+1}^{i j}$. Para cada $S_{t+1}^{i j}$ diminua o choque de oferta $u_{t+1}^{k}$ gerando um vetor de disponibilidade total $S_{t+1}^{i j k}$.

\section{LOOP PARA CADA $S_{t+1}^{i j k}$}

Passo 4 - Para cada $S_{t+1}^{i j k}$ resolva numericamente a função implícita:

$$
\begin{array}{ll}
P_{t+1}^{i j k}\left(S_{t+1}^{i j k}-I_{t+1}^{i j k}\right)-k-\delta \psi\left(I_{t+1}^{i j k}\right)=0 & I_{t+1}^{i j k}>0 \\
P_{t+1}^{i j k}\left(S_{t+1}^{i j k}-I_{t+1}^{i j k}\right)-k-\delta \psi\left(I_{t+1}^{i j k}\right)<0 & I_{t+1}^{i j k}=0
\end{array}
$$

a solução é encontrar os pares de valores de $S_{t+1}^{i j k}$ e $I_{t+1}^{i j k}$ que resolvem a equação acima, ou seja, a raiz da equação para o intervalo possível de estoque $0<I<S$. A raiz é obtida pelo método de Newton.

Passo 5 - O estoque de equilíbrio determina, simultaneamente as demais variáveis endógenas incluindo $P_{t+1}^{i j k}$. Usando o vetor destes preços calcule o preço esperado:

$$
E_{t}\left(P_{t+1}^{i}\left(I_{t}^{i}\right)\right)=\sum_{j=1}^{m} \sum_{k=1}^{K} P_{t+1}^{i j k}\left(S_{t+1}^{i j k}-I_{t+1}^{i j k}\right)\left(\omega_{j}\right)\left(\gamma_{k}\right)
$$

Passo 6 - Calcule a receita por hectare esperada pelos produtores $E R$ : 


$$
E R^{i}=\sum_{j=1}^{m} Y_{t+1}^{j} E\left(P_{t+1}^{i}\left(I_{t}^{i}\right)\right)
$$

Verifique se a área inicial é consistente com a receita esperada:

Se $\left[A_{t}\left(E R^{i}\right)-A_{t}^{i}\right]>\varepsilon$ onde $\varepsilon$ é um número pequeno, escolha novo valor para a área e repita os passos 2 a 6. Do contrário, $A_{t}^{i}$ é a área de equilíbrio.

Passo 7 - Obtidas as áreas de equilíbrio, ajuste um polinômio $\psi^{1}$ do quarto grau de $P_{t+1}$ em função de $I_{t}^{i}$. Substitua $\psi^{0}$ por $\psi^{1}$ e reinicie o processo. Quando $\left[\psi^{l}-\psi^{l-1}\right] \leq \varepsilon$ então $\psi^{l}$ é o polinômio final. Faça o mesmo procedimento para ajustar um polinômio de quarto grau $(\phi)$ de $A_{t}^{i}$ em função de $I_{t}^{i}$. Quando $\left[\phi^{l}-\phi^{l-1}\right\rfloor \leq \varepsilon$ então $\phi^{l}$ é o polinômio final.

\subsubsection{Mercado fechado com intervenção}

\section{LOOP PARA $\psi$}

Passo 1 - Escolha um vetor $I_{t}$ de $N$ valores discretos $\left(I_{t}^{i}\right)$ para o estoque, igualmente espaçados.

Passo 2 - Escolha um vetor de $N$ valores para a área plantada $\left(A_{t}^{i}\right)$; associado a cada $I_{t}^{i}$

\section{LOOP PARA CADA $I_{t}^{i}$}

Passo 3 - Multiplique $A_{t}^{i}$ por cada valor $Y_{t+1}^{j}$ gerando um vetor de produção $H_{t+1}^{i j}$. Some $H_{t+1}^{i j}$ a cada $I_{t}^{i}$ obtendo um vetor de disponibilidade $S_{t+1}^{i j}$. Para cada 
$S_{t}^{i j}$ diminua o choque de oferta $u_{t+1}^{k}$ gerando um vetor de disponibilidade total $S_{t+1}^{i j k}$.

\section{LOOP PARA CADA $S_{t+1}^{i j k}$}

Passo 4 - Para cada $S_{t+1}^{i j k}$ resolva numericamente a função implícita:

$$
\begin{array}{ll}
P_{t+1}^{i j k}\left(S_{t+1}^{i j k}-I_{t+1}^{i j k}\right)-k-\delta \psi\left(I_{t+1}^{i j k}\right)=0 & I_{t+1}^{i j k}>0 \\
P_{t+1}^{i j k}\left(S_{t+1}^{i j k}-I_{t+1}^{i j k}\right)-k-\delta \psi\left(I_{t+1}^{i j k}\right)<0 & I_{t+1}^{i j k}=0
\end{array}
$$

a solução é encontrar os pares de valores de $S_{t+1}^{i j k}$ e $I_{t+1}^{i j k}$ que resolvem a equação acima, ou seja, a raiz da equação para o intervalo possível de estoque $0<I<S$. A raiz é obtida pelo método de Newton.

Passo 5 - O estoque de equilíbrio determina, simultaneamente as demais variáveis endógenas incluindo $P_{t+1}^{i j k}$. Usando o vetor destes preços calcule o preço esperado:

$$
E_{t}\left(P_{t+1}^{i}\left(I_{t}^{i}\right)\right)=\sum_{j=1}^{m} \sum_{k=1}^{K} P_{t+1}^{i j k}\left(S_{t+1}^{i j k}-I_{t+1}^{i j k}\right)\left(\omega_{j}\right)\left(\gamma_{k}\right)
$$

Passo 6 - Calcule a receita por hectare esperada pelos produtores $E R$ :

$$
E R^{i}=\sum_{j=1}^{m} Y_{t+1}^{j} E\left(P_{t+1}^{i}\left(I_{t}^{i}\right)\right)
$$


Se $E\left(P_{t+1}^{i}\left(I_{t}^{i}\right)\right)<P^{M}$ faça $E R^{i}=\sum_{j=1}^{m} Y^{j} P^{M}$

Verifique se a área inicial é consistente com a receita esperada:

Se $\left[A_{t}\left(E R^{i}\right)-A_{t}^{i}\right]>\varepsilon$ onde $\varepsilon$ é um número pequeno, escolha novo valor para a área e repita os passos 2 a 6 . Do contrário, $A_{t}^{i}$ é a área de equilíbrio.

Passo 7 - Se $P_{t+1}^{i j k}<P^{M}$ calcule $\phi_{t+1}^{i j k}=P^{M}-P_{t+1}^{i j k}$ e $G_{t+1}^{i j k}=\phi_{t+1}^{i j k} H_{t+1}^{i j k}$

Passo 8 - Calcule os valores esperados para o prêmio e o gasto do governo:

$$
\begin{aligned}
& E_{t} \phi_{t+1}^{i}=\sum_{j=1}^{m} \sum_{k=1}^{K} \phi_{t+1}^{i j k}\left(\omega_{j}\right)\left(\gamma_{k}\right) \\
& E_{t} G_{t+1}^{i}=\sum_{j=1}^{m} \sum_{k=1}^{K} G_{t+1}^{i j k}\left(\omega_{j}\right)\left(\gamma_{k}\right)
\end{aligned}
$$

Passo 9 - Obtidas as áreas de equilíbrio, ajuste um polinômio $\psi^{1}$ do quarto grau de $P_{t+1}$ em função de $I_{t}^{i}$. Substitua $\psi^{0}$ por $\psi^{1}$ e reinicie o processo. Quando $\left[\psi^{l}-\psi^{l-1}\right] \leq \varepsilon$ então $\psi^{l}$ é o polinômio final. Faça o mesmo procedimento para ajustar um polinômio de quarto grau $(\phi)$ de $A_{t}^{i}$ em função de $I_{t}^{i}$. Quando $\left[\phi^{l}-\phi^{l-1}\right] \leq \varepsilon$ então $\phi^{l}$ é o polinômio final.

\subsubsection{Mercado aberto sem intervenção}

LOOP PARA $\psi$ 
Passo 1 - Escolha um vetor $I_{t}$ de $N$ valores discretos $\left(I_{t}^{i}\right)$ para o estoque, igualmente espaçados.

Passo 2 - Escolha um vetor de $N$ valores para a área plantada $\left(A_{t}^{i}\right)$; associado a cada $I_{t}^{i}$

LOOP PARA CADA $I_{t}^{i}$

Passo 3 - Multiplique $A_{t}^{i}$ por cada valor $Y_{t+1}^{j}$ gerando um vetor de produção $H_{t+1}^{i j}$. Some $H_{t+1}^{i j}$ a cada $I_{t}^{i}$ obtendo um vetor de disponibilidade $S_{t+1}^{i j}$. Para cada $S_{t}^{i j}$ diminua o choque de oferta $u_{t+1}^{k}$ gerando um vetor de disponibilidade total $S_{t+1}^{i j k}$.

LOOP PARA CADA $S_{t+1}^{i j k}$

Passo 4 - Para cada $S_{t+1}^{i j k}$ de $S_{t+1}^{i}$ resolva numericamente a função implícita:

$$
\begin{array}{ll}
P_{t+1}^{i j k}\left(S_{t+1}^{i j k}-I_{t+1}^{i j k}\right)-k-\delta \psi\left(I_{t+1}^{i j k}\right)=0 & I_{t+1}^{i j k}>0 \\
P_{t+1}^{i j k}\left(S_{t+1}^{i j k}-I_{t+1}^{i j k}\right)-k-\delta \psi\left(I_{t+1}^{i j k}\right)<0 & I_{t+1}^{i j k}=0
\end{array}
$$

a solução é encontrar os pares de valores de $S_{t+1}^{i j k}$ e $I_{t+1}^{i j k}$ que resolvem a equação acima, ou seja, a raiz da equação para o intervalo possível de estoque $0<I<S$. A raiz é obtida pelo método de Newton. 
Passo 5 - O estoque de equilíbrio determina, simultaneamente as demais variáveis endógenas incluindo $P_{t+1}^{i j k}$. Verifique o preço de equilíbrio em relação ao mercado externo:

Passo 5a - preço de importação: Se $P_{t+1}^{i j k}>P^{C I F}$ faça $D_{t+1}=D_{t+1}\left(P^{C I F}\right)$ e calcule $M^{i j k}{ }_{t}=\left(D_{t+1}\left(P^{C I F}\right)-S_{t+1}^{i j k}\right)$ que corresponde o volume a ser importado.

Nestes casos não se formam estoques, $I_{t+1}^{i j k}=0$.

Passo 5b - preço de exportação: Se $P_{t+1}^{i j k}<P^{F O B}$ faça $D_{t+1}=D_{t+1}\left(P^{F O B}\right)$. Esta condição implica que $P_{t+1}^{i j k}=P^{F O B}$. Calcule o estoque de equilíbrio para este preço corrente a partir da inversa do polinômio atendendo a condição de equilíbrio da arbitragem temporal, obtendo $I_{t+1}^{i j k}\left(P^{F O B)}\right)$

$M^{i j k}{ }_{t}=\left(S_{t+1}^{i j k}-D_{t+1}\left(P^{F O B}\right)-I_{t+1}^{i j k}\left(P^{F O B)}\right)\right)$ que corresponde o volume a ser exportado.

Usando o vetor dos preços $P_{t+1}^{i j k}$ calcule o preço esperado:

$$
E_{t}\left(P_{t+1}^{i}\left(I_{t}^{i}\right)\right)=\sum_{j=1}^{m} \sum_{k=1}^{K} P_{t+1}^{i j k}\left(S_{t+1}^{i j k}-I_{t+1}^{i j k}\right)\left(\omega_{j}\right)\left(\gamma_{k}\right)
$$

Passo 6 - Calcule a receita por hectare esperada pelos produtores $E R$ :

$$
E R^{i}=\sum_{j=1}^{m} Y_{t+1}^{j} E\left(P_{t+1}^{i}\left(I_{t}^{i}\right)\right)
$$

Verifique se a área inicial é consistente com a receita esperada: 
Se $\left[A_{t}\left(E R^{i}\right)-A_{t}^{i}\right]>\varepsilon$ onde $\varepsilon$ é um número pequeno, escolha novo valor para a área e repita os passos 2 a 6 . Do contrário, $A_{t}^{i}$ é a área de equilíbrio.

Passo 7 - Obtidas as áreas de equilíbrio, ajuste um polinômio $\psi^{1}$ do quarto grau de $P_{t+1}$ em função de $I_{t}^{i}$. Substitua $\psi^{0}$ por $\psi^{1}$ e reinicie o processo. Quando $\left[\psi^{l}-\psi^{l-1}\right] \leq \varepsilon$ então $\psi^{l}$ é o polinômio final. Faça o mesmo procedimento para ajustar um polinômio de quarto grau $(\phi)$ de $A_{t}^{i}$ em função de $I_{t}^{i}$. Quando $\left|\phi^{l}-\phi^{l-1}\right| \leq \varepsilon$ então $\phi^{l}$ é o polinômio final.

\subsubsection{Mercado aberto com intervenção}

\section{LOOP PARA $\psi$}

Passo 1 - Escolha um vetor $I_{t}$ de $N$ valores discretos $\left(I_{t}^{i}\right)$ para o estoque, igualmente espaçados.

Passo 2 - Escolha um vetor de $N$ valores para a área plantada $\left(A_{t}^{i}\right)$; associado a cada $I_{t}^{i}$.

\section{LOOP PARA CADA $I_{t}^{i}$}

Passo 3 - Multiplique $A_{t}^{i}$ por cada valor $Y_{t+1}^{j}$ gerando um vetor de produção $H_{t+1}^{i j}$. Some $H_{t+1}^{i j}$ a cada $I_{t}^{i}$ obtendo um vetor de disponibilidade $S_{t+1}^{i j}$. Para cada $S_{t}^{i j}$ diminua o choque de oferta $u_{t+1}^{k}$ gerando um vetor de disponibilidade total $S_{t+1}^{i j k}$. 
LOOP PARA CADA $S_{t+1}^{i j k}$

Passo 4 - Para cada $S_{t+1}^{i j k}$ de $S_{t+1}^{i}$ resolva numericamente a função implícita:

$$
\begin{array}{ll}
P_{t+1}^{i j k}\left(S_{t+1}^{i j k}-I_{t+1}^{i j k}\right)-k-\delta \psi\left(I_{t+1}^{i j k}\right)=0 & I_{t+1}^{i j k}>0 \\
P_{t+1}^{i j k}\left(S_{t+1}^{i j k}-I_{t+1}^{i j k}\right)-k-\delta \psi\left(I_{t+1}^{i j k}\right)<0 & I_{t+1}^{i j k}=0
\end{array}
$$

a solução é encontrar os pares de valores de $S_{t+1}^{i j k}$ e $I_{t+1}^{i j k}$ que resolvem a equação acima, ou seja, a raiz da equação para o intervalo possível de estoque $0<I<S$. A raiz é obtida pelo método de Newton.

Passo 5 - O estoque de equilíbrio determina, simultaneamente as demais variáveis endógenas incluindo $P_{t+1}^{i j k}$. Verifique o preço de equilíbrio em relação ao mercado externo:

Passo 5a - preço de importação: Se $P_{t+1}^{i j k}>P^{C I F}$ faça $D_{t+1}=D_{t+1}\left(P^{C I F}\right)$ e calcule $M^{i j k}{ }_{t}=\left(D_{t+1}\left(P^{C I F}\right)-S_{t+1}^{i j k}\right)$ que corresponde o volume a ser importado.

Nestes casos não se formam estoques, $I_{t+1}^{i j k}=0$.

Passo 5b - preço de exportação: Se $P_{t+1}^{i j k}<P^{F O B}$ faça $D_{t+1}=D_{t+1}\left(P^{F O B}\right)$. Esta condição implica que $P_{t+1}^{i j k}=P^{F O B}$. Calcule o estoque de equilíbrio para este preço corrente a partir da inversa do polinômio atendendo a condição de equilíbrio da arbitragem temporal, obtendo $I_{t+1}^{i j k}\left(P^{F O B)}\right)$ 
$M_{t}^{i j k}=\left(S_{t+1}^{i j k}-D_{t+1}\left(P^{F O B}\right)-I_{t+1}^{i j k}\left(P^{F O B)}\right)\right)$ que corresponde o volume a ser exportado.

Usando o vetor dos preços $P_{t+1}^{i j k}$ calcule o preço esperado:

$$
E_{t}\left(P_{t+1}^{i}\left(I_{t}^{i}\right)\right)=\sum_{j=1}^{m} \sum_{k=1}^{K} P_{t+1}^{i j k}\left(S_{t+1}^{i j k}-I_{t+1}^{i j k}\right)\left(\omega_{j}\right)\left(\gamma_{k}\right)
$$

Passo 6 - Calcule a receita por hectare esperada pelos produtores ER:

$$
E R^{i}=\sum_{j=1}^{m} Y_{t+1}^{j} E\left(P_{t+1}^{i}\left(I_{t}^{i}\right)\right)
$$

Se $E\left(P_{t+1}^{i}\left(I_{t}^{i}\right)\right)<P^{M}$ faça $E R^{i}=\sum_{j=1}^{m} Y^{j} P^{M}$

Verifique se a área inicial é consistente com a receita esperada:

Se $\left[A_{t}\left(E R^{i}\right)-A_{t}^{i}\right]>\varepsilon$ onde $\varepsilon$ é um número pequeno, escolha novo valor para a área e repita os passos 2 a 6 . Do contrário, $A_{t}^{i}$ é a área de equilíbrio.

Passo 7 - Se $P_{t+1}^{i j k}<P^{M}$ calcule $\phi_{t+1}^{i j k}=P^{M}-P_{t+1}^{i j k}$ e $G_{t+1}^{i j k}=\phi_{t+1}^{i j k} H_{t+1}^{i j k}$

Passo 8 - Calcule os valores esperados para o prêmio e o gasto do governo:

$$
\begin{aligned}
& E_{t} \phi_{t+1}^{i}=\sum_{j=1}^{m} \sum_{k=1}^{K} \phi_{t+1}^{i j k}\left(\omega_{j}\right)\left(\gamma_{k}\right) \\
& E_{t} G_{t+1}^{i}=\sum_{j=1}^{m} \sum_{k=1}^{K} G_{t+1}^{i j k}\left(\omega_{j}\right)\left(\gamma_{k}\right)
\end{aligned}
$$


Passo 9 - Obtidas as áreas de equilíbrio, ajuste um polinômio $\psi^{1}$ do quarto grau de $P_{t+1}$ em função de $I_{t}^{i}$. Substitua $\psi^{0}$ por $\psi^{1}$ e reinicie o processo. Quando $\left[\psi^{l}-\psi^{l-1}\right] \leq \varepsilon$ então $\psi^{l}$ é o polinômio final. Faça o mesmo procedimento para ajustar um polinômio de quarto grau $(\phi)$ de $A_{t}^{i}$ em função de $I_{t}^{i}$. Quando $\left.\mid \phi^{l}-\phi^{l-1}\right\rfloor \leq \varepsilon$ então $\phi^{l}$ é o polinômio final.

A função do preço esperado converge quando os coeficientes do polinômio não se alteram significativamente, ou seja: $\varepsilon=0,0000000001$ e uma nova iteração não altera as variáveis de decisão (área e estoque). Neste ponto, a regra de armazenamento está obtida e consiste nos pares ordenados de $S_{t+1}^{i j k}$ e $I_{t+1}^{i j k}$.

\section{Médias de longo prazo}

O próximo passo é realizar a análise de longo prazo do comportamento das variáveis endógenas no tempo ou, em outras palavras, as médias de longo prazo das variáveis. Estas médias são obtidas através de simulações de Monte Carlo (Wright \& Williams, 1991; Judd, 1999, Miranda \& Fackler, 2001). As simulações foram feitas de acordo com Wright \& Williams (1991) para uma sequência de 10 anos. Esta seqüência é que deve ser simulada gerando um número suficiente de valores para cada ano, que são usados para obter as médias de longo prazo das variáveis endógenas.

\subsection{Dados}

A análise da distribuição de freqüência da produtividade do milho no país foi feita através do SAS testando o tipo de distribuição (normal, lognormal, triangular ou uniforme). A análise foi feita para o período 1984 a 2000, no qual a produtividade média 
brasileira foi de $2.400 \mathrm{Kg} / \mathrm{ha}$ e desvio padrão de $367 \mathrm{Kg} / \mathrm{ha}$. A partir da média e do desvio padrão, foi construída uma distribuição de probabilidade discreta, com oito valores de produtividade (e as probabilidades associadas), através da função qnorm do Matlab. Estes oito valores foram usados na obtenção da regra de armazenamento. Para obtenção das médias de longo prazo foram utilizados 25 mil valores para a produtividade e igual número para os cheques de demanda, gerados a partir da função normrnd do programa Matlab. A simulações dos quatro modelos, para obtenção das médias de longo prazo das variáveis endógenas dos modelos foram feitas para os mesmos choques tornando os resultados comparáveis. Foram realizadas 2.500 simulações para cada modelo.

Não foi encontrada na literatura especializada nacional nenhuma estimativa para a obtenção da função de oferta de área de milho no Brasil. Para obter esta função foram calculados os custos variáveis por hectare no período de plantio (julho a dezembro), utilizando-se dos preços dos insumos para a cultura no Paraná (cuja fonte é o Departamento de Economia Rural da Secretaria de Agricultura e Abastecimento do Paraná) e dos coeficientes técnicos para plantio convencional de milho, da mesma fonte, utilizados como representativos da produção nacional. Admite-se, neste procedimento, que o custo marginal é igual ao custo variável médio de produção, ou seja, não há economia de escala e o custo por um hectare a mais é igual ao custo da última unidade de área a mais plantada pelos produtores.

A área plantada utilizada na análise foi obtida junto ao IBGE. A oferta de área foi estimada por mínimos quadrados ordinários tendo o custo por hectare como variável independente. O ajustamento da regressão não foi satisfatório, mas mesmo assim esta oferta foi utilizada porque uma análise criteriosa da evolução da área plantada no Brasil indica que pode se tratar de uma variável estocástica (random walk), pois nem uma regressão da área contra a própria variável defasada não é significativa. Uma explicação para este comportamento pode ser a dispersão geográfica da área plantada com milho no Brasil. A região Norte e Nordeste participa com cerca de $30 \%$ da área 
plantada na safra de verão e esta região freqüentemente apresenta fortes variações na área plantada em função do clima. Mesmo tendo a intenção de ampliar ou manter a área plantada numa determinada safra os agricultores não conseguem realizar suas pretensões por falta de chuva. Nas outras regiões ocorre o mesmo (choques exógenos na função de área plantada), mas em menor intensidade do que no norte/nordeste.

A função demanda para consumo foi estimada através de mínimos quadrados ordinários tendo como variável dependente o consumo aparente em cada safra estimado pela CONAB e como variáveis independentes o preço médio do milho da colheita até o mês anterior a próxima colheita (marco a fevereiro) e a renda per capita. $\mathrm{Na}$ estimação do modelo a renda foi mantida constante utilizando o valor médio do período considerado na estimação. Foram computados os resíduos desta regressão bem como o desvio padrão dos mesmos. Os choques de demanda foram simulados através do programa Matlab (assim como as produtividades) assumindo distribuição normal, média zero e a variância dos resíduos desta regressão.

O preço do milho é o preço médio nacional da Fundação Getulio Vargas. Todos os valores utilizados foram deflacionados pelo IGP-DI para marco de 2001. O custo de transporte internacional foi considerado constante em dólar sem imposto de importação ou exportação. Os custos de frete levaram em conta uma distancia media de $300 \mathrm{~km}$ ate o porto e foi utilizada uma media em dólar (constante). Os custos de embarque e desembarque portuários, de despachante e operações cambiais também são constantes em dólar. O preço internacional se refere à média mensal das cotações do milho na Bolsa de Chicago para o período analisado. Os valores em dólar foram transformados em moeda nacional pela cotação média do dólar do mesmo mês, e depois, deflacionados pelo mesmo índice e data dos demais valores utilizados no estudo. $\mathrm{O}$ custo do armazenamento físico foi obtido através das tabelas de preços da CONAB para produto a granel. A taxa de juros utilizada foi de $12 \%$ ao ano. 


\section{RESULTADOS E DISCUSSÃO}

A Tabela 5 apresenta os valores dos parâmetros utilizados na estimação dos modelos. Exceto a geração dos números aleatórios e da distribuição de frequiência discreta das variáveis, todos os demais procedimentos numéricos foram realizados em planilha eletrônica.

Tabela 5. Dados e parâmetros dos modelos

Parâmetros

Termo constante da função inversa da demanda para consumo

Coeficiente do preço

Coeficiente da renda

Renda anual média

Termo constante da função de oferta de área

Coeficiente angular da função de oferta de área

Produtividade média (Kg/ha)

Desvio padrão da produtividade ( $\mathrm{Kg} / \mathrm{ha})$

Desvio padrão dos choques de demanda (Em mil toneladas)

Taxa anual de juros (\%)

Custo unitário anual de armazenamento (R $\$$ /tonelada)

Preço mínimo (R $\$$ tonelada)

Preço importação (R $\$$ tonelada)

Preço exportação ( $\mathrm{R}$ /tonelada)

Custo de exportação/importação
Valor

401,8700906

$-0,0131006$

257,0432

$7,229,31$

$12.554,99766$

0,718457

2.400

367

$1.794,908856$

$12 \%$

25,17

218,00

300,00

190,00

110,00 
Tendo estimado a demanda de milho para consumo, a oferta de área, os choques de demanda e a produtividade aleatória, o custo de armazenamento físico, a taxa de juros (obtendo a taxa de desconto) já e possível estimar o modelo representativo do mercado de milho no Brasil sem intervenção do governo. O procedimento é o mesmo descrito por Wright \& Williams (1991) com uma diferença: a oferta de área. O algoritmo foi adaptado para levar em conta a oferta de área e não a produção planejada - o que os agricultores efetivamente decidem é área que irão plantar - a produção depende da produtividade (clima), uma variável aleatória.

$\mathrm{O}$ algoritmo começa com a escolha de um vetor $I_{t}$ de $\mathrm{n}$ valores para o estoque no ano $t$, igualmente espaçados. Foram escolhidos 12 valores entre zero a 11 milhões de toneladas crescendo a um montante constante de 1 milhão de toneladas. Assim, $\mathrm{n}=12$ e cada estoque pode ser definido como $I_{t}^{i}$. A opção por este conjunto de estoques se baseia numa faixa de valores possíveis para o estoque dado que o maior estoque final de milho no Brasil foi de 9 milhões de toneladas e as simulações do modelo mostraram que este intervalo é adequado.

A seguir o algoritmo exige a definição de um valor inicial para a área plantada para cada $I_{t}^{i}$. Dada a área plantada inicial $\left(A_{t}^{i}\right)$, calculam-se os 8 valores possíveis de produtividade $Y_{t+1}^{j}$ com $\mathrm{j}=1, \ldots, 8$, resultando $H^{i j}{ }_{t+1}$ produções. A disponibilidade inicial é a soma do estoque $\left(I_{t}^{i}\right)$ e da produção $\left(H^{i j}{ }_{t+1}\right)$, gerando um total de 96 valores até o momento. Como foram utilizados 6 choques de demanda $u_{t+1}^{k}$ com $\mathrm{k}$ $=1, \ldots, 6$ que podem ocorrer para qualquer estoque, área e produtividade, são incluídos estes choques para cada uma das situações construídas até o momento. A disponibilidade total $\mathrm{S}_{t+1}^{i j k}$ é a combinação de estoque inicial, área plantada, produtividade e choque de demanda ou 576 valores. O choque é deduzido da disponibilidade calculada somando o estoque e a área de forma que um choque negativo equivale a aumentar a disponibilidade e reduzir no caso de um choque positivo. 
A estimação do modelo depende do polinômio para aproximação do preço esperado como função do estoque inicial $\left(I_{t}{ }_{t}\right)$. Em todos os modelos a primeira função foi linear, com parâmetros próximos aos da função de demanda. Outras funções iniciais foram experimentadas e nenhuma altera os resultados.

Para cada uma das 576 situações consideradas, foi calculado o estoque de equilíbrio procurando o estoque que soluciona a arbitragem temporal que se tornou neste ponto uma equação não linear de quarta ordem. $O$ estoque é a raiz da equação no intervalo em que o estoque é viável, ou seja, entre zero e a disponibilidade de milho. O estoque é encontrado pelo Método de Newton que, de forma geral, é uma expansão de Taylor incluindo apenas a primeira derivada (Judd, 1999; Miranda \& Fackler, 2001, Wright \& Williams, 1991). Em 4 ou 5 iterações o método encontra a raiz. Só é necessário obter a raiz quando há possibilidade de estocagem, pois nos casos em que a combinação de choque positivo de demanda e produtividade abaixo da média, a disponibilidade de produto é pequena e o preço corrente supera o preço esperado ou a diferença é inferior ao custo de armazenamento. Nestes casos o estoque ótimo é nulo.

Obtendo o estoque de equilíbrio em cada situação o próximo passo é obter o preço esperado para o período $t+1$. O preço esperado é a média ponderada dos preços a vigorar no mercado para cada situação possível e cada estoque inicial. Cada estoque inicial gera um preço esperado. A ponderação é a probabilidade de ocorrência de cada valor de produtividade e cada choque de demanda (probabilidade conjunta). Como são 12 estoques iniciais, foram calculados 12 preços esperados. Estes preços são ajustados através de mínimos quadrados ordinários, a um polinômio do quarto grau tendo como variável independente os estoques iniciais. Este polinômio será usado na próxima iteração como a aproximação para a função do preço esperado para o período $t+2$.

Em no máximo 10 iterações o polinômio converge, ou seja, seus coeficientes não mudam de forma significativa e as variáveis de decisão (área e estoque) 
não se alteram. Este polinômio passa a representar a função de preço esperado e, nesta última iteração, são obtidos os estoques de equilíbrio para cada disponibilidade inicial, ou seja, a política ótima ou regra do armazenamento.

Para o mercado com PEP o procedimento de estimação é praticamente o mesmo, com duas diferenças. A primeira é que a área plantada passa a ser função do preço mínimo a partir do ponto em que este supera o preço esperado. O principal efeito é que a função de oferta de área passa a ser uma linha reta a partir da disponibilidade inicial que torna o preço esperado inferior ao preço mínimo. A segunda diferença é o cálculo do prêmio para escoamento de produto, que equivale à diferença entre o preço de mercado e o preço mínimo. Este valor permite ainda calcular o subsídio total que o governo deveria desembolsar naquela circunstância. O gasto esperado com subsídio é calculado de forma idêntica ao preço esperado para o período $t+1$.

O caso da economia aberta sem governo introduz diversas mudanças no método de estimação. Importação e exportação dependem da relação entre o preço no mercado interno e externo e do custo de importar/exportar. O país importa quando o preço de mercado interno seria maior do que a paridade de importação pela pequena disponibilidade interna. O modelo calcula o volume de produto a ser consumido no mercado interno ao preço de paridade de importação. $\mathrm{O}$ volume a importar é a diferença entre este montante e o volume disponível no ano safra. Importando, o preço no mercado interno iguala a paridade de importação. No caso do país importar não ser formam estoques porque o preço esperado para o período seguinte não pode superar o preço de paridade de importação. Como este valor é um parâmetro do modelo, será o mesmo para o período seguinte inviabilizando a formação de estoques.

Para exportar, o preço no mercado interno deve ser inferior à paridade de exportação. O volume crítico é aquele que torna o preço no mercado interno igual à esta paridade mas observe que, ao contrário do caso da importação, é possível formar estoques mesmo diante de exportações. Portanto isto exige um equilíbrio simultâneo 
entre consumo, estoque e exportação. Por construção, quando se formam estoques, o preço esperado (a valor presente) iguala o preço corrente mais o custo de armazenamento. Foi calculado o preço esperado nestas circunstâncias e obtido o estoque de equilíbrio para estes valores. A diferença entre o volume disponível e o consumo e estoques resulta no volume a exportar. É por este mecanismo que o estoque no mercado interno se torna constante a partir de determinada disponibilidade de produto.

Para a situação de mercado aberto e com PEP as mudanças são as mesmas do caso de mercado fechado com PEP. A área plantada é aquela que atende a condição de equilíbrio que iguala o custo por hectare à receita marginal esperada por hectare, dada pelo produto da produtividade média esperada e do preço esperado ou do preço mínimo, o quer for maior. Os prêmios são calculados para cada disponibilidade inicial.

\subsection{A política ótima de estoques e as funções de preço esperado e área plantada}

\section{Economia fechada e sem intervenção do governo}

Cada modelo gerou uma política ótima de estoques. Para o modelo de economia fechada sem intervenção do governo, a disponibilidade inicial varia de um mínimo de 9.061,6 mil toneladas até 63.764,6 mil de toneladas. Os números são resultado das combinações de produtividade, estoque inicial e choques de demanda e estes valores extremos têm pequena probabilidade de ocorrência.

A formação de estoques passa a ocorrer a partir da disponibilidade de 34.987,8 mil toneladas, que corresponde ao valor crítico da disponibilidade para viabilizar a estocagem. Antes deste patamar os preços correntes são relativamente altos, inviabilizando os estoques - é a "quina" da regra do armazenamento. O estoque a ser formado para este volume de milho disponível é de 127,3 mil toneladas e cresce a partir deste ponto junto com a disponibilidade até atingir um máximo de 19.091,2 mil toneladas no caso extremo da maior disponibilidade. A relação apresentada na Figura 7 
reflete as 576 situações simuladas e não considera a probabilidade de ocorrência destas disponibilidades. O que a regra define é o valor ótimo de estoque para cada disponibilidade inicial de milho no Brasil, sujeito aos pressupostos e parâmetros do modelo.

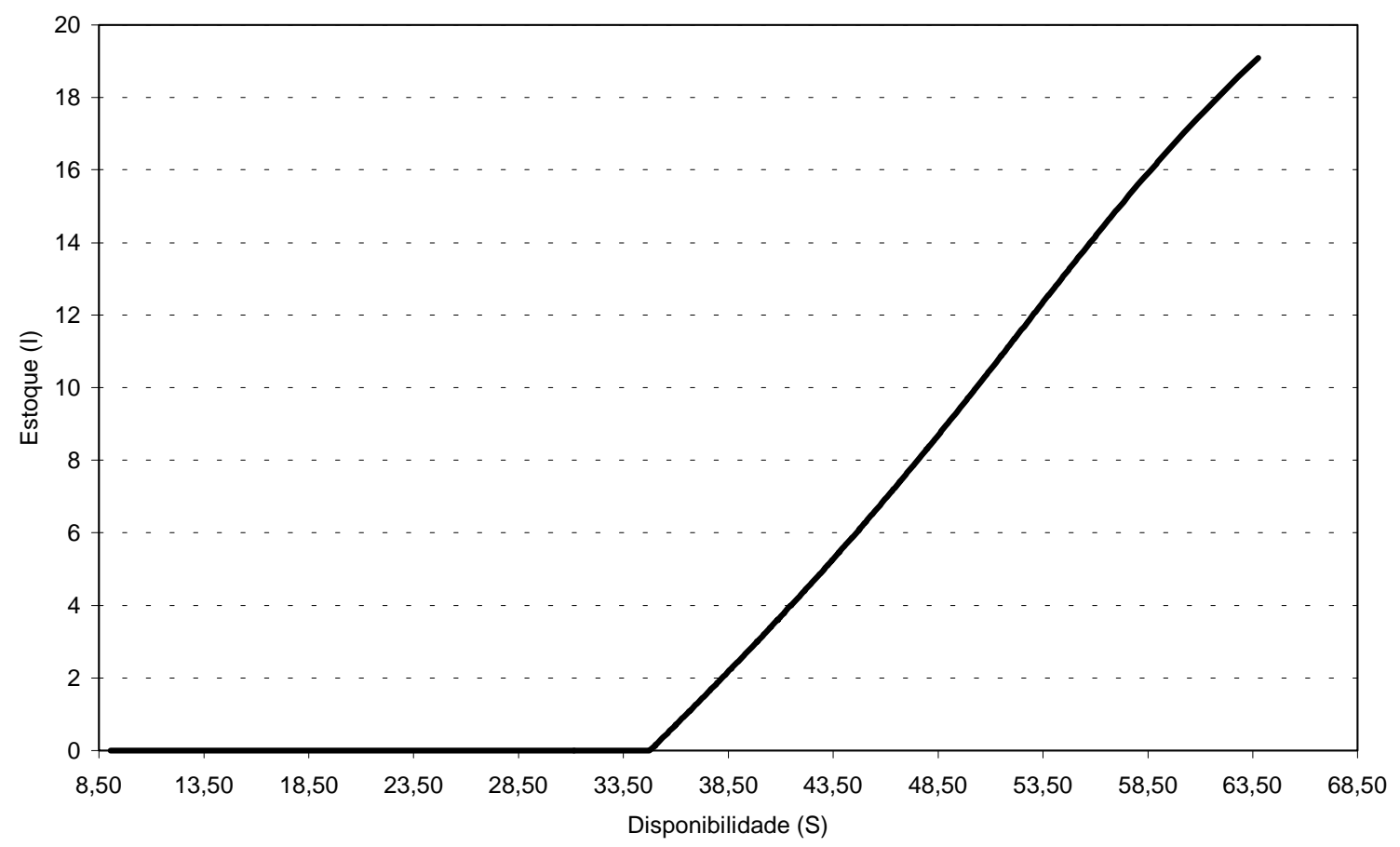

Figura 7 - Disponibilidade inicial e estoque de milho, em milhões de toneladas, economia fechada e sem intervenção do governo.

A função do preço esperado em relação ao estoque, ajustada pelo polinômio do quarto grau é apresentada na Figura 8 que contém ainda os coeficientes do polinômio e o coeficiente de ajustamento $\left(\mathrm{R}^{2}\right)$. Neste modelo o preço máximo esperado é de $\mathrm{R} \$ 254,04 /$ tonelada quando não se formam estoques. A Figura 9 apresenta o polinômio da área plantada em função do estoque 


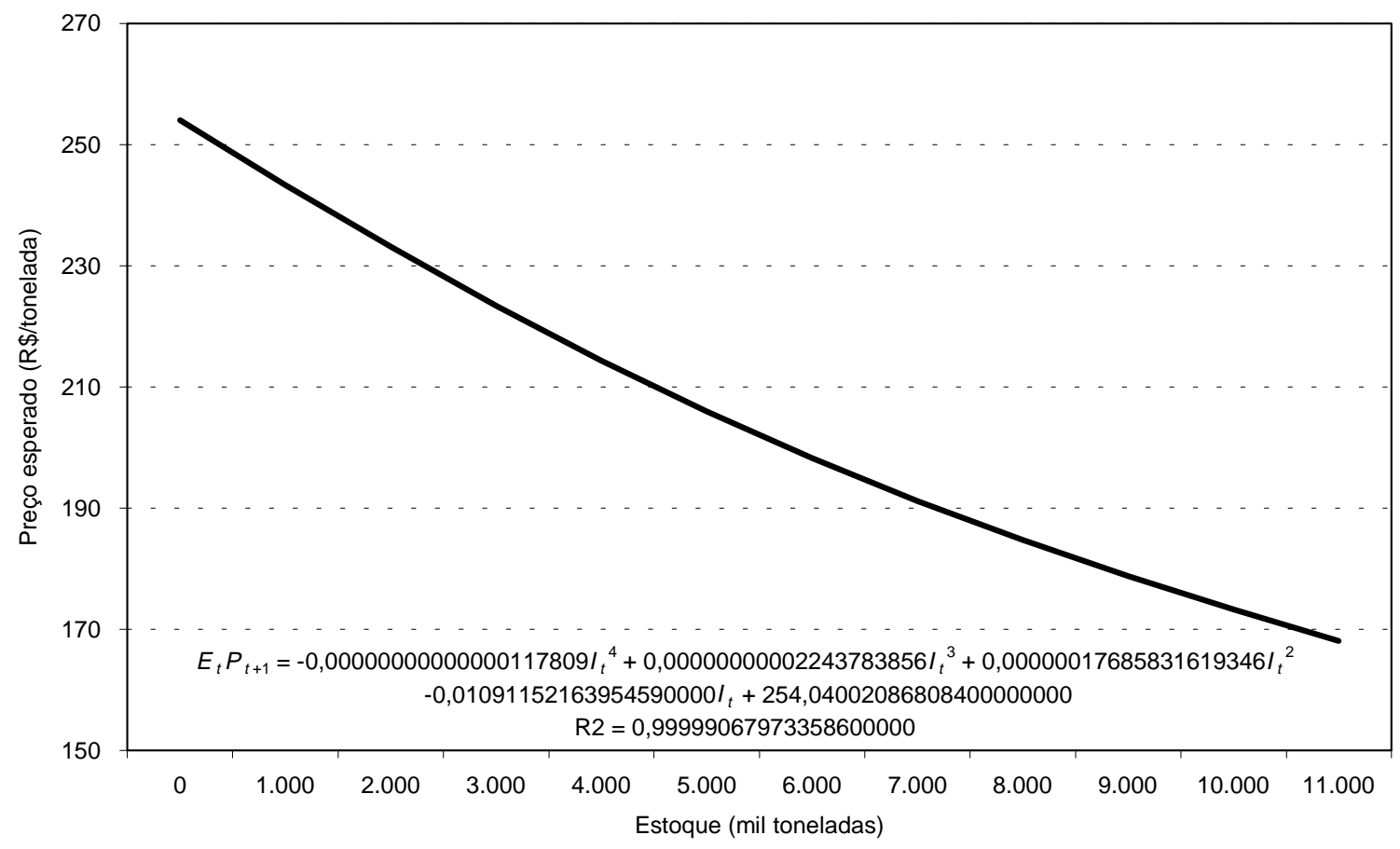

Figura 9 - Preço esperado em função do estoque, economia fechada sem PEP

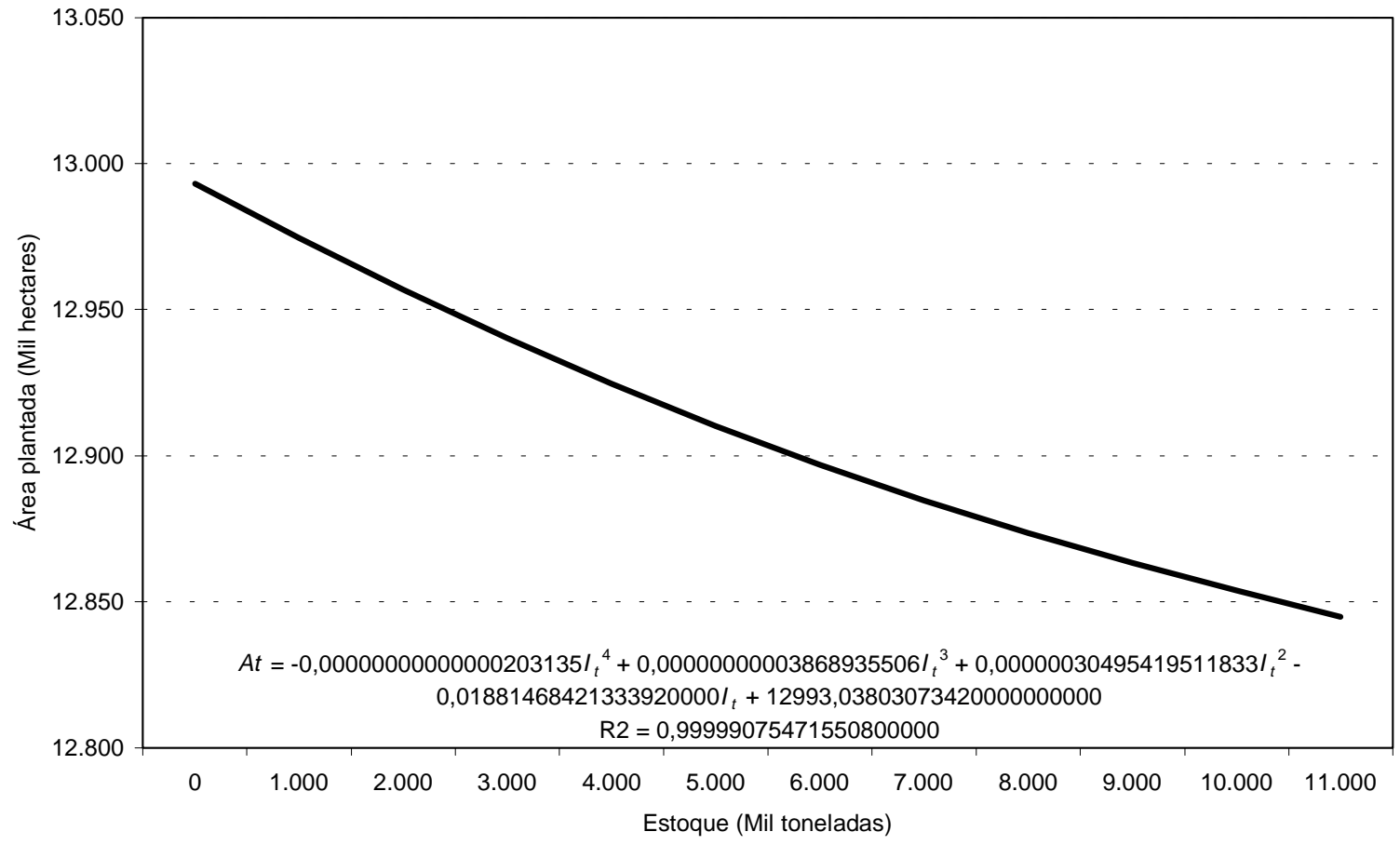

Figura 9 - Área plantada em função do estoque, economia fechada sem PEP 


\section{Economia fechada e intervenção via PEP}

Para estas circunstâncias a política ótima, apresentada na Figura 10, sofre ligeira modificação. A disponibilidade mínima neste modelo é igual à do modelo anterior mas o valor extremo passa para 64.078,6 mil toneladas superando e extremo do modelo anterior em 314 mil toneladas. $O$ estoque se torna positivo a partir de uma disponibilidade de 34.792,6 mil toneladas de milho, praticamente o mesmo do modelo anterior. Para disponibilidades iguais, no modelo com PEP, o estoque é maior, em cerca de 2 mil toneladas, do que no modelo sem intervenção.

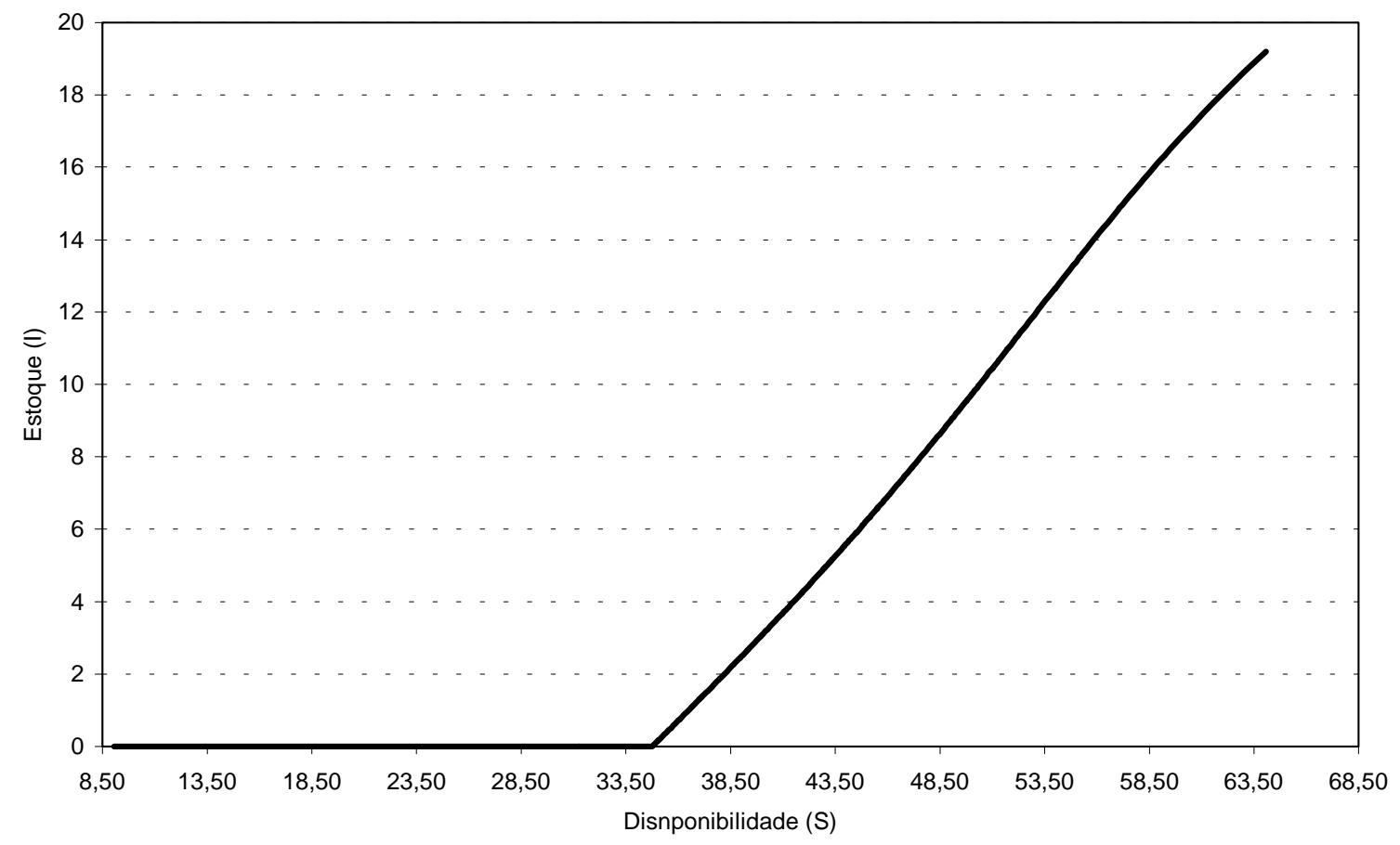

Figura 10 - Disponibilidade inicial e estoque de milho, em milhões de toneladas, economia fechada e intervenção via PEP.

Portanto, observando apenas a política ótima, o efeito de um subsídio de preço ao produtor amplia a disponibilidade interna porque o preço mínimo impede a redução na área que, de outra forma, iria ocorrer para preços esperados abaixo do preço mínimo. A grande alteração é na função de área plantada que passa se estabilizar quando o preço esperado pelo produtor atinge e permanece igual ao preço mínimo. As 
funções de preço esperado e área plantada são apresentadas nas Figuras 11 e 12, respectivamente.

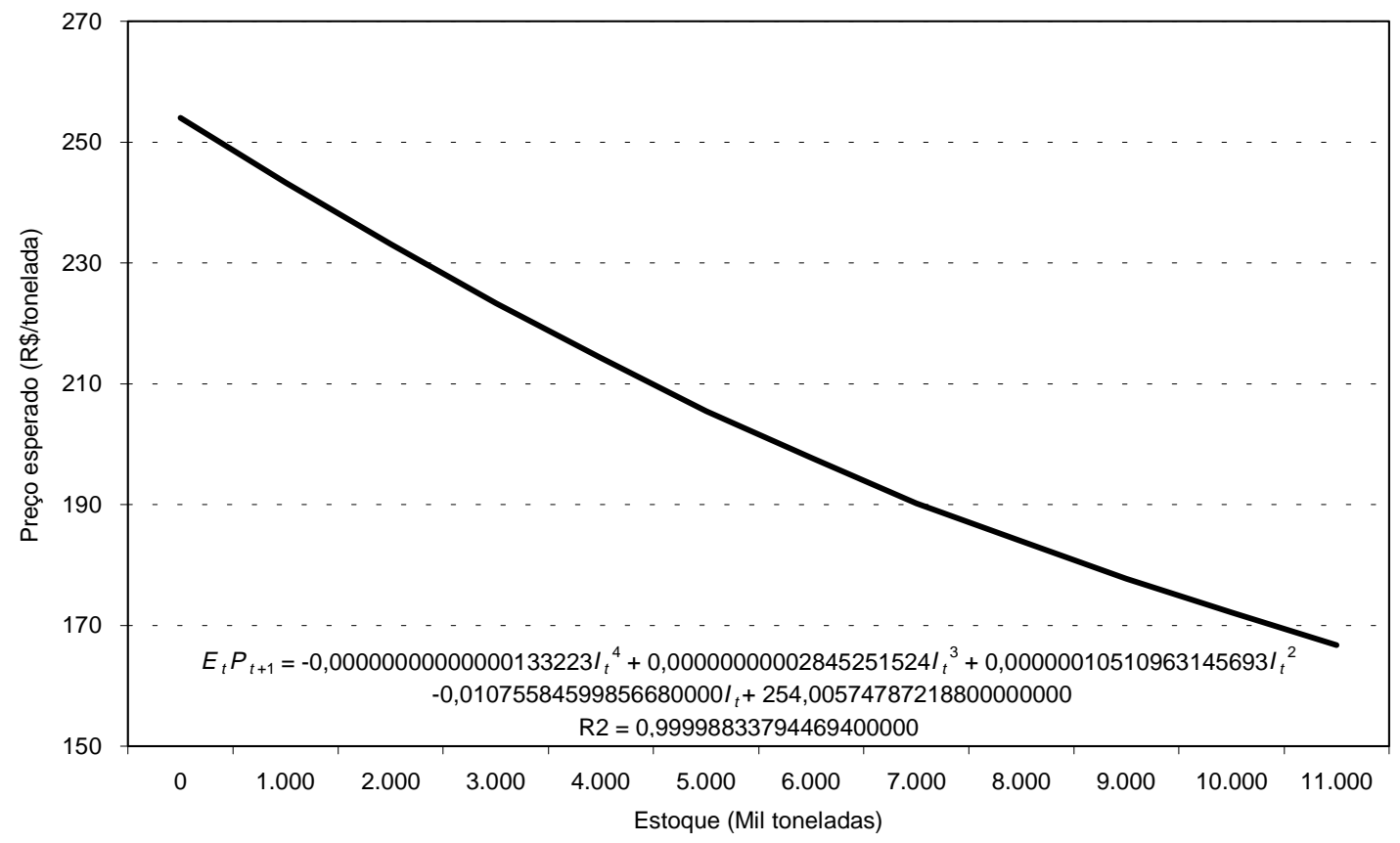

Figura 11 - Preço esperado em função do estoque, economia fechada com PEP

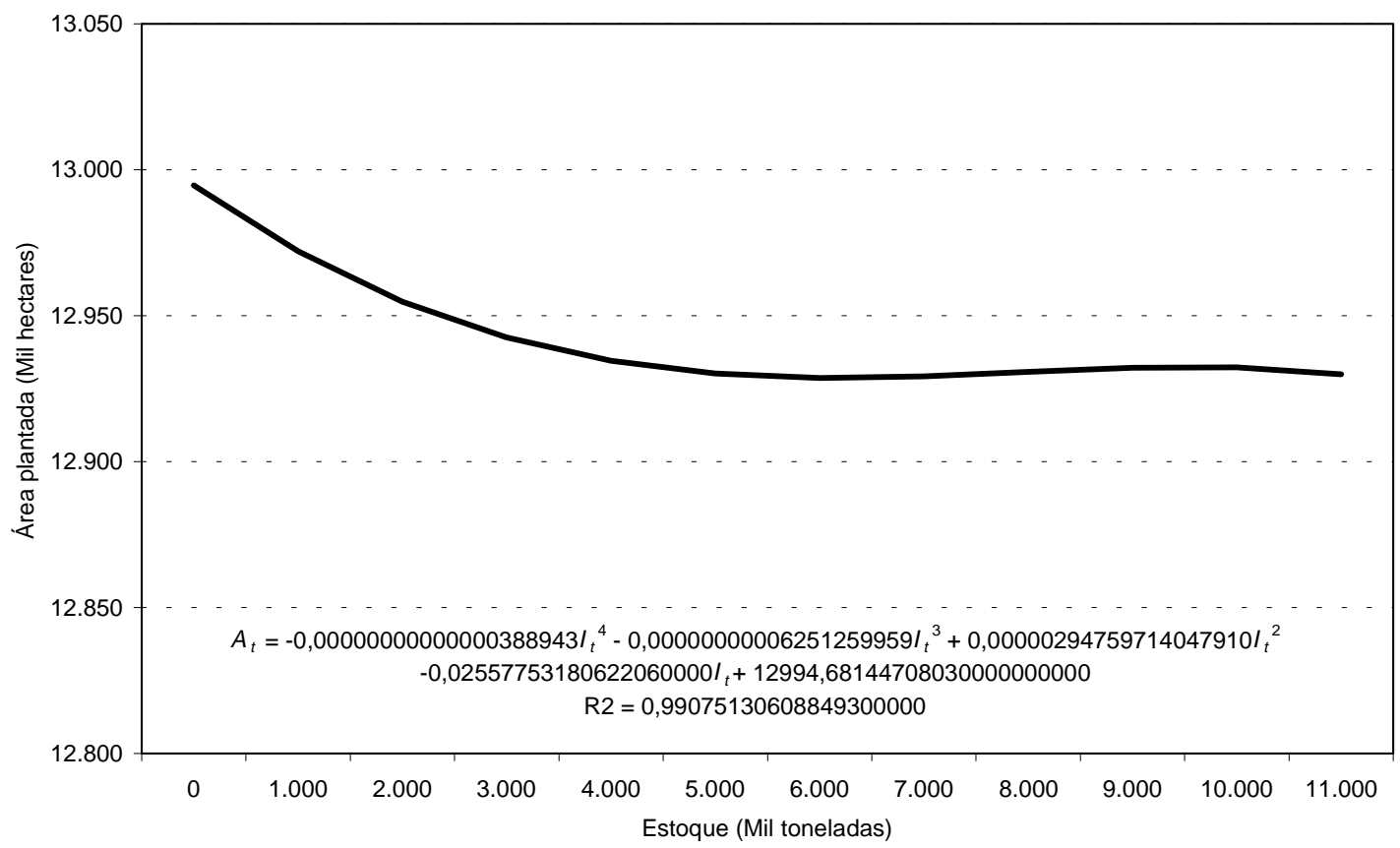

Figura 12 - Área plantada em função do estoque, economia fechada com PEP. 


\section{Mercado aberto sem intervenção do governo}

A construção do modelo do mercado aberto implica em que o preço no mercado interno não pode superar o preço do produto importado e não pode ser inferior ao preço do produto exportado. Isto impõe uma faixa de preços possíveis para o milho no mercado brasileiro - a faixa é fixa porque os preços externos são parâmetros e admitiu-se que o Brasil é pequeno no comércio mundial e, assim, é um tomador de preços. A limitação desta abordagem aparece nos resultados do modelo que mantém preços estáveis no mercado internacional mesmo nas situações em que o país compra ou vende grandes volumes. Portanto, os resultados apresentados contêm esta limitação.

A política ótima de armazenamento, apresentada na Figura 15, reflete este rigidez de preços. A disponibilidade apresentada na Figura 13 inclui importações. A formação de estoques no mercado interno também obedece a uma determinada faixa. Quando o país importa não é viável formar estoques porque o preço no mercado interno iguala o preço internacional e o preço esperado no ano seguinte não será maior do que este mesmo valor o que inviabiliza os estoques. 


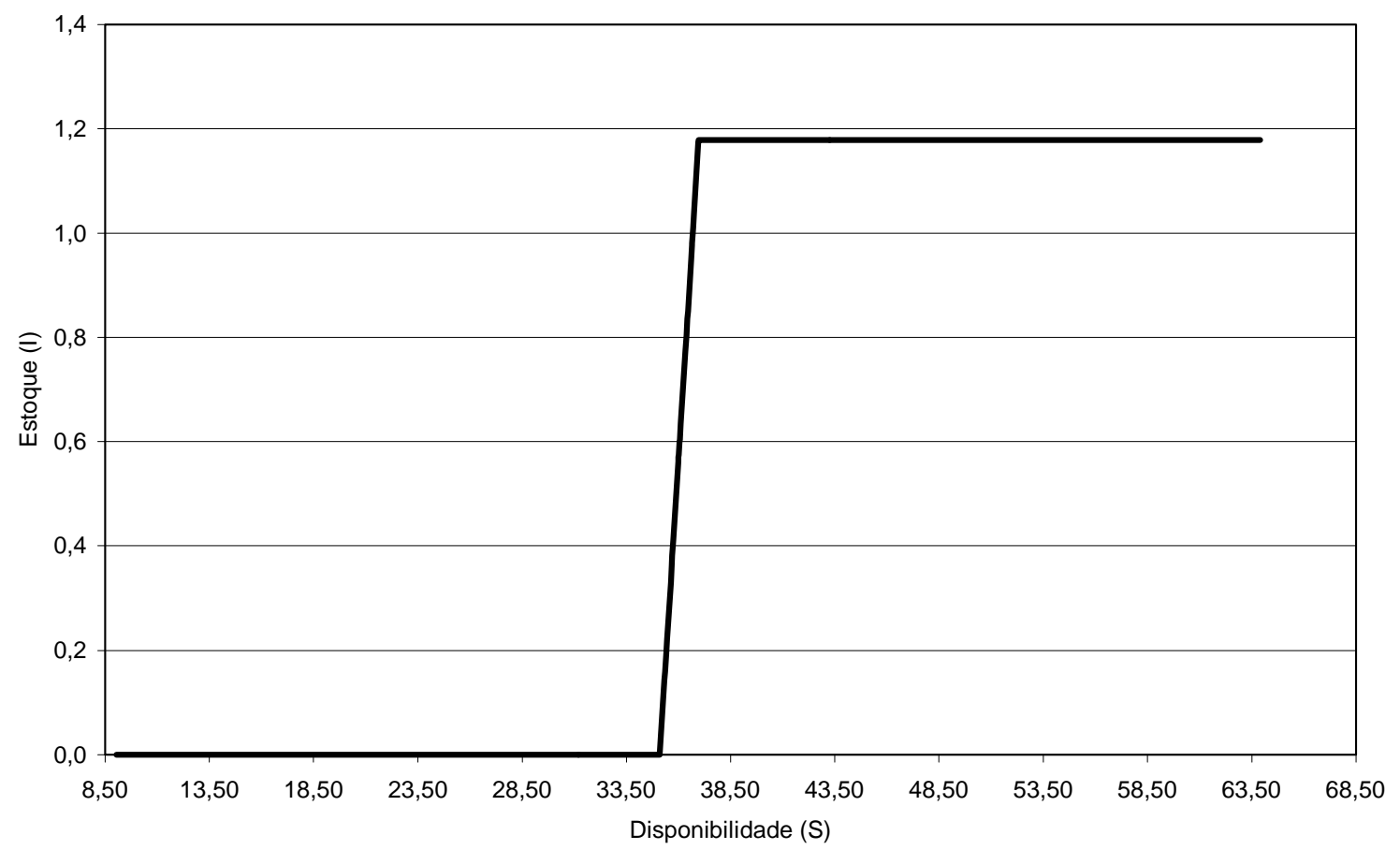

Figura 15 - Disponibilidade inicial e estoque de milho, em milhões de toneladas, economia aberta e sem intervenção do governo.

Quando o país exporta, o preço no mercado interno iguala o preço de exportação e o estoque de equilíbrio iguala este preço mais o custo de armazenamento ao preço esperado no período seguinte (a valor presente). O estoque de equilíbrio, nesta circunstância, é constante. O excesso de oferta no mercado interno quando há exportações é canalizado para o resto do mundo e não para compor estoques no mercado interno. O modelo indica que o estoque máximo de equilíbrio entre anos, no país, é de 1.178,2 mil toneladas.

A função do preço esperado para o mercado aberto, apresentada na Figura 14, muda significativamente em relação à economia fechada. Quando não se formam estoques o preço esperado é inferior a $\mathrm{R} \$ 250 /$ tonelada e o menor preço esperado se aproxima do preço de paridade de exportação. A função de área é apresentada na Figura 15. 


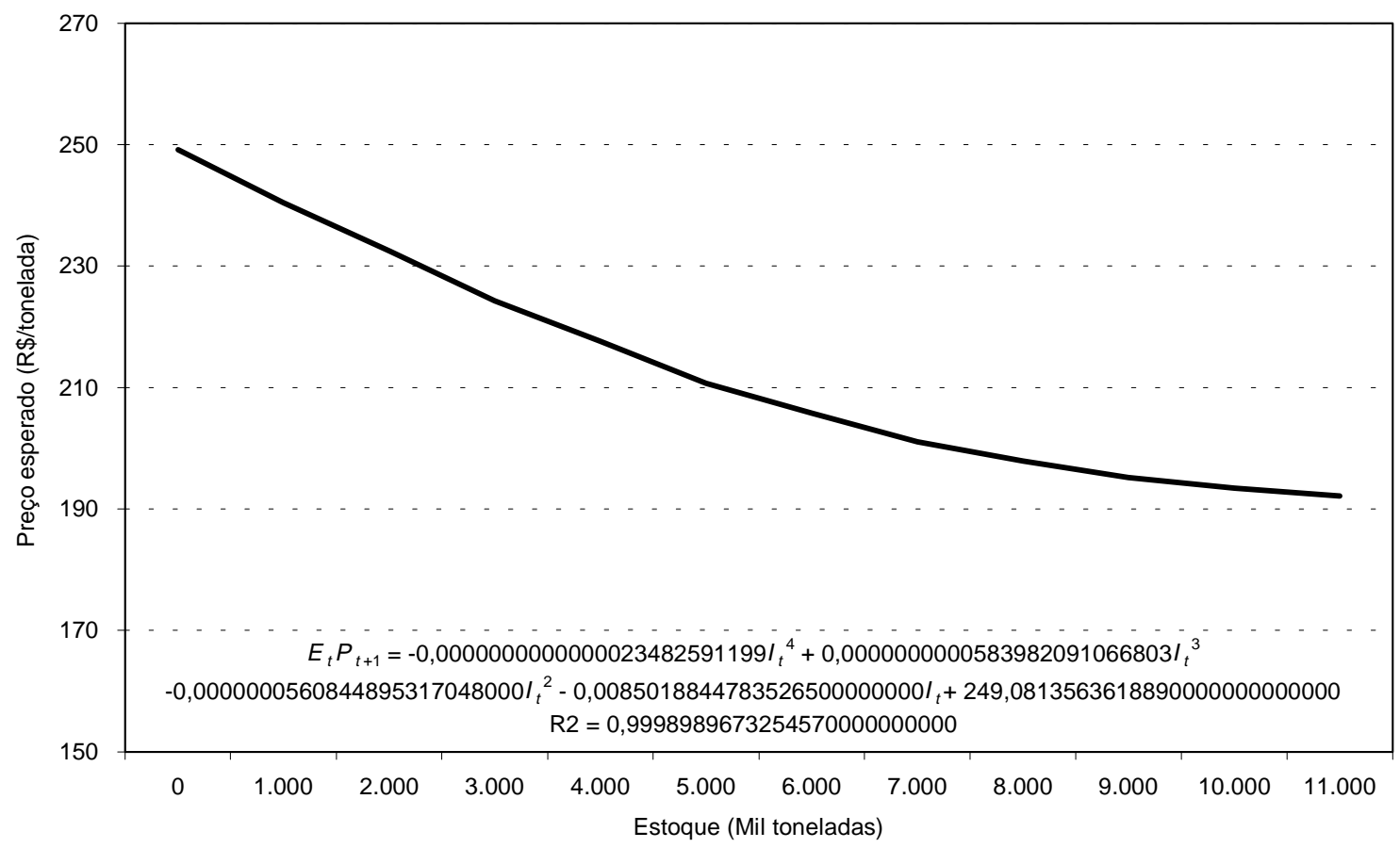

Figura 14 - Preço esperado em função do estoque, economia aberta sem PEP.

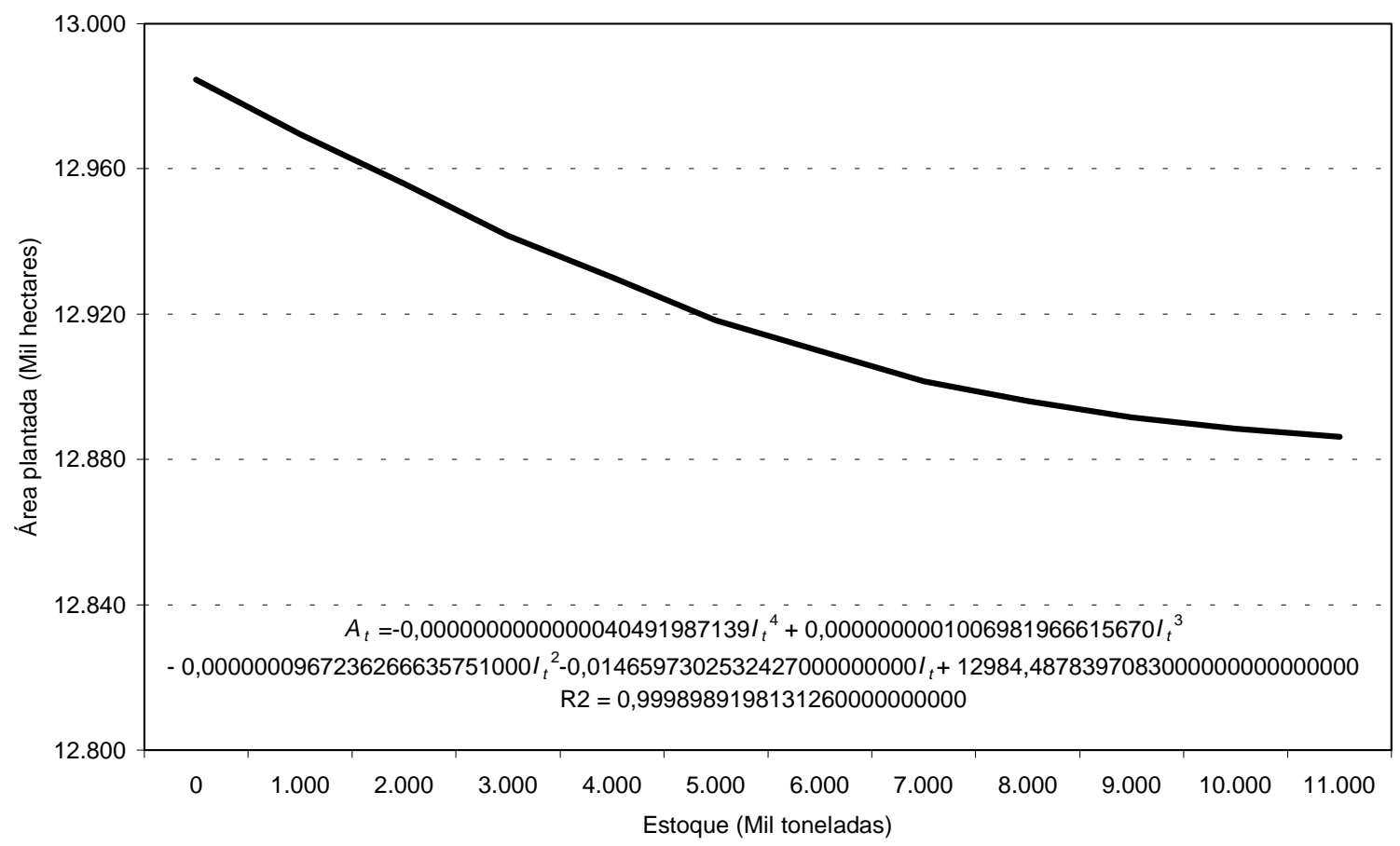

Figura 15 - Área plantada em função do estoque, economia aberta sem PEP. 


\section{Economia aberta e intervenção via PEP}

A Figura 16 apresenta a política ótima de estoques para o modelo de economia aberta com subsídio via PEP. Apesar de semelhante à política ótima para economia aberta sem intervenção, no caso de subsídio o estoque é maior, em volumes que podem chegar a 4,7 mil toneladas. Da mesma forma que no caso de economia fechada, o subsídio ao produtor aumenta a disponibilidade de produto e permite estoques maiores, apesar de que a diferença é pequena.

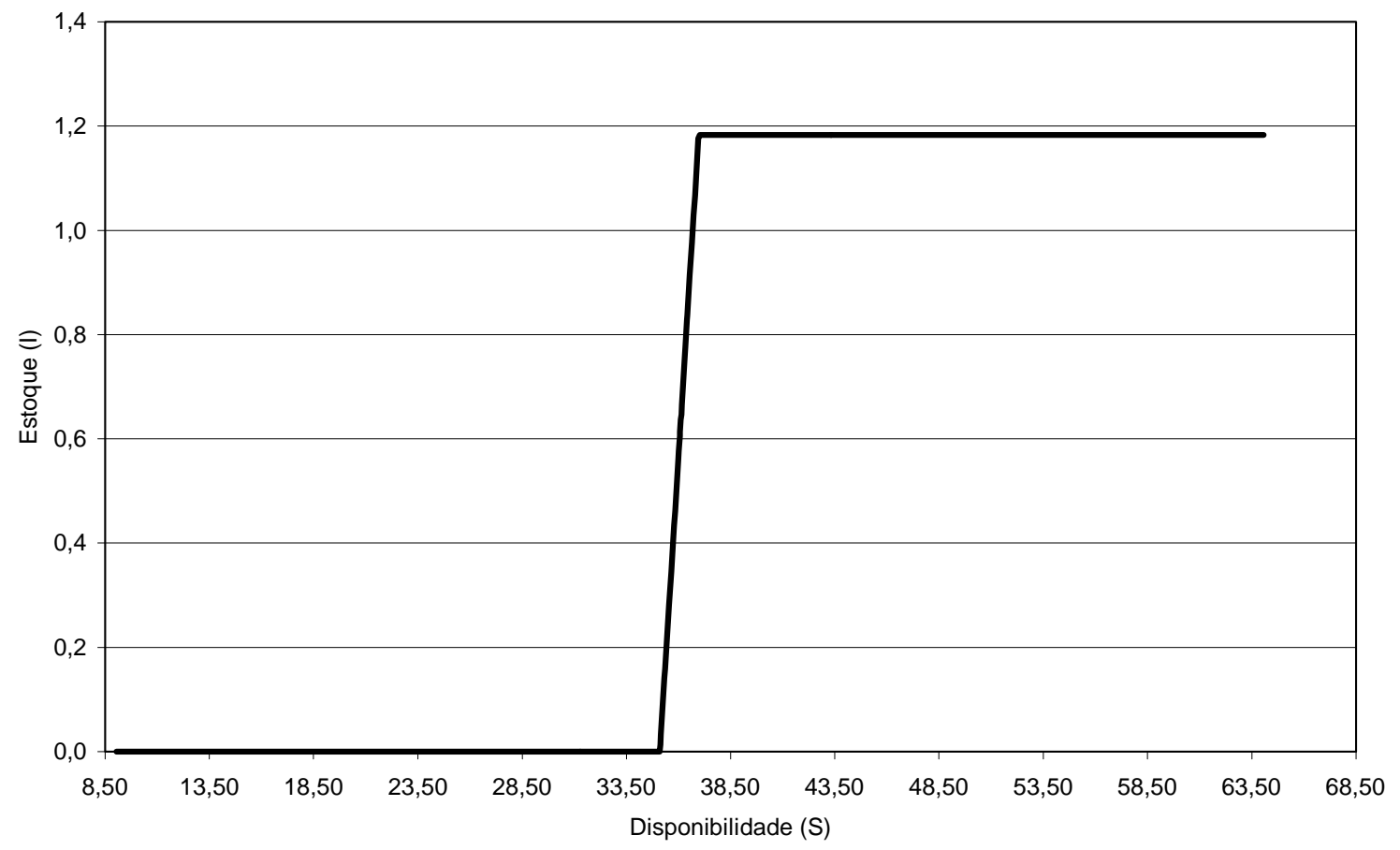

Figura 16 - Disponibilidade inicial e estoque de milho, em milhões de toneladas, economia aberta com PEP. 


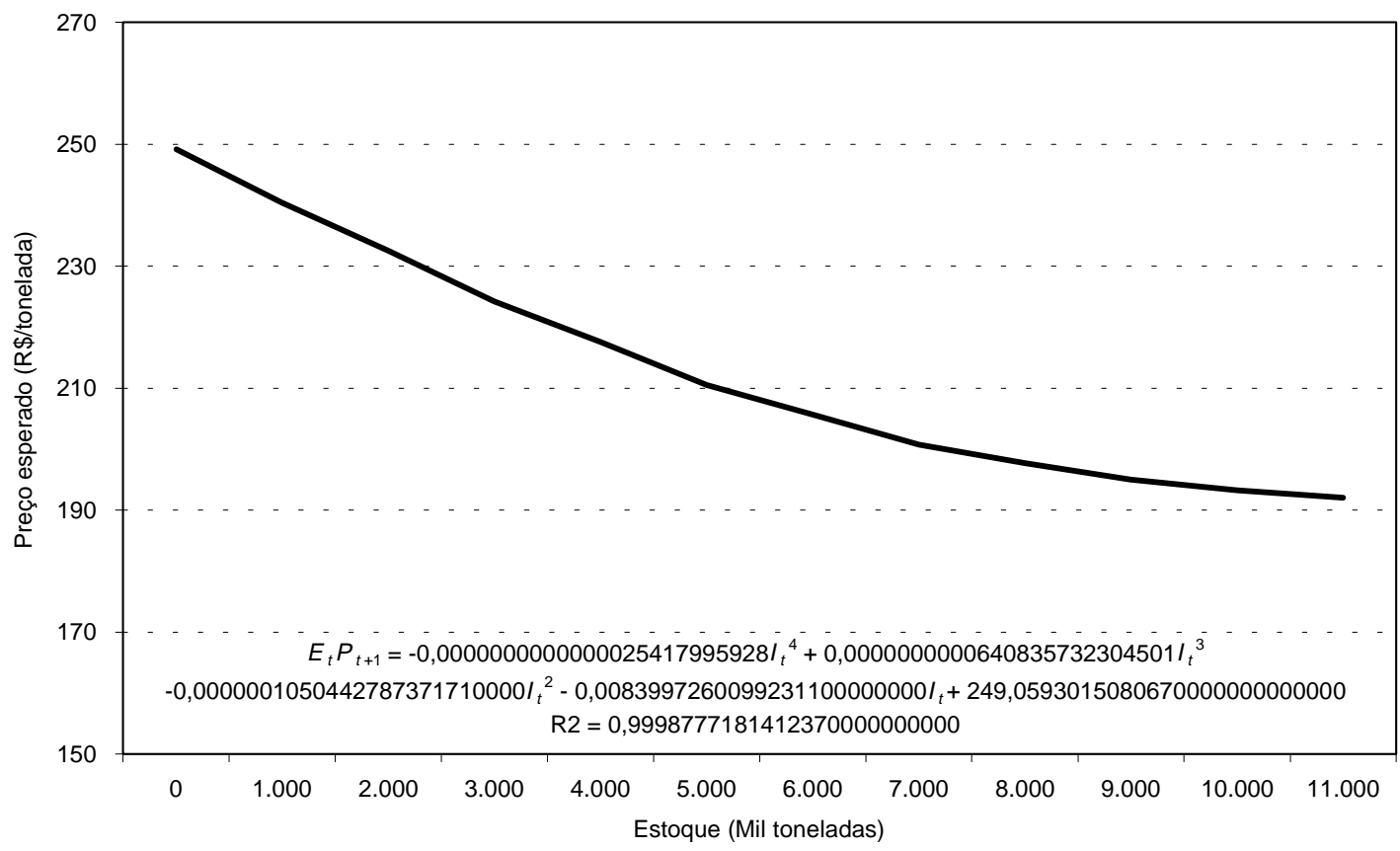

Figura 17 - Preço esperado em função do estoque, economia aberta com PEP.

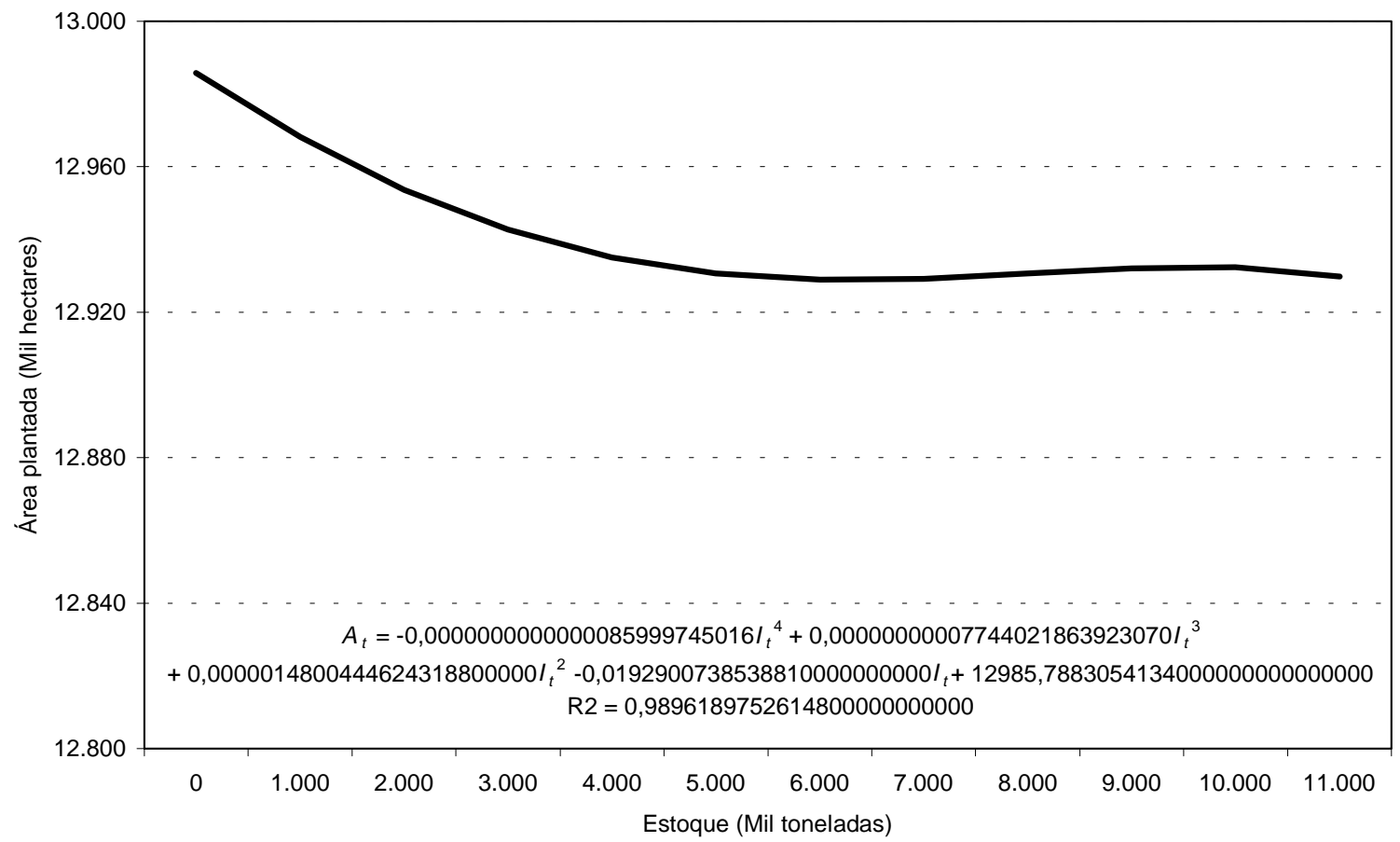

Figura 18 - Área plantada em função do estoque, economia aberta com PEP. 
Não é possível uma comparação direta destes resultados com os valores de disponibilidade e estoques finais observados para o milho no Brasil por dois motivos: a política ótima obtida pelo modelo está condicionada aos parâmetros que não são os mesmos para um ano particular do passado e, até a safra 96/97 o governo agia através de uma política de estoques reguladores (mesmo que falha), uma hipótese não considerada nos modelos deste estudo. Mas é possível avaliar se os volumes de estoque e disponibilidade são, ao menos, próximos ou totalmente distantes, ou seja, se há sinais de coerência nos resultados para os anos recentes, sob a nova política. Pela política ótima (ou regra do armazenamento), para uma disponibilidade de 39,08 milhões de toneladas (observada na safra 97/98) o estoque ótimo seria de 2,58 milhões de toneladas. Como mostra a Tabela 2, naquele ano safra o estoque está estimado em 3,12 milhões de toneladas, $20 \%$ acima do volume indicado pelo modelo, valores razoavelmente próximos.

\subsection{Médias de longo prazo}

As médias de longo prazo foram obtidas através de simulações para um período de 10 anos começando no ano zero, no qual a disponibilidade inicial foi igual para todos os modelos. Segundo Wright \& Williams (1991) e Miranda \& Fackler (2001), as simulações devem partir de um ano com disponibilidade inicial acima ou abaixo da média para permitir avaliar de que forma um choque inicial positivo ou negativo é absorvido pelo sistema. O importante é que, partindo de um período de excesso de oferta ou de escassez, o modelo deve convergir para a média de longo prazo. A opção de simulação foi para uma disponibilidade inicial acima da média, de 40 milhões de toneladas, resultado de um estoque anterior de 5 milhões de toneladas e nova produção de 35 milhões. Esta seqüência de 10 anos foi simulada 2500 vezes para cada modelo e a média de cada ano é a média destes 2500 valores. Este tipo de análise permite averiguar de que maneira o sistema absorve o excesso de oferta inicial. 
A Tabela 6 apresenta as médias de longo prazo para o modelo de economia fechada e sem intervenção do governo. A forma de apresentação dos dados procura evidenciar o aspecto dinâmico do armazenamento. A política ótima define o estoque de um ano safra para o outro (dado que o modelo é anual) e, assim, o estoque final de um ano é o estoque inicial do ano seguinte.

Tabela 6. Médias de longo prazo das variáveis endógenas, para o modelo de economia fechada sem intervenção.

Em mil toneladas

\begin{tabular}{|c|c|c|c|c|c|c|c|}
\hline Ano & $\begin{array}{c}\text { Estoque } \\
\text { Inicial } \\
\left(I_{t-1}\right)\end{array}$ & $\begin{array}{l}\text { Produção } \\
\qquad\left(H_{t}\right)\end{array}$ & $\begin{array}{c}\text { Disponibilidade }^{1} \\
\left(S_{t}\right)\end{array}$ & $\begin{array}{c}\text { Consumo } \\
\left(D_{t}\right)\end{array}$ & $\begin{array}{c}\text { Estoque } \\
\text { Final } \\
\left(I_{t}\right)\end{array}$ & $\begin{array}{c}P_{\mathrm{t}} \\
(\mathrm{R} \$ / \mathrm{t})\end{array}$ & $\begin{array}{c}A_{t} \\
\text { (Mil ha) }\end{array}$ \\
\hline 0 & $5.000,0$ & $35.000,0$ & $40.000,0$ & $36.920,7$ & $3.079,3$ & 172,23 & $12.936,0$ \\
\hline 1 & $3.079,3$ & $30.900,8$ & $33.979,4$ & $33.028,3$ & 951,0 & 226,22 & $12.976,1$ \\
\hline 2 & 951,0 & $31.297,3$ & $32.245,9$ & $31.618,3$ & 627,6 & 244,70 & $12.982,1$ \\
\hline 3 & 627,6 & $31.205,0$ & $31.832,0$ & $31.254,7$ & 577,2 & 249,46 & $12.983,4$ \\
\hline 4 & 577,2 & $31.217,2$ & $31.793,6$ & $31.271,6$ & 522,0 & 249,24 & $12.984,1$ \\
\hline 5 & 522,0 & $31.093,7$ & $31.615,1$ & $31.120,2$ & 495,0 & 251,22 & $12.984,5$ \\
\hline 6 & 495,0 & $31.100,3$ & $31.595,7$ & $31.087,4$ & 508,3 & 251,65 & $12.984,2$ \\
\hline 7 & 508,3 & $30.947,1$ & $31.455,1$ & $30.943,0$ & 512,1 & 253,54 & $12.984,1$ \\
\hline 8 & 512,1 & $31.056,8$ & $31.569,7$ & $31.038,2$ & 531,5 & 252,29 & $12.983,7$ \\
\hline 9 & 531,5 & $31.204,6$ & $31.735,5$ & $31.174,0$ & 561,5 & 250,51 & $12.983,2$ \\
\hline 10 & 561,5 & $31.269,7$ & $31.831,2$ & $31.265,1$ & 566,1 & 249,32 & $12.983,1$ \\
\hline
\end{tabular}

${ }^{1}$ Inclui os choques de demanda

A disponibilidade no ano zero, definida arbitrariamente, provém de um estoque inicial de 5 milhões de toneladas e produção de 35 milhões. No modelo de economia fechada e sem intervenção, das 40 milhões de toneladas, 36,92 milhões de 
toneladas serão consumidas a um preço anual de $\mathrm{R} \$ 172,23 /$ tonelada e 3.079,3 mil toneladas serão armazenadas para o ano safra seguinte. A área plantada para o ano seguinte é de 12.936 mil hectares.

No ano 1, ao estoque inicial soma-se uma produção de 30,9 milhões de toneladas totalizando pouco menos de 33,98 milhões de toneladas das quais 33.028,3 mil toneladas serão consumidas a um preço maior, de $\mathrm{R} \$ 226,22 /$ tonelada. Como o estoque reduz, o preço esperado aumenta o que faz crescer a área plantada para a safra seguinte, que passa para $12.976,1$ mil hectares. $\mathrm{O}$ estoque deste ano reduz para 951 mil toneladas. No ano 2 a produção cresce (área plantada foi maior) para cerca de 31,3 milhões de toneladas, o estoque de equilíbrio reduz ainda mais para 627,6 mil toneladas, o preço aumenta para $\mathrm{R} \$ 244,70 / \mathrm{t}$ e o consumo cai para $31.618,3$ mil toneladas. Da mesma forma a análise prossegue para os anos seguintes. Observe que as variáveis se comportam dentro do esperado, ou seja, o consumo reduz quando o preço aumenta, a área plantada aumenta quando o estoque reduz (preço esperado cresce) e o estoque reduz quando o preço corrente é maior. O preço esperado é obtido através do polinômio de quarta ordem ajustado para este modelo e apresentado na seção anterior.

Quando a economia é fechada os excessos de produto têm de ser absorvidos internamente. Para isto, o preço se reduz aumentando o consumo e permitindo que parte do produto seja armazenado. Observe que o excesso é absorvido após dois ou três anos safra quando o consumo passa para um patamar ao redor de 31,2 milhões de toneladas. O preço anual de equilíbrio a partir do ano 3 gira em torno de $\mathrm{R} \$$ 250,20/tonelada e o estoque final médio é de 544,6 mil toneladas.

A Tabela 7 apresenta as médias de longo prazo das variáveis endógenas para o modelo do mercado de economia fechada com intervenção através de PEP. As variáveis da Tabela 7 são as mesmas do modelo anterior, mas inclui também a média de longo prazo do prêmio (subsídio) ao produtor. Note que esta modelagem considera que a 
política passa a existir no ano 0 e não é antecipada pelo mercado mas, uma vez definida, é a mesma para todos os períodos (Wright \& Williams, 1991).

Tabela 7. Médias de longo prazo das variáveis endógenas, para o modelo de economia fechada com intervenção através de PEP.

Em mil toneladas

\begin{tabular}{rcccccccc}
\hline \multicolumn{2}{c}{ Estoque } & Produção & Disponi- & Consumo & Estoque & $P_{\mathrm{t}}$ & $\theta_{t}$ & $A_{t}$ \\
Ano & Inicial & $\left(H_{t}\right)$ & bilidade $^{1}$ & $\left(D_{t}\right)$ & Final & $(\mathrm{R} \$ / \mathrm{t})$ & $(\mathrm{R} \$ / \mathrm{t})$ & (Mil ha) \\
& $\left(I_{t-1}\right)$ & & $\left(S_{t}\right)$ & & $\left(I_{t}\right)$ & & & \\
\hline 0 & $5.000,0$ & $35.000,0$ & $40.000,0$ & $36.923,8$ & $3.076,2$ & 175,19 & 42,81 & $12.913,9$ \\
1 & $3.076,2$ & $30.856,4$ & $33.932,0$ & $32.966,0$ & 936,0 & 226,65 & 15,62 & $12.975,0$ \\
2 & 936,0 & $31.294,7$ & $32.228,3$ & $31.608,0$ & 620,3 & 244,83 & 10,88 & $12.983,6$ \\
3 & 620,3 & $31.208,6$ & $31.828,2$ & $31.254,3$ & 573,9 & 249,46 & 9,92 & $12.988,1$ \\
4 & 573,9 & $31.228,7$ & $31.801,7$ & $31.280,8$ & 521,0 & 249,12 & 9,19 & $12.986,5$ \\
5 & 521,0 & $31.099,5$ & $31.619,9$ & $31.125,8$ & 494,1 & 251,15 & 8,94 & $12.987,1$ \\
6 & 494,1 & $31.106,5$ & $31.601,1$ & $31.094,0$ & 507,1 & 251,56 & 9,02 & $12.986,3$ \\
7 & 507,1 & $30.952,2$ & $31.459,0$ & $30.948,0$ & 511,1 & 253,48 & 8,99 & $12.985,5$ \\
8 & 511,1 & $31.060,4$ & $31.572,2$ & $31.042,1$ & 530,1 & 252,24 & 9,25 & $12.985,1$ \\
9 & 530,1 & $31.207,9$ & $31.737,4$ & $31.177,3$ & 560,1 & 250,47 & 9,74 & $12.984,5$ \\
10 & 560,1 & $31.272,6$ & $31.832,7$ & $31.268,8$ & 563,9 & 249,27 & 9,94 & $12.984,7$ \\
\hline
\end{tabular}

${ }^{1}$ Inclui os choques de demanda

A mesma análise por ano safra apresentada para o modelo com economia fechada pode ser realizada para o modelo com intervenção. No ano inicial o estoque será um pouco inferior ao observado no mercado sem intervenção porque o preço esperado com subsídio do governo ao produtor é menor do que na situação anterior. Isto acontece porque a redução na área plantada pelos produtores irá ocorrer apenas até que o preço esperado seja superior ao mínimo. Caso contrário a área plantada terá o preço mínimo como referência. Se a área reduz menos, haverá mais produto disponível do que na 
situação anterior, reduzindo o preço esperado, os estoques e aumentando o consumo e reduzindo o preço corrente. Este ajuste ocorre a partir do quarto ano que é o tempo necessário para que o mercado como um todo se ajuste ao fato do governo ter instituído um subsídio ao produtor.

Os gastos do governo ao longo dos 11 anos apresentados na Tabela 7 pode ser visualizado na Figura 19 e corresponde ao produto do prêmio médio do ano pela produção do mesmo ano. Após 11 anos da política, o gasto anual tende para um valor médio de 370 milhões de Reais por ano. A probabilidade (condicional as parâmetros e disponibilidade inicial do modelo) de que o governo tenha de subsidiar os produtores num determinado ano é de 37,28\%, que corresponde à proporção dos anos simulados em que o governo teve de intervir.

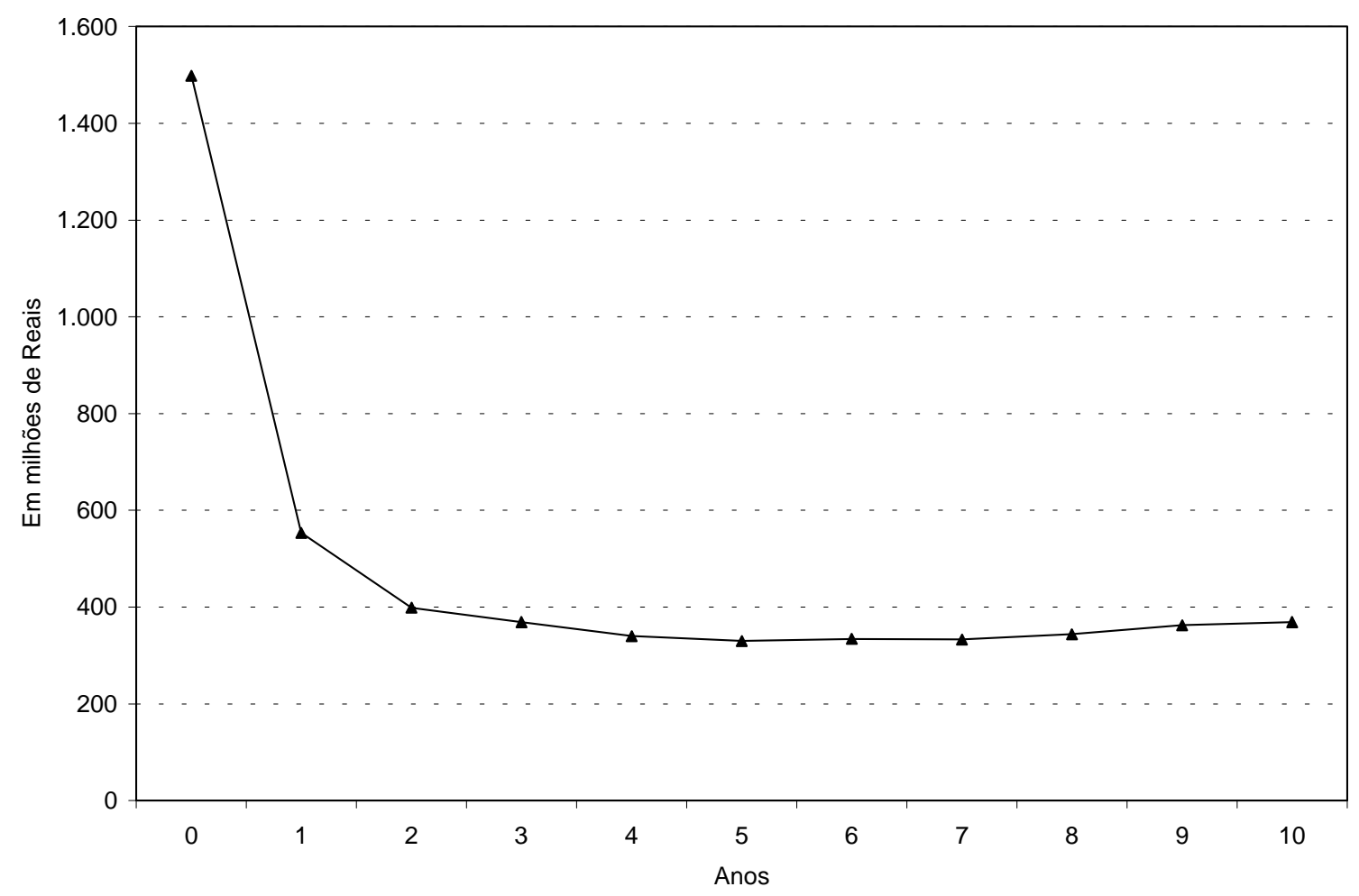

Figura 19 - Gastos do governo com PEP para o modelo de economia fechada com intervenção. 
A Tabela 8 apresenta as médias de longo prazo das variáveis endógenas do modelo com economia aberta e sem intervenção. Como são médias de 2.500 situações, em cada ano há um valor diferente de zero tanto para importação quanto para exportação. Isto não significa que num mesmo ano o país exporta e importa, uma hipótese que o modelo não permite dado o diferencial entre o preço de exportação e de importação. Mas em 2.500 situações há anos em que ocorre importação, em outros exportação e em outros, não há comércio com o exterior. A probabilidade condicional aos parâmetros e disponibilidade inicial de o país importar neste modelo é de $2 \%$ e de exportar é de 1,4\% A Tabela 8 contém média destas situações.

Tabela 8. Médias de longo prazo das variáveis endógenas, para o modelo de economia aberta sem intervenção.

Em mil toneladas

\begin{tabular}{cccccccccc}
\hline \multicolumn{7}{c}{ Estoque Produção Impor- } & \multicolumn{2}{c}{ Disponi- Consumo } & \multicolumn{2}{c}{ Expor- } & Estoque \\
Ano Inicial & $\left(H_{t}\right)$ & tação & bilidade & $\left(D_{t}\right)$ & tação & Final & $P_{\mathrm{t}}$ & $A_{t}$ \\
& $\left(I_{t-1}\right)$ & & $\left(M_{t}\right)$ & $\left(S_{t}\right)$ & & $\left(M_{t}\right)$ & $\left(I_{t}\right)$ & \\
\hline 0 & $5.000,0$ & $35.000,0$ & - & $40.000,0$ & $35.793,3$ & $3.028,6$ & $1.178,2$ & $190,012.967,2$ \\
1 & $1.178,2$ & $30.974,5$ & 471,7 & $32.623,6$ & $31.955,9$ & 406,3 & 261,5 & $240,312.980,7$ \\
2 & 261,5 & $31.308,2$ & 602,0 & $32.169,2$ & $31.575,1$ & 369,8 & 224,4 & $245,312.981,2$ \\
3 & 224,4 & $31.202,7$ & 629,2 & $32.055,7$ & $31.438,5$ & 390,9 & 226,2 & $247,012.981,2$ \\
4 & 226,2 & $31.212,0$ & 565,0 & $32.002,4$ & $31.455,8$ & 344,1 & 202,5 & $246,812.981,5$ \\
5 & 202,5 & $31.087,4$ & 629,6 & $31.919,0$ & $31.390,7$ & 331,7 & 196,6 & $247,712.981,6$ \\
6 & 196,6 & $31.093,3$ & 659,5 & $31.949,8$ & $31.403,5$ & 336,0 & 210,2 & $247,512.981,4$ \\
7 & 210,2 & $30.940,4$ & 736,9 & $31.887,3$ & $31.331,6$ & 348,0 & 207,8 & $248,512.981,4$ \\
8 & 207,8 & $31.050,4$ & 672,1 & $31.931,0$ & $31.358,9$ & 355,4 & 216,7 & $248,112.981,3$ \\
9 & 216,7 & $31.198,7$ & 652,1 & $32.066,9$ & $31.453,2$ & 387,8 & 225,9 & $246,912.981,2$ \\
10 & 225,9 & $31.264,8$ & 636,5 & $32.127,3$ & $31.521,8$ & 385,1 & 220,5 & $246,012.981,3$ \\
\hline
\end{tabular}

${ }^{1}$ Inclui os choques de demanda 
A primeira consequiência da abertura do mercado é a redução nos estoques que são parcialmente substituídos pelo mercado externo, que assume a função de amortecedor de choques de oferta e demanda (considerando que os preços externos neste estudo são parâmetros) e que o país foi considerado pequeno no mercado internacional. Após o segundo ano de mercado aberto, o estoque final não passa de 225 mil toneladas. A razão é que o mercado externo estabelece um limite inferior e outro superior para o preço interno o que se reflete diretamente na função do preço esperado (menor). O preço anual oscila ao redor de $\mathrm{R} \$ 247 / \mathrm{t}$ ou 3 reais por tonelada abaixo da média da situação de mercado fechado sem intervenção.

Tabela 9. Médias de longo prazo das variáveis endógenas, para o modelo de economia aberta com intervenção através de PEP.

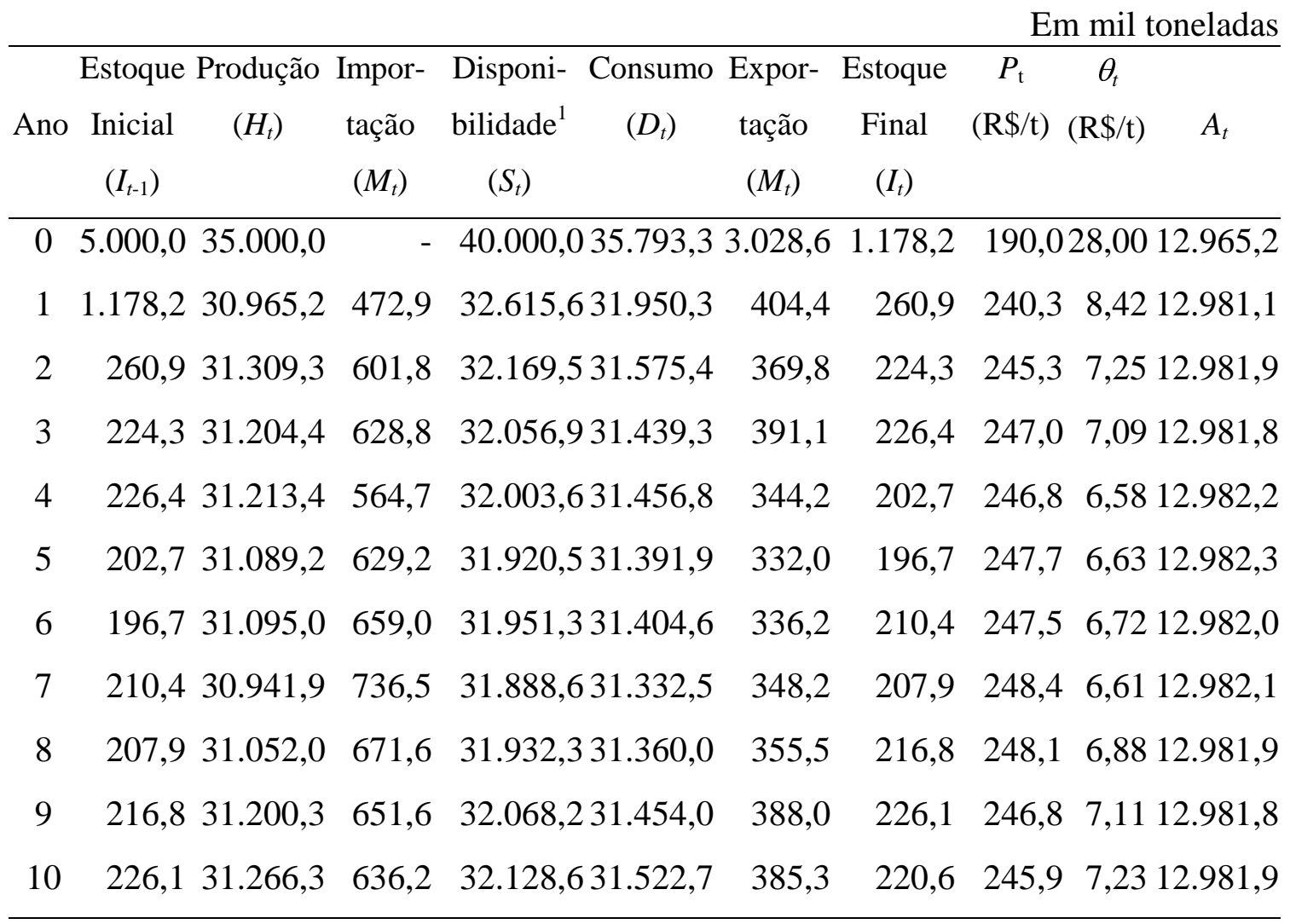

${ }^{1}$ Inclui os choques de demanda 
Finalmente, na Tabela 9 são apresentados os valores médios para a situação de mercado aberto com intervenção via PEP. Como o mercado externo garante que o preço de mercado não será inferior ao preço de paridade de exportação, o gasto do governo com subsídio é menor neste caso do que com economia fechada (para os parâmetros do modelo). Os resultados mudam pouco em relação ao mercado aberto sem subsídio. A mudança, novamente é na área plantada que se mantém ligeiramente acima da situação anterior, dados valores relativos do preço mínimo e dos preços de importação e exportação considerados no estudo. Como o mercado externo se torna um balizador para os preços internos, os gastos do governo com subsídio nas condições analisadas são menores do que no caso de mercado fechado. Os valores dos gastos anuais médios esperados do governo para este modelo são apresentados na Figura 20.

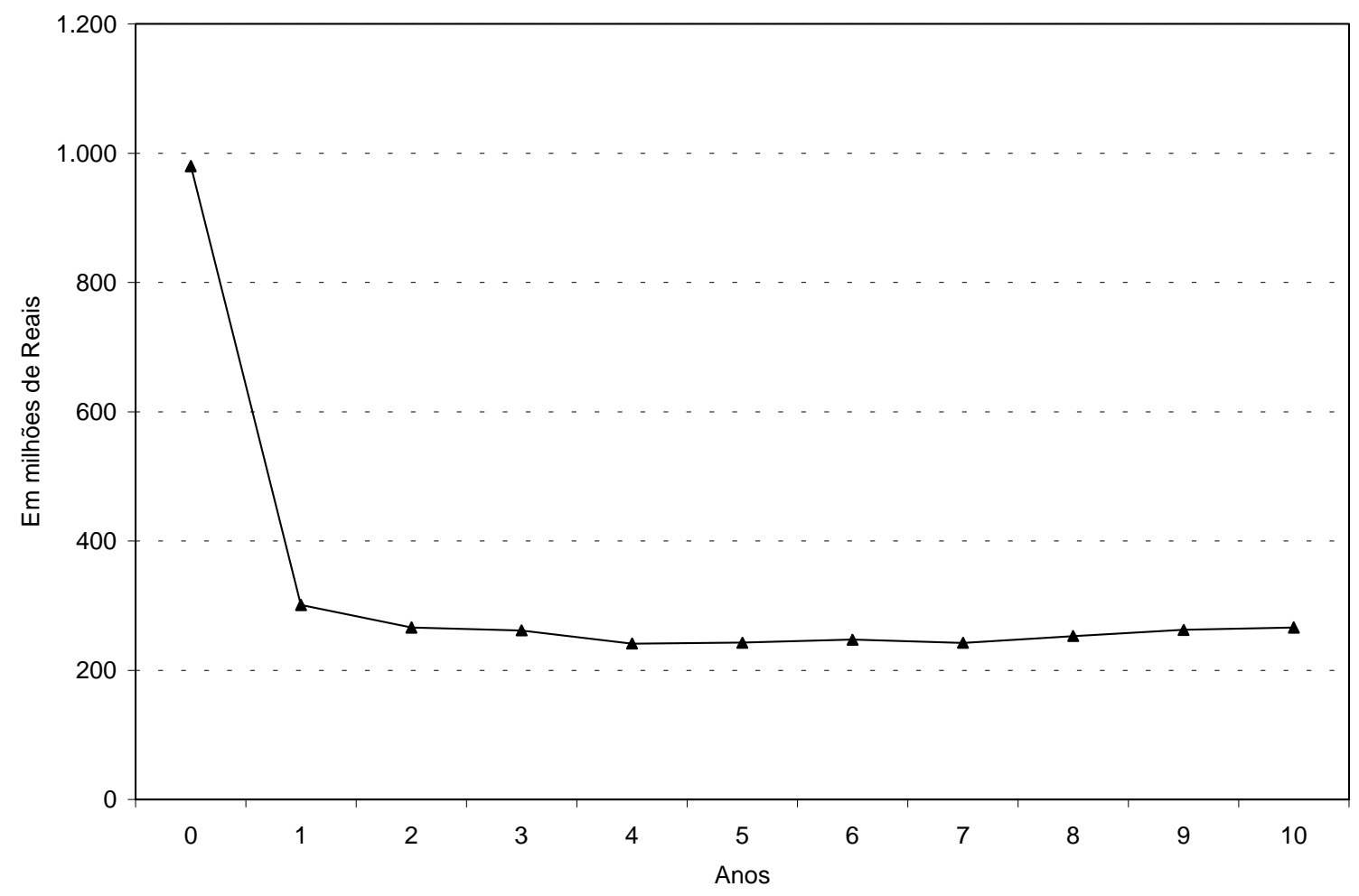

Figura 20 - Gastos do governo com PEP para o modelo de economia aberta com intervenção 
Em média, neste modelo, os gastos são 30\% inferiores aos da situação de mercado fechado com intervenção. A probabilidade (condicional aos parâmetros do modelo e à disponibilidade inicial de 40 milhões de toneladas) de que o governo tenha de subsidiar os produtores é de apenas 1,36\%. Este é o número relativo de anos em que o

subsídio é positivo no universo de anos simulados deste modelo. É claro que, quanto maior a diferença entre o preço mínimo e o preço de paridade de exportação, maior os gastos com subsídio e a probabilidade de intervenção. A probabilidade, também condicional, de haver importação é de $0,081 \%$ e de $0,05 \%$ de haver exportação.

\section{Convergência}

Em todos os modelos, os valores de longo prazo convergem para um determinado patamar. Isto fica mais claro através da Figura 21 que apresenta os volumes de disponibilidade dos modelos de economia fechada sem intervenção e aberta com intervenção, transformados em índice tendo como base o volume disponível no ano zero para o modelo de economia fechada e sem intervenção. Ambos convergem, mas para o mercado aberto a disponibilidade média é $2 \%$ maior do que para o mercado fechado. A análise dos valores para os dois modelos intermediários (fechada com intervenção e aberta sem intervenção) mostra que são muito próximos dos valores para os dois modelos extremos. Por isto a opção de apresentar graficamente apenas estes dois modelos. Com economia fechada e sem intervenção, o excesso de produto do ano zero leva três anos safra para ser absorvido enquanto com economia aberta isto ocorre em dois anos. 


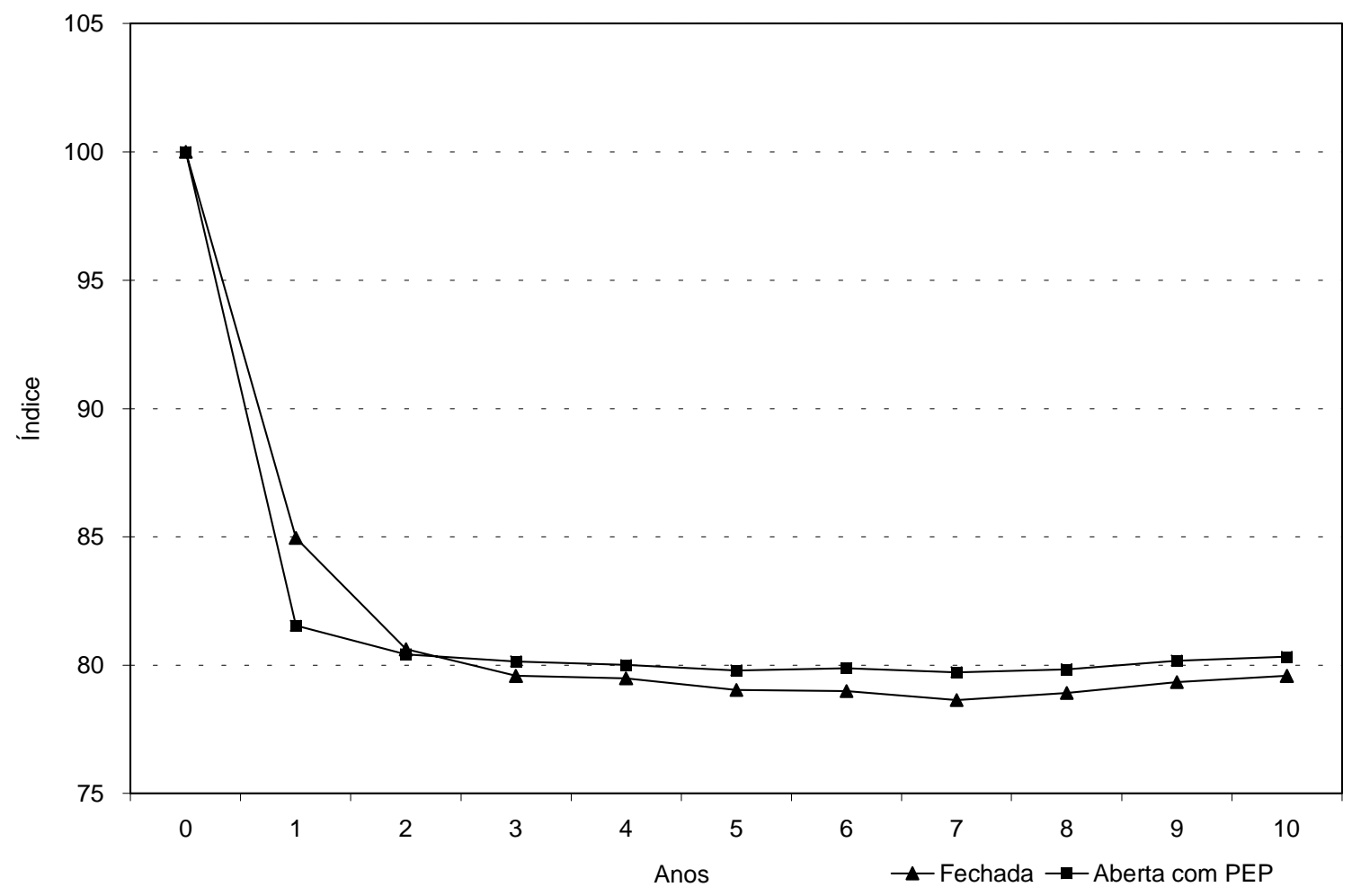

Figura 21 - Índice da disponibilidade total média de longo prazo de milho $\left(S_{t}\right)$, para os modelos de economia fechada sem intervenção e aberta com intervenção via PEP.

Os valores médios de longo prazo para o consumo no período de 11 anos são apresentados na Figura 22 e já foram apresentados nas tabelas correspondentes a cada modelo. Como se pode observar, o comportamento no tempo do consumo é muito semelhante ao da disponibilidade de produto. De forma geral, a economia aberta, nos moldes deste estudo, proporciona um volume para consumo ligeiramente superior ao da situação de economia fechada. 


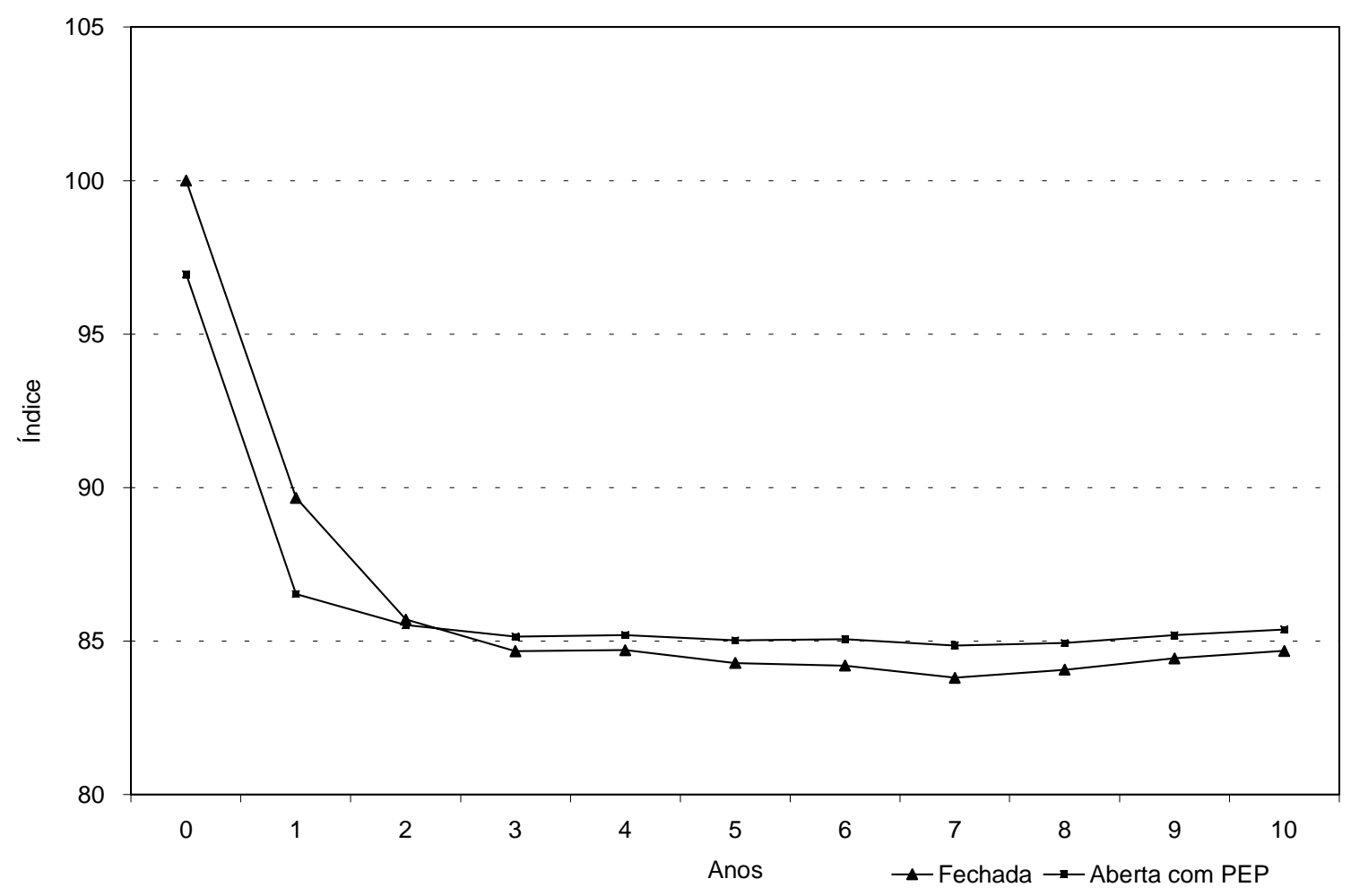

Figura 22 - Índice do consumo médio de longo prazo de milho $\left(D_{t}\right)$, para os modelos de economia fechada sem intervenção e aberta com intervenção via PEP.

A Figura 23 apresenta os valores médios para o estoque anual para os mesmos modelos das figuras anteriores. Aqui aparece a grande diferença entre as duas situações que é transferir para o mercado externo o papel de amortecer os choques de oferta e demanda. Observe que em ambos os casos o estoque converge para uma média de longo prazo, mas o volume de estoque no mercado aberto corresponde a metade do volume que se formaria no mercado fechado. 


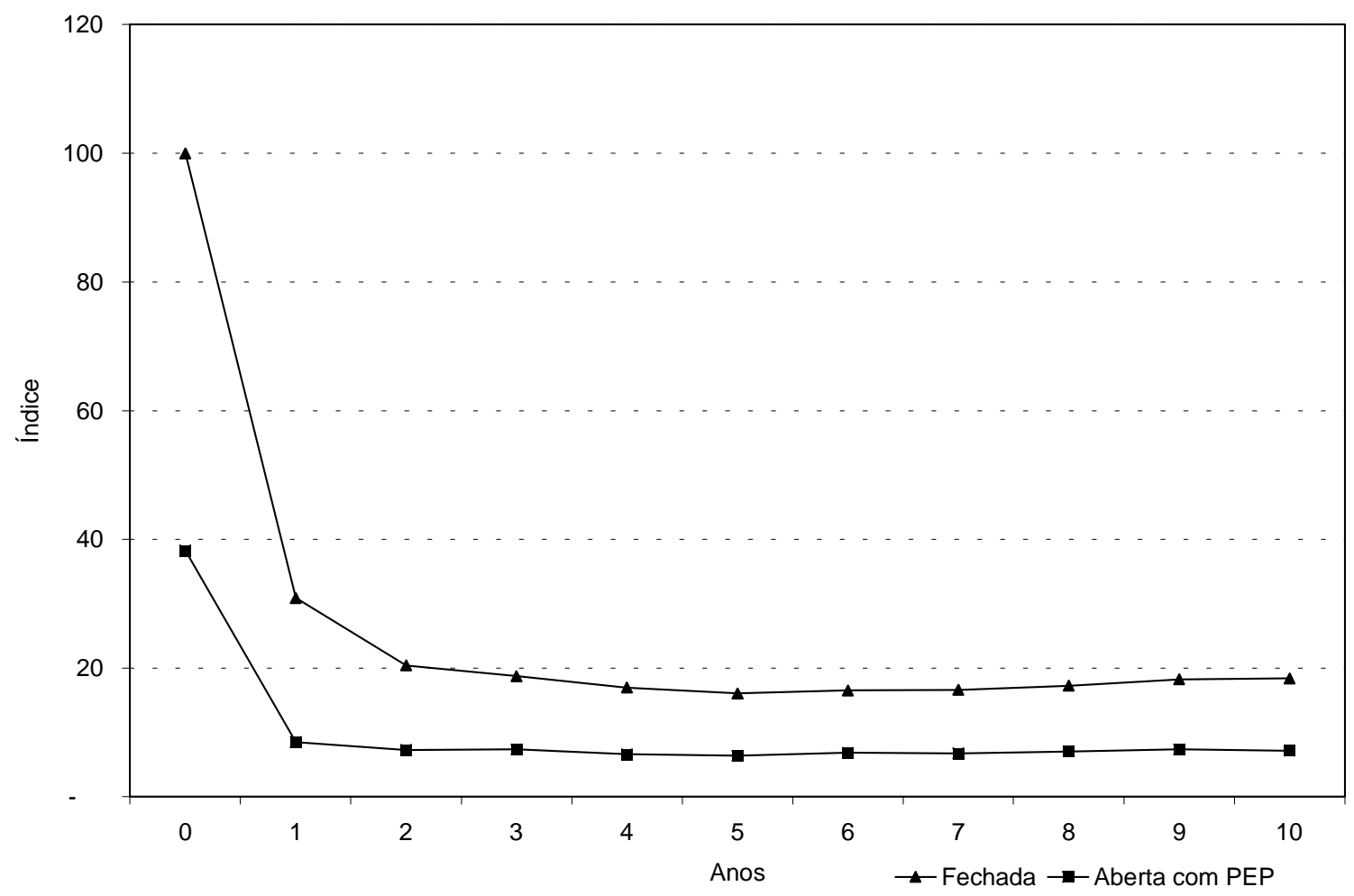

Figura 23 - Índice do estoque médio de longo prazo de milho $\left(I_{t}\right)$, para os modelos de economia fechada sem intervenção e aberta com intervenção via PEP.

O comportamento dos preços correntes médios de longo prazo pode ser observado na Figura 24. Os resultados estão dentro do esperado, com valores menores para a economia aberta e maiores para a economia fechada. A principal razão é que o mercado externo, da forma apresentada no estudo, impõe uma faixa de preços para o mercado brasileiro. O efeito é semelhante ao pretendido por uma política de estoques reguladores, mas sem que o governo forme estoques. Na prática, esta faixa muda de posição freqüentemente, acompanhando as oscilações do mercado internacional. Os preços internos devem variar dentro da faixa imposta pelos preços de paridade com o exterior, mas a faixa muda de posição o que torna impossível, a médio e longo prazos, estabilizar os preços internos apenas garantir uma faixa de variação que não seria possível com economia fechada. 


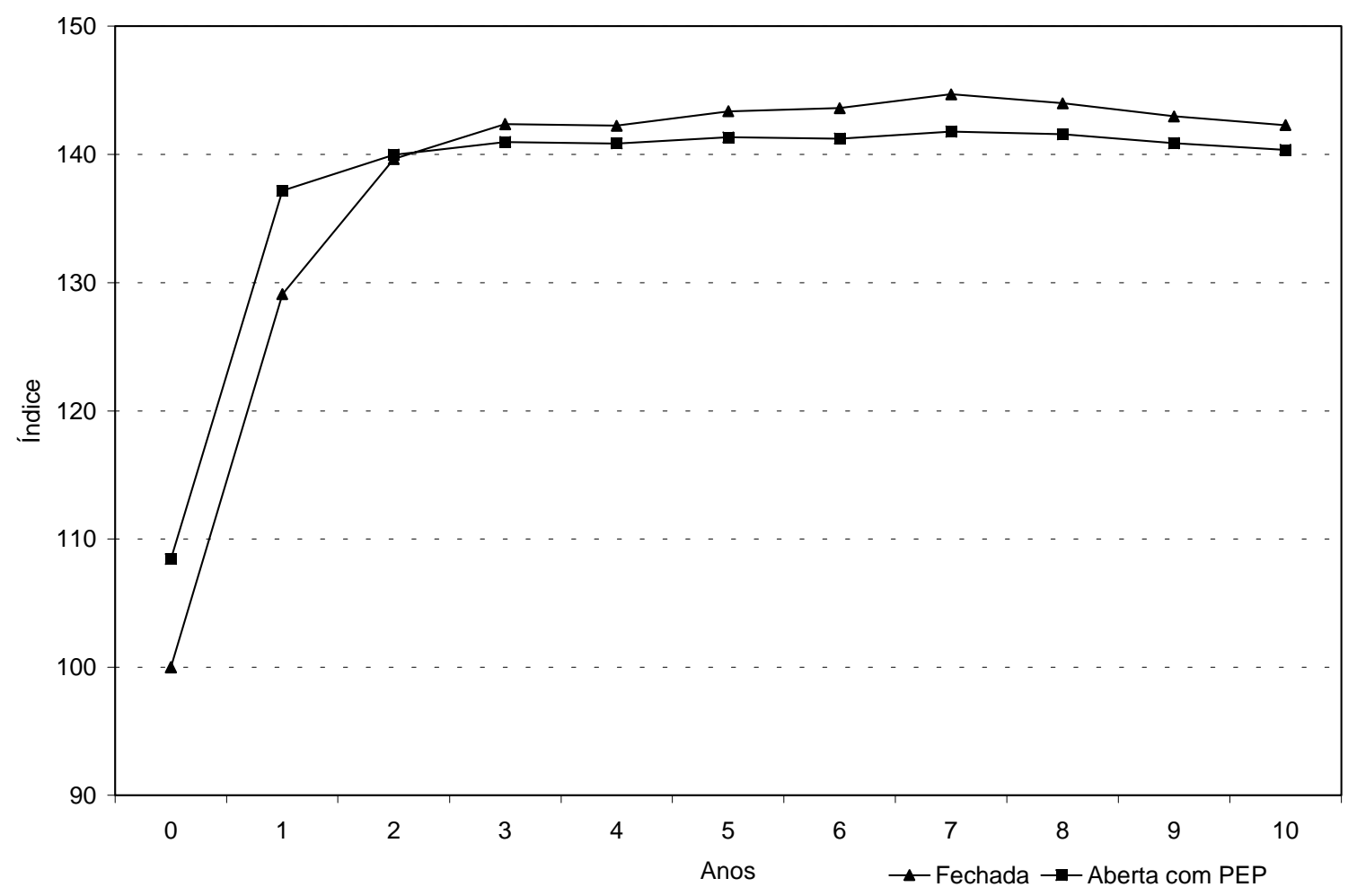

Figura 24 - Índice do preço médio de longo prazo de milho $\left(P_{t}\right)$, para os modelos de economia fechada sem intervenção e aberta com intervenção via PEP.

A faixa de preços determinada neste estudo pelo mercado externo torna o preço esperado no caso de economia aberta, inferior aos valores esperados para a economia fechada, como pode ser visualizado na Figura 25. Ambos os preços convergem para uma média mas para a economia aberta esta média é $2 \%$ inferior ao valor da economia fechada.

O preço ao produtor, apresentado na Figura 26 é igual ao preço corrente quando não há intervenção e supera o preço de equilíbrio pelo montante do prêmio no caso de subsídio através de PEP. 


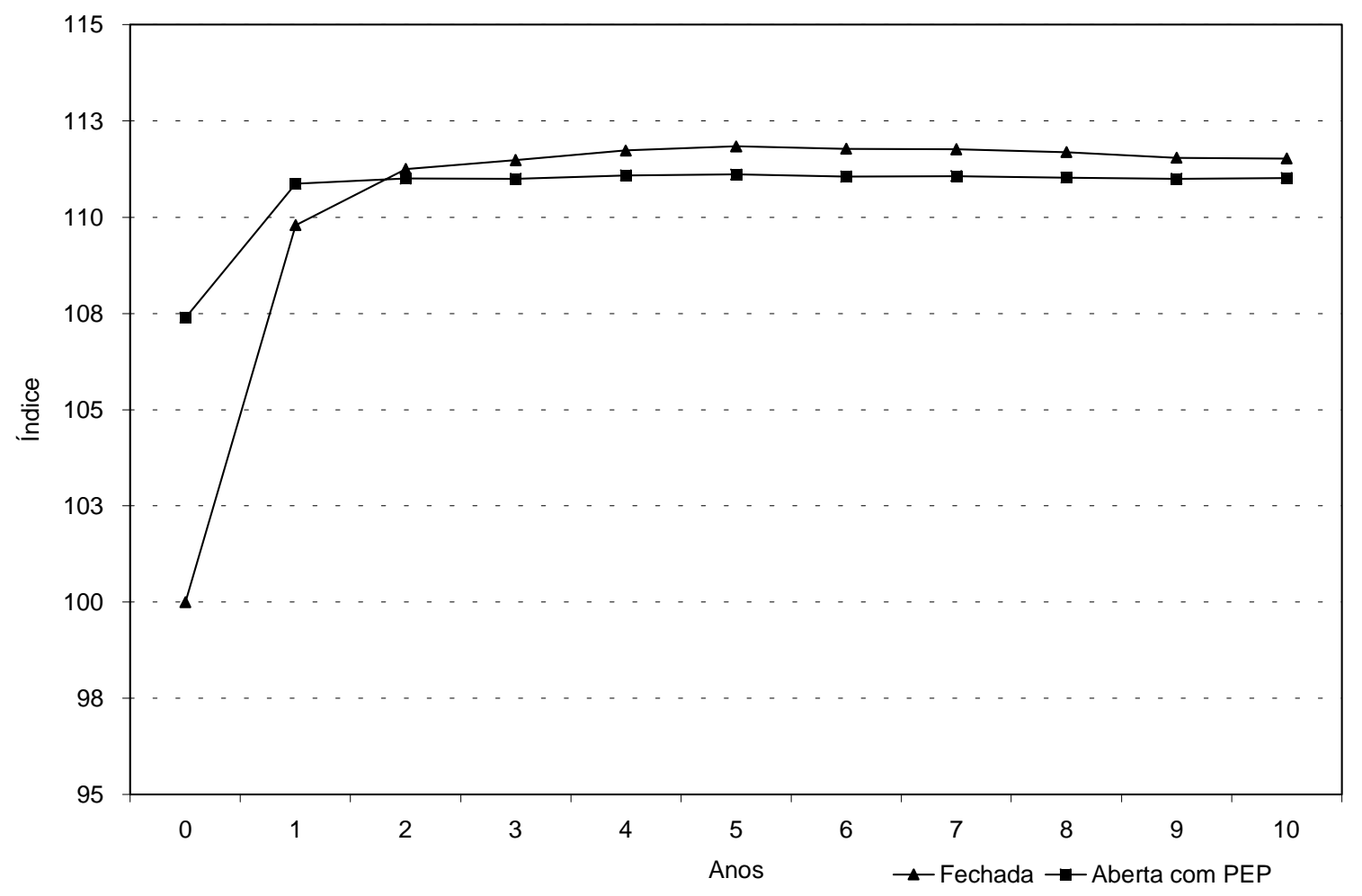

Figura 25 - Índice do preço médio de longo prazo de milho $\left(P_{t}\right)$, para os modelos de economia fechada sem intervenção e aberta com intervenção via PEP. 


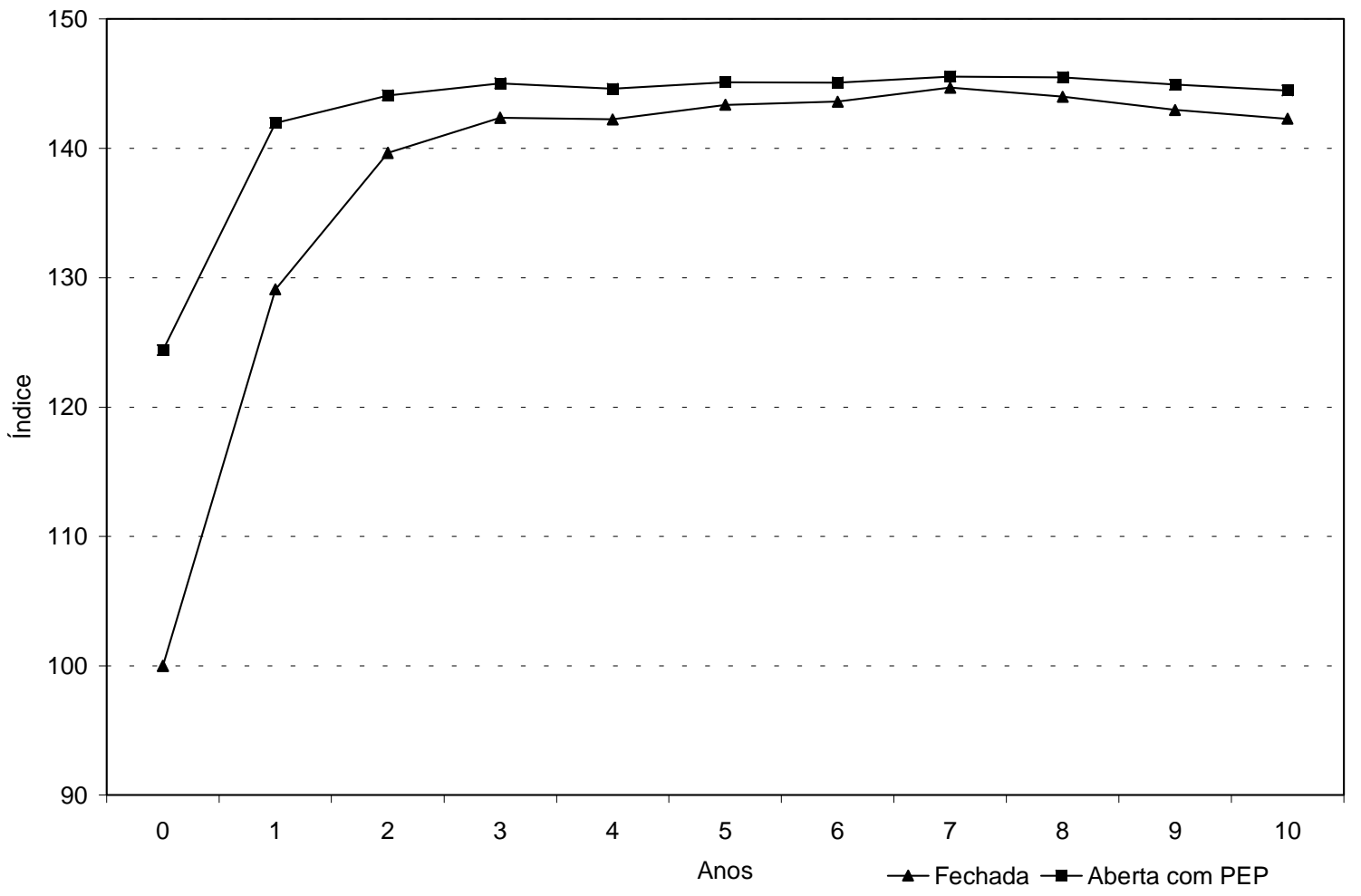

Figura 26 - Índice do preço médio de longo prazo ao produtor de milho $\left(\mathrm{P} P_{t}\right)$, para os modelos de economia fechada sem intervenção e aberta com intervenção via PEP.

\subsection{Exemplos selecionados}

Tão interessante quanto o comportamento médio de longo prazo reproduzido pelos modelos é a utilização de cada modelo para analisar situações particulares. Esta seção analisa dois exemplos das simulações que geraram as médias de longo prazo, apresentadas e analisadas na seção anterior. Das 2500 simulações realizadas foi escolhida uma, ao acaso, em que houve uma seqüência de produtividades acima da média e/ou choques negativos de demanda, aumentando a disponibilidade de produto e outra seqüência para a situação inversa. Os modelos foram comparados nas mesmas condições, ou seja, com os mesmos choques, cujos valores são apresentados na Tabela 10. O ano zero é o mesmo da simulação das médias de longo prazo. 
Tabela 10. Choques de demanda e produtividades para duas simulações.

\begin{tabular}{cccccc}
\hline Ano & \multicolumn{2}{c}{ Simulação 1 } & \multicolumn{2}{c}{ Simulação 2 } \\
\cline { 2 - 5 } & $\begin{array}{c}\text { Choque de } \\
\text { demanda }^{1}\end{array}$ & Produtividade $^{2}$ & $\begin{array}{c}\text { Choque de } \\
\text { demanda }^{1}\end{array}$ & Produtividade $^{2}$ \\
\hline 1 & -571 & 2,82 & -267 & 1,70 \\
2 & -1.789 & 2,34 & 516 & 2,58 \\
3 & -602 & 3,21 & 585 & 2,12 \\
4 & -1.072 & 2,56 & 220 & 2,15 \\
5 & -1.550 & 2,64 & 325 & 2,63 \\
6 & -4.271 & 3,11 & -1.076 & 2,39 \\
7 & 1.368 & 2,39 & -1.466 & 1,80 \\
8 & -2.689 & 1,62 & -1.522 & 2,18 \\
9 & -1.543 & 2,38 & 226 & 1,94 \\
10 & 712 & 2,82 & 1.107 & 1,85 \\
\hline
\end{tabular}

${ }^{1}$ Em mil toneladas

${ }^{2}$ Em toneladas/hectare

A disponibilidade inicial para estas simulações é a mesma apresentada para a média de longo prazo. $\mathrm{O}$ interesse desta seção é compreender que tipo de análises se pode realizar com estes modelos além do comportamento de longo prazo. Estas seqüências não são simulações especiais, mas duas das simulações realizadas que compõem a média e representam uma seqüência possível de ser observada para o mercado de milho.

Na Tabela 11 são apresentados os valores das variáveis endógenas para o modelo de economia fechada relativos à simulação ou seqüência 1. A disponibilidade 
inicial, acima da média no ano zero não consegue ser reduzida no ano seguinte porque a produção aumenta (produtividade acima da média) e o consumo se mantém praticamente o mesmo, elevando o estoque final e reduzindo o preço corrente do ano e a área plantada no ano 1 cuja produção é colhida no ano 2. No ano seguinte a produtividade é inferior à média reduzindo a produção mas ocorre um choque negativo de demanda. A disponibilidade reduz, o preço de equilíbrio aumenta, consumo e o estoque diminuem mas a área plantada cresce (preço esperado aumenta com estoque menor). No ano 3 novos choques de oferta (produtividade alta) e de demanda aumentam a disponibilidade. O preço de equilíbrio e a área plantada diminuem enquanto o estoque e consumo aumentam.

Tabela 11. Valores das variáveis endógenas, em mil toneladas, para o modelo de economia fechada sem intervenção, para a seqüência 1.

\begin{tabular}{rrrrrrrr}
\hline & Estoque & Produção & Disponibilidade & Consumo & Estoque & \multicolumn{1}{c}{$P_{\mathrm{t}}$} & $A_{t}$ \\
Ano & Inicial & $\left(H_{t}\right)$ & $\left(S_{t}\right)$ & $\left(D_{t}\right)$ & \multicolumn{1}{c}{ Final } & $(\mathrm{R} \$ / \mathrm{t})$ & $($ Mil ha) \\
& $\left(I_{t-1}\right)$ & & & & $\left(I_{t}\right)$ & & \\
\hline 0 & $5.000,0$ & $35.000,0$ & $40.000,0$ & $36.920,7$ & $3.079,3$ & 175,23 & $12.936,1$ \\
1 & $3.079,3$ & $36.471,4$ & $40.121,8$ & $36.968,2$ & $3.153,6$ & 174,61 & $12.934,9$ \\
2 & $3.153,6$ & $30.293,3$ & $35.235,4$ & $34.966,2$ & 269,2 & 200,83 & $12.991,8$ \\
3 & 269,2 & $41.671,3$ & $42.542,8$ & $37.879,0$ & $4.663,7$ & 162,68 & $12.914,3$ \\
4 & $4.663,7$ & $33.052,0$ & $38.787,8$ & $36.440,5$ & $2.347,3$ & 181,52 & $12.949,3$ \\
5 & $2.347,3$ & $34.207,0$ & $38.104,7$ & $36.164,2$ & $1.940,6$ & 185,14 & $12.956,8$ \\
6 & $1.940,6$ & $40.245,6$ & $46.456,7$ & $39.200,5$ & $7.256,3$ & 145,36 & $12.865,7$ \\
7 & $7.256,3$ & $30.698,0$ & $36.586,0$ & $35.536,8$ & $1.049,2$ & 193,36 & $12.973,3$ \\
8 & $1.049,2$ & $21.040,9$ & $24.779,5$ & $24.779,5$ & 0,0 & 334,29 & $12.993,1$ \\
9 & 0,0 & $30.966,7$ & $32.509,5$ & $32.509,5$ & 0,0 & 233,02 & $12.993,0$ \\
10 & 0,0 & $36.626,2$ & $35.914,3$ & $35.254,4$ & 659,9 & 197,06 & $12.981,0$ \\
\hline
\end{tabular}

\footnotetext{
${ }^{1}$ Inclui os choques de demanda
} 
No ano 4 o equilíbrio do mercado se caracteriza por aumento preço e área plantada e redução de consumo, de estoque. No ano seguinte o estoque de equilíbrio reduz cerca de 400 mil toneladas e o preço aumenta $2 \%$. No ano 6 novo choque de oferta com a produtividade ultrapassando 3 toneladas por hectare e novo choque negativo de demanda. Neste ano o preço de equilíbrio atinge $\mathrm{R} \$ 145,33 /$ tonelada, o valor mais baixo desta seqüência. $\mathrm{O}$ estoque supera sete milhões de toneladas e a área plantada se torna inferior a 12,9 milhões de hectares. No ano seguinte a produtividade é baixa, a disponibilidade diminui e $85 \%$ dos estoques são consumidos. No ano oito, outra frustração de safra reduz a produção para pouco mais de 21 milhões de toneladas e o preço no mercado ultrapassa $\mathrm{R} \$ 330 /$ tonelada. Os estoques são consumidos, o preço esperado aumenta (porque o estoque diminui) levando ao aumento também da área plantada. No ano nove a produção se recupera mas não o suficiente para permitir formação de novos estoques o que só ocorre no ano dez.

A leitura em linha da tabela demonstra os valores de equilíbrio para cada ano dependendo dos choques de oferta e demanda. A mesma análise pode ser feita para os resultados dos demais modelos. A Tabela 12 apresenta os valores endógenos para o mercado fechado com intervenção através de PEP. Neste modelo, de forma geral, os estoques tendem a ser menores do que no caso de não intervenção. A razão é que o preço esperado leva em conta que os produtores devem reduzir menos a área plantada do que fariam se não houvesse subsídio e deve haver mais produto disponível no ano seguinte.

Observe que, nesta seqüência, o governo terá de subsidiar o produtor em 8 dos dez anos da simulação, pois o excesso de produto e/ou choques negativos de demanda tornam o preço de equilíbrio inferior ao preço mínimo. O subsídio por tonelada chega a R \$ 72,95 ou 50\% do preço de mercado do ano. Como a produção do ano supera 40 milhões de toneladas (ano 6), o gasto do governo chega a 2.933 milhões de reais. Do ano zero até o ano sete o gasto acumulado do governo é de cerca de 11,82 bilhões de reais. 
Tabela 12. Valores das variáveis endógenas, em mil toneladas, para o modelo de economia fechada com intervenção através de PEP, para a seqüência 1.

\begin{tabular}{|c|c|c|c|c|c|c|c|c|}
\hline Ano & $\begin{array}{c}\text { Estoque } \\
\text { Inicial } \\
\left(I_{t-1}\right)\end{array}$ & $\begin{array}{c}\text { Produção } \\
\qquad\left(H_{t}\right)\end{array}$ & $\begin{array}{c}\text { Disponi- } \\
\text { bilidade }^{1} \\
\left(S_{t}\right)\end{array}$ & $\begin{array}{l}\text { Consumo } \\
\qquad\left(D_{t}\right)\end{array}$ & $\begin{array}{c}\text { Estoque } \\
\text { Final } \\
\left(I_{t}\right)\end{array}$ & $\begin{array}{c}P_{\mathrm{t}} \\
(\mathrm{R} \$ / \mathrm{t})\end{array}$ & $\begin{array}{c}\theta_{t} \\
(\mathrm{R} \$ / \mathrm{t})\end{array}$ & $\begin{array}{c}A_{t} \\
\text { (Mil ha) }\end{array}$ \\
\hline 0 & $5.000,0$ & $35.000,0$ & $40.000,0$ & $36.923,8$ & $3.076,2$ & 175,19 & 42,81 & $12.913,8$ \\
\hline 1 & $3.076,2$ & $36.408,8$ & $40.056,1$ & $36.945,9$ & $3.110,3$ & 174,90 & 43,10 & 12.915 \\
\hline 2 & $3.110,3$ & $30.246,5$ & $35.145,3$ & $34.928,0$ & 217,3 & 201,34 & 16,66 & 13.026, \\
\hline 3 & 217,3 & $41.781,2$ & $42.600,8$ & $37.914,7$ & $4.686,0$ & 162,21 & 55,79 & 12.923, \\
\hline 4 & $4.686,0$ & $33.075,1$ & $38.833,2$ & $36.458,5$ & $2.374,7$ & 181,29 & 36,71 & 12.933, \\
\hline 5 & $2.374,7$ & $34.163,9$ & $38.089,0$ & $36.156,2$ & $1.932,9$ & 185,25 & 32,75 & 12.944, \\
\hline 6 & $1.932,9$ & $40.208,2$ & $46.411,7$ & $39.224,1$ & $7.187,5$ & 145,05 & 72,95 & 12.777, \\
\hline 7 & $7.187,5$ & $30.488,0$ & $36.307,3$ & $35.417,9$ & 889,4 & 194,92 & 23,08 & $12.971,9$ \\
\hline 8 & 889,4 & $21.038,6$ & $24.617,3$ & $24.617,3$ & 0,0 & 336,41 & 0,00 & 12.995, \\
\hline 9 & 0,0 & $30.972,6$ & $32.515,4$ & $32.515,4$ & 0,0 & 232,94 & 0,00 & $12.994,7$ \\
\hline 10 & 0,0 & $36.630,9$ & $35.918,9$ & $35.254,8$ & 664,2 & 197,05 & 20,95 & 12.981, \\
\hline
\end{tabular}

${ }^{1}$ Inclui os choques de demanda

Na Tabela 13 estão os resultados da sequiência 1 para o mercado aberto e sem intervenção. O que chama a atenção de imediato é o estoque que não supera 1.178,2 que é o estoque de equilíbrio quando há exportação. $\mathrm{O}$ excesso de produto é escoado para o mercado externo ao invés de compor estoques para o ano safra seguinte. Com isto, o preço de mercado se mantém em níveis superiores aos observados para os casos de mercado fechado. Como é possível exportar, a escassez do ano oito é compensada com importação e o preço não supera a paridade com o importado (R \$ 300,00/tonelada). Observe ainda que, quando há exportação, os volumes são grandes, pois excessos 
menores viabilizam o armazenamento sem exportação como no caso dos anos quatro, cinco e dez.

Tabela 13. Valores das variáveis endógenas, em mil toneladas, para o modelo de economia aberta sem intervenção, para a seqüência 1.

\begin{tabular}{|c|c|c|c|c|c|c|c|c|}
\hline $\begin{array}{c}\text { Estoque } \\
\text { Ano Inicial } \\
\left(I_{t-1}\right)\end{array}$ & $\left(H_{t}\right)$ & $\begin{array}{l}\text { Impor- } \\
\text { tação } \\
\left(M_{t}\right)\end{array}$ & $\begin{array}{c}\text { Disponi- } \\
\text { bilidade }^{1} \\
\left(S_{t}\right)\end{array}$ & $\begin{array}{c}\text { Consumo } \\
\qquad\left(D_{t}\right)\end{array}$ & $\begin{array}{c}\text { Expor- } \\
\text { tação } \\
\left(M_{t}\right)\end{array}$ & $\begin{array}{c}\text { Estoque } \\
\text { Final } \\
\left(I_{t}\right)\end{array}$ & $P_{\mathrm{t}}$ & $A_{t}$ \\
\hline $05.000,0$ & $35.000,0$ & 0,0 & $40.000,0$ & $35.793,3$ & $3.028,6$ & $1.178,2$ & 190,00 & $12.967,2$ \\
\hline $11.178,2$ & $36.559,7$ & 0,0 & $38.309,0$ & $35.793,3$ & $1.337,6$ & $1.178,2$ & 190,00 & $12.967,2$ \\
\hline $21.178,2$ & $30.369,0$ & 0,0 & $33.335,6$ & $33.335,6$ & 0,0 & 0,0 & 222,20 & $12.984,4$ \\
\hline 0,0 & $41.647,5$ & 0,0 & $42.249,8$ & $35.793,3$ & $5.278,3$ & $1.178,2$ & 190,00 & $12.967,4$ \\
\hline $41.178,2$ & $33.187,9$ & 0,0 & $35.438,1$ & $35.228,6$ & 0,0 & 209,6 & 197,40 & $12.981,4$ \\
\hline 209,6 & $34.291,8$ & 0,0 & $36.051,8$ & $35.455,1$ & 0,0 & 596,7 & 194,43 & $12.975,8$ \\
\hline 596,7 & $40.304,5$ & 0,0 & $45.171,9$ & $35.793,3$ & $8.200,4$ & $1.178,2$ & 190,00 & $12.967,4$ \\
\hline $71.178,2$ & $30.940,6$ & 0,0 & $30.750,5$ & $30.750,5$ & 0,0 & 0,0 & 256,06 & $12.984,5$ \\
\hline 0,0 & $21.059,0$ & $3.648,4$ & $27.396,7$ & $27.396,7$ & 0,0 & 0,0 & 300,00 & $12.984,5$ \\
\hline 0,0 & $30.946,2$ & 0,0 & $32.489,1$ & $32.489,1$ & 0,0 & 0,0 & 233,29 & $12.984,4$ \\
\hline 0,0 & $36.601,9$ & 0,0 & $35.889,9$ & $35.395,4$ & 0,0 & 494,6 & 195,21 & $12.977,3$ \\
\hline
\end{tabular}

${ }^{1}$ Inclui os choques de demanda

A situação de mercado aberto com intervenção através de PEP para a sequiência 1 é apresentada na Tabela 14. Observe que, nos dois casos de mercado aberto, em períodos de escassez o consumo é maior do que no caso de economia fechada e em períodos de excesso o consumo é menor. Na primeira situação, a razão é simples: o que falta internamente é compensado por compras externas. Mas, no caso de excesso, a razão é a faixa possível de preços do mercado interno - entre 190 e 300 reais a tonelada. 
Para o mercado fechado a amplitude de variação dos preços é muito maior e o preço esperado supera o preço esperado na economia aberta.

Tabela 14. Valores das variáveis endógenas, em mil toneladas, para o modelo de economia aberta com intervenção através de PEP, para a sequiência 1.

\begin{tabular}{|c|c|c|c|c|c|c|c|c|c|c|}
\hline Ano & $\begin{array}{c}\text { Estoque } 1 \\
\text { Inicial } \\
\left(I_{t-1}\right)\end{array}$ & $\begin{array}{c}\text { Produção } \\
\left(H_{t}\right)\end{array}$ & $\begin{array}{c}\text { Impor- } \\
\text { tação } \\
\left(M_{t}\right)\end{array}$ & $\begin{array}{c}\text { Disponi- } \\
\text { bilidade }^{1} \\
\left(S_{t}\right)\end{array}$ & $\begin{array}{l}\text { Consumo } \\
\qquad\left(D_{t}\right)\end{array}$ & $\begin{array}{c}\text { Expor- } \\
\text { tação } \\
\left(M_{t}\right)\end{array}$ & $\begin{array}{c}\text { Estoque } \\
\text { Final } \\
\left(I_{t}\right)\end{array}$ & $\begin{array}{c}P_{\mathrm{t}} \\
(\mathrm{R} \$ / \mathrm{t})\end{array}$ & $\begin{array}{c}\theta_{t} \\
(\mathrm{R} \$ \mathrm{t})\end{array}$ & $A_{t}$ \\
\hline 0 & $5.000,0$ & $35.000,0$ & 0,0 & $40.000,0$ & $35.793,3$ & $3.028,56$ & $1.178,2$ & 190,00 & 28,00 & 12.965,2 \\
\hline 1 & $1.178,2$ & $36.547,9$ & 0,0 & $38.297,2$ & $35.793,3$ & $1.325,73$ & $1.178,2$ & 190,00 & 28,00 & 12.965,2 \\
\hline 2 & $1.178,2$ & $30.364,2$ & 0,0 & $33.330,9$ & $33.330,9$ & 0,00 & 0,0 & 222,26 & & - $12.987,8$ \\
\hline 3 & 0,0 & $41.658,7$ & 0,0 & $42.261,0$ & $35.793,3$ & $5.289,53$ & $1.178,2$ & 190,00 & 28,00 & O 12.963,2 \\
\hline 4 & $1.178,2$ & $33.177,2$ & 0,0 & $35.427,4$ & $35.224,7$ & 0,00 & 202,6 & 197,45 & 20,55 & $512.981,9$ \\
\hline 5 & 202,6 & $34.293,1$ & 0,0 & $36.046,1$ & $35.452,0$ & 0,00 & 594,1 & 194,47 & 23,53 & $3 \quad 12.974,4$ \\
\hline 6 & 594,1 & $40.300,2$ & 0,0 & $45.164,9$ & $35.793,3$ & $8.193,49$ & $1.178,2$ & 190,00 & 28,00 & 0 12.963,2 \\
\hline 7 & $1.178,2$ & $30.930,6$ & 0,0 & $30.740,5$ & $30.740,5$ & 0,00 & 0,0 & 256,19 & & - $12.985,8$ \\
\hline 8 & 0,0 & $21.061,2$ & $3.646,2$ & $27.396,7$ & $27.396,7$ & 0,00 & 0,0 & 300,00 & & - $12.985,8$ \\
\hline 9 & 0,0 & $30.949,3$ & 0,0 & $32.492,2$ & $32.492,2$ & 0,00 & 0,0 & 233,25 & & - $12.987,3$ \\
\hline 10 & 0,0 & $36.610,0$ & 0,0 & $35.898,0$ & $35.397,6$ & 0,00 & 500,4 & 195,18 & 22,82 & $212.976,1$ \\
\hline
\end{tabular}

${ }^{1}$ Inclui os choques de demanda

Quanto aos gastos do governo no caso de economia aberta são bem inferiores aos apresentados para economia fechada porque os preços neste segundo caso reduzem menos. Novamente a magnitude do gasto está condicionada aos valores estabelecidos para o preço mínimo e de exportação e importação.

Para uma visualização comparativa dos resultados entre os modelos para esta simulação, algumas das variáveis apresentadas nas tabelas acima, para os modelos 
de economia fechada sem intervenção e aberta com intervenção através de PEP, foram transformadas em índice e reportadas em figuras. Em todos os casos o índice $=100 \mathrm{se}$ refere ao valor da variável no ano zero para o modelo de economia fechada. Os valores absolutos das variáveis podem ser encontrados nas tabelas apresentadas acima.

A Figura 27 apresenta a disponibilidade total de produto no mercado nacional para as condições mencionadas. A principal diferença se percebe no ano oito quando há escassez, a qual é suprida pelo mercado externo no caso de mercado aberto. Em períodos de excesso de produto a disponibilidade no mercado fechado é sempre superior ao do mercado aberto, como seria de se esperar.

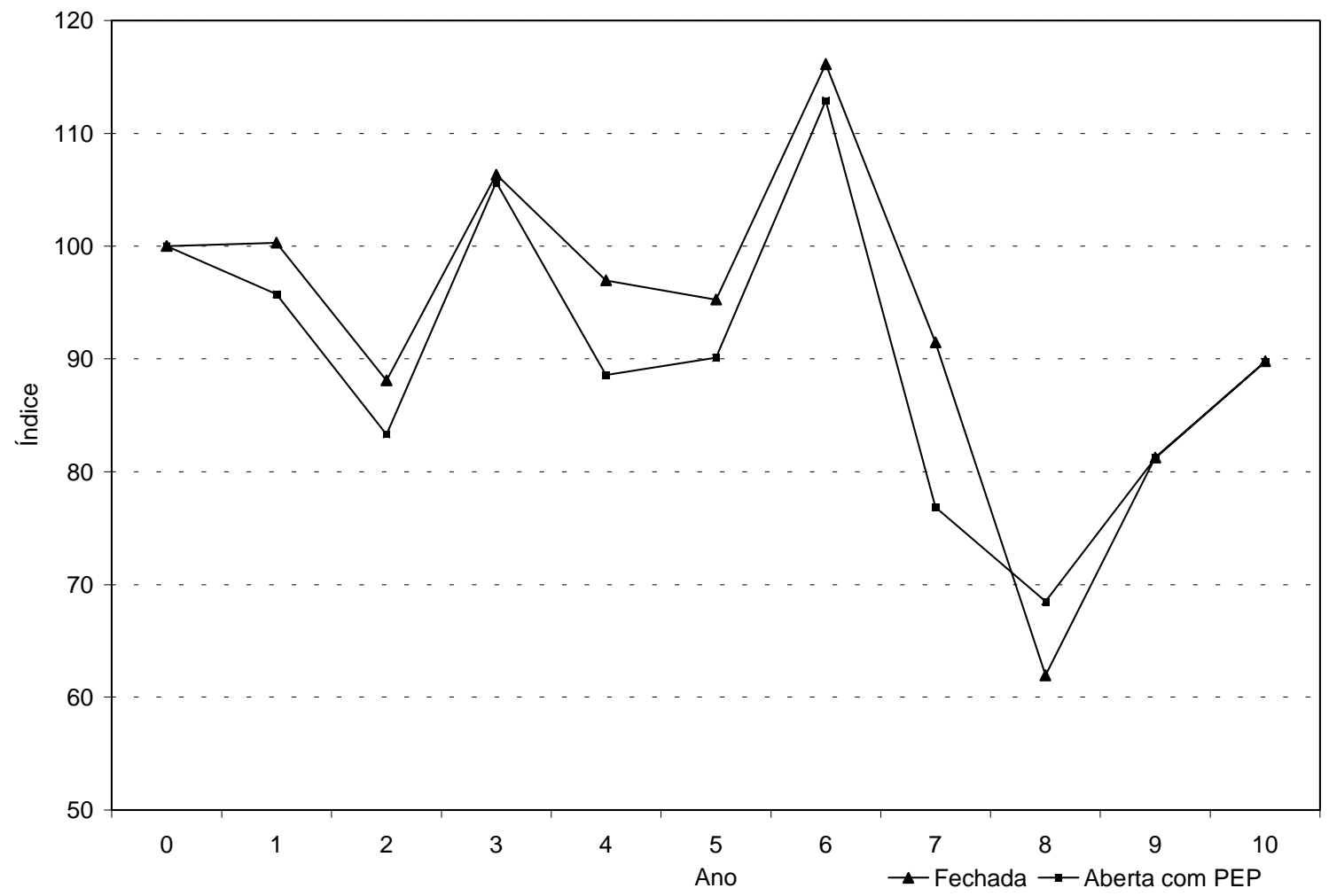

Figura 27 - Índice da disponibilidade anual de milho $\left(S_{t}\right)$, para os modelos de economia fechada sem intervenção e aberta com intervenção via PEP, seqüência 1. 
A evolução do consumo entre os dois modelos é apresentada na Figura 28 que confirma o comportamento esperado de que, com economia aberta o consumo é menor do que no caso alternativo quando há excedente e o inverso quando há escassez. A diferença entre os modelos chega a $10 \%$.

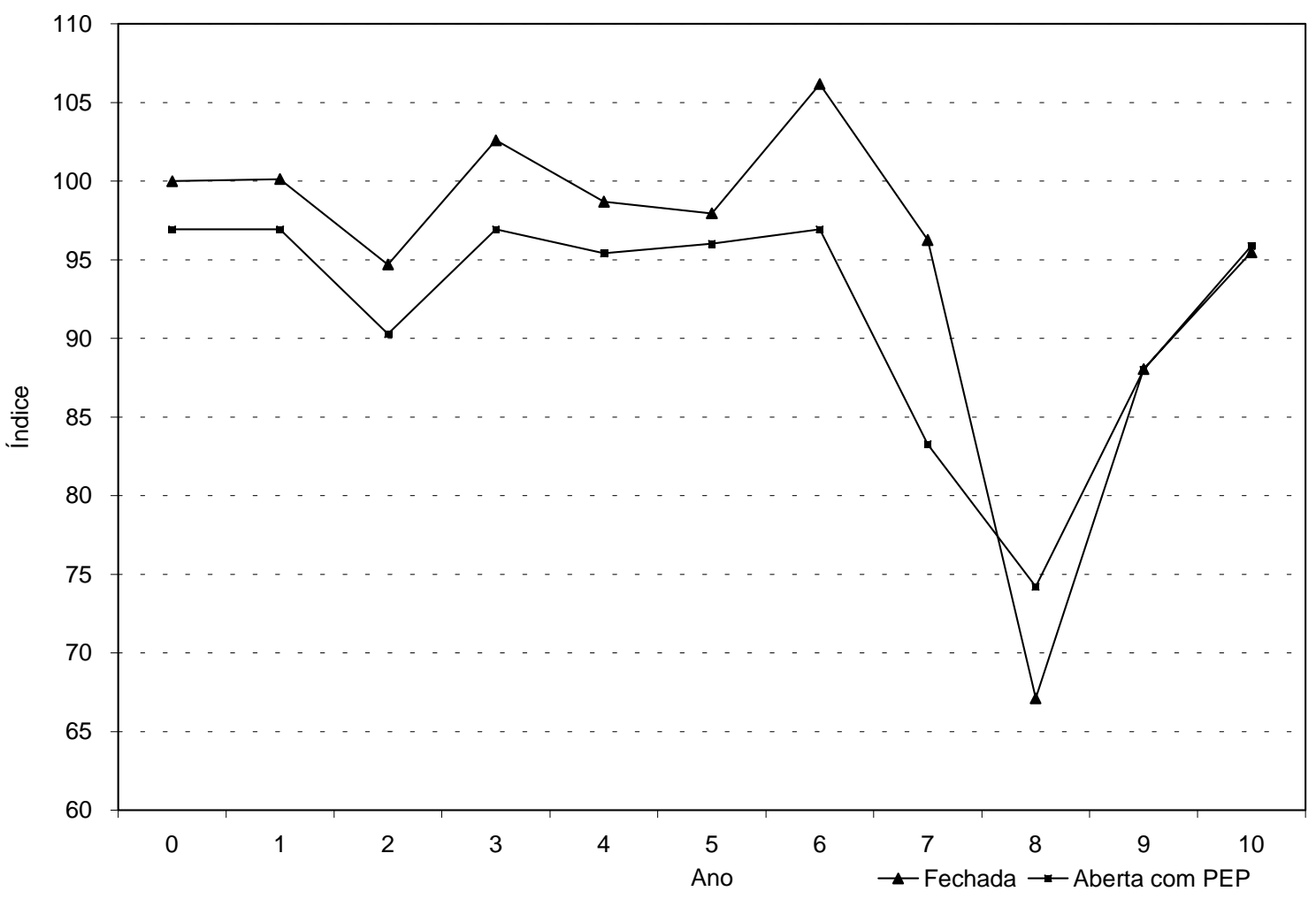

Figura 28 - Índice do consumo anual de milho $\left(D_{t}\right)$, para os modelos de economia fechada sem intervenção e aberta com intervenção via PEP, seqüência 1.

Os preços de equilíbrio do ano refletem o consumo nas duas situações e podem ser visualizados na Figura 29. A diferença de preço entre uma situação e outra para um mesmo ano na seqüência de simulação pode chegar a 32,5\% (ano 7). Com consumo menor, os preços no mercado aberto são maiores do que no mercado fechado quando há períodos de excedente. O inverso é verdadeiro. A figura contém ainda o preço ao produtor para a situação de mercado aberto com PEP, pois no caso de economia 
fechada o preço ao produtor é o preço de mercado. A diferença de preço ao produtor chega a $50 \%$ no ano seis.

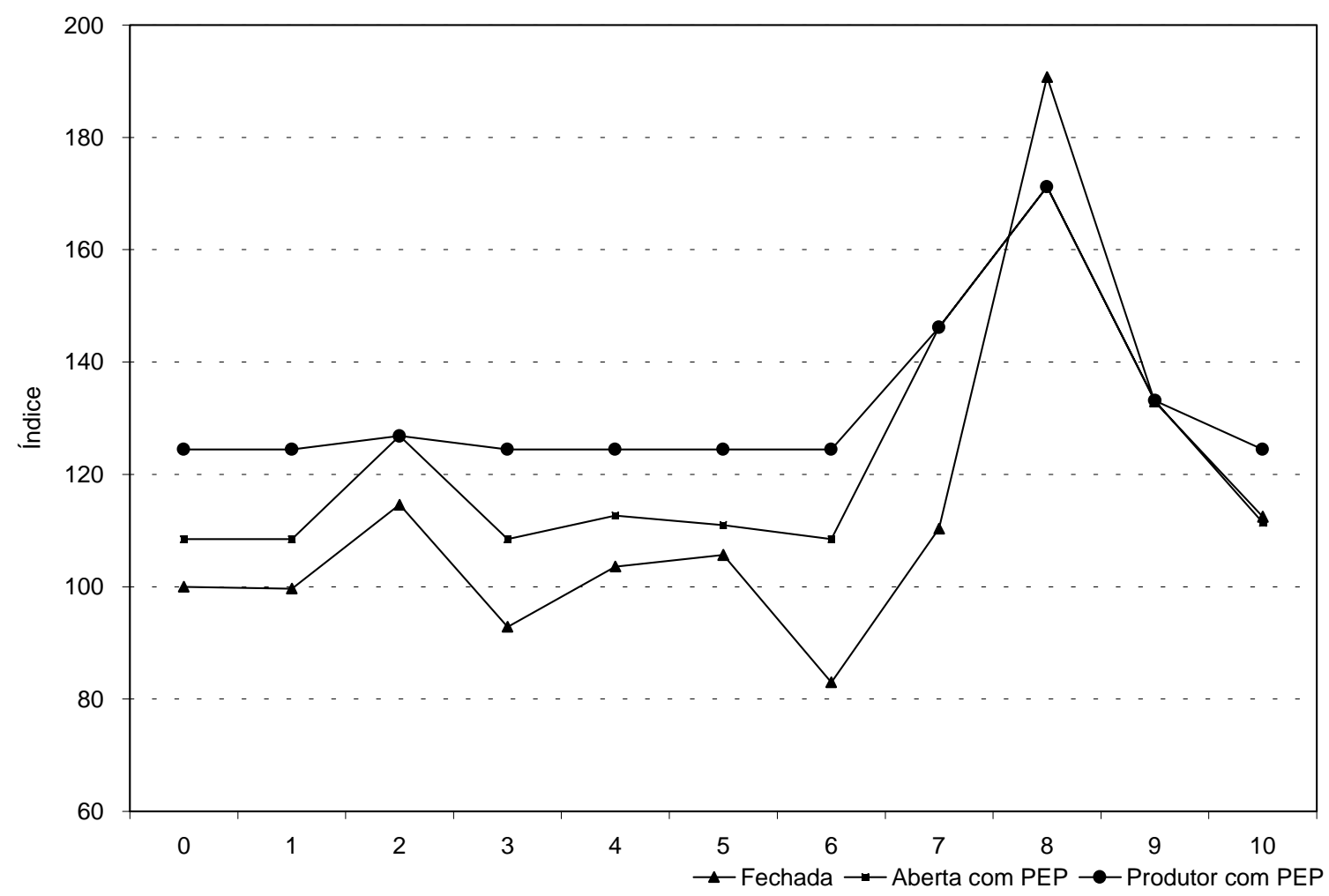

Figura 29 - Índice do preço anual de milho $\left(P_{t}\right)$, para os modelos de economia fechada sem intervenção e aberta com intervenção via PEP, sequiência 1.

Outra análise interessante é quanto ao comportamento do preço esperado sob as duas condições. A Figura 30 apresenta estes valores que, por sua vez, explicam o comportamento do estoque e da área plantada em cada ano. Observe como a variabilidade do preço esperado na economia aberta é muito menor do que no caso de economia fechada. A razão, já discutida anteriormente, é a faixa de preços imposta pelos preços internacionais, que são parâmetros no modelo. 


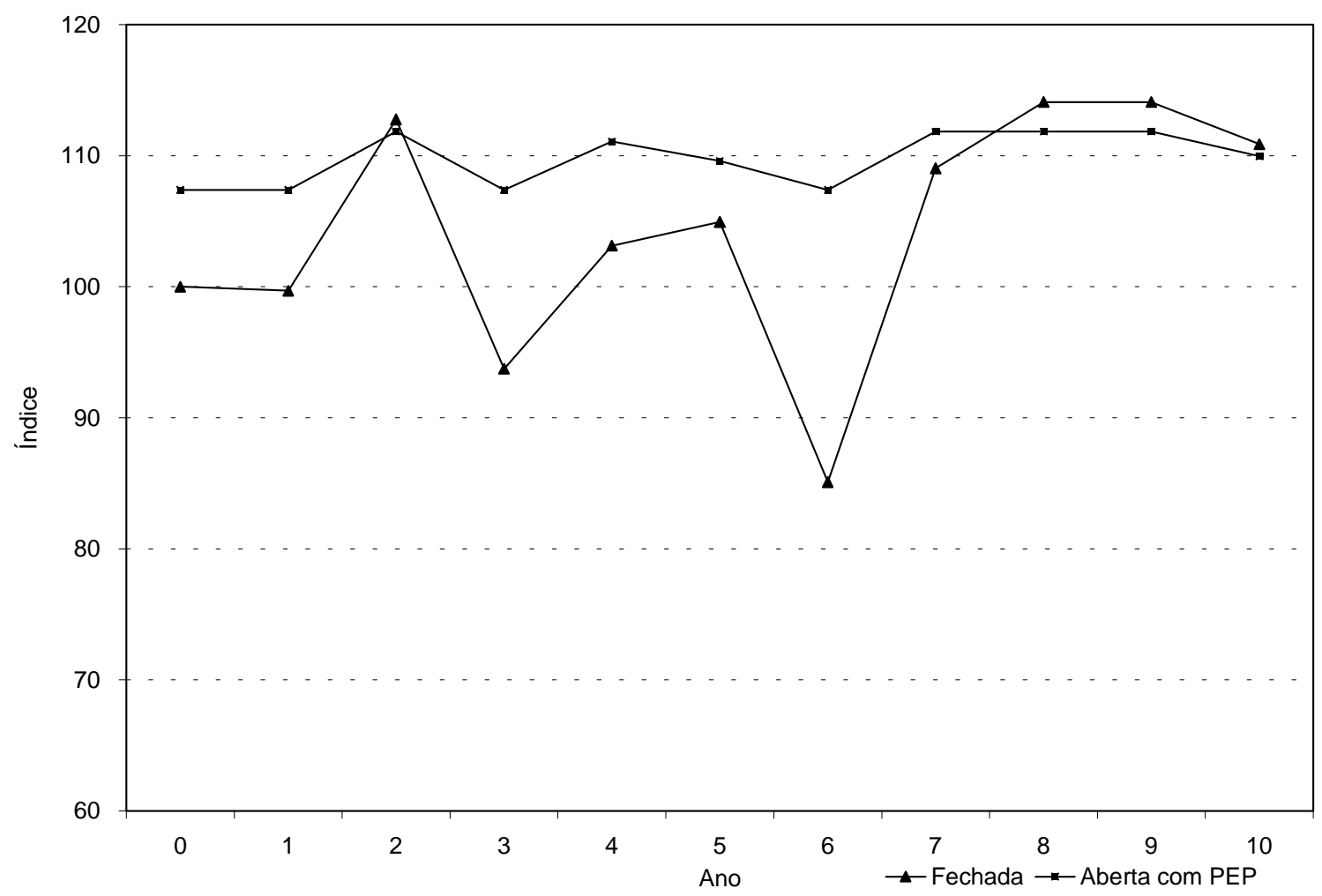

Figura 30 - Índice do preço anual esperado de milho $\left(E_{t} P_{t+1}\right)$, para os modelos de economia fechada sem intervenção e aberta com intervenção via PEP, sequiência 1.

Os resultados da simulação 2, para o mercado fechado e sem intervenção são apresentados na Tabela 15. Por uma combinação sucessiva de choques negativos de oferta e/ou positivos de demanda, a partir do ano 1 não se formam estoques pois os preços correntes são suficientemente altos para inviabilizá-los. Com menos disponibilidade, o consumo diminui e há uma seqüência de preços altos. A área plantada supera 13 milhões de hectares em dois dos dez anos simulados. O preço chega a se aproximar de 359 reais por tonelada no ano dez e nada há a fazer, pois não há reservas e não é possível importar. Os resultados ajudam a compreender o que Townsend (1977) prova, ou seja, de que uma seqüência de safras pequenas esgota os estoques do governo e os preços superam os limites desejados por políticas de estabilização. 
Tabela 15. Valores das variáveis endógenas, em mil toneladas, para o modelo de economia fechada sem intervenção, para a seqüência 2 .

\begin{tabular}{rrrrrrrr}
\hline & Estoque & Produção & Disponibilidade & Consumo & Estoque & $P_{\mathrm{t}}$ & $A_{t}$ \\
Ano & Inicial & $\left(H_{t}\right)$ & $\left(S_{t}\right)$ & $\left(D_{t}\right)$ & $\begin{array}{c}\text { Final } \\
(\mathrm{R} \$ \mathrm{t})\end{array}$ & $($ Mil ha) \\
& $\left(I_{t-1}\right)$ & & & & $\left(I_{t}\right)$ & & \\
\hline 0 & $5.000,0$ & $35.000,0$ & $40.000,0$ & $36.920,7$ & $3.079,3$ & 175,2 & $12.936,0$ \\
1 & $3.079,3$ & $21.974,6$ & $25.321,3$ & $25.321,3$ & 0,0 & 327,2 & $12.993,0$ \\
2 & 0,0 & $33.458,7$ & $32.943,0$ & $32.943,0$ & 0,0 & 227,3 & $12.993,0$ \\
3 & 0,0 & $27.499,8$ & $26.914,8$ & $26.914,8$ & 0,0 & 306,3 & $13.005,6$ \\
4 & 0,0 & $27.955,1$ & $27.735,3$ & $27.735,3$ & 0,0 & 295,6 & $12.993,0$ \\
5 & 0,0 & $34.124,1$ & $33.799,1$ & $33.799,1$ & 0,0 & 216,1 & $12.993,0$ \\
6 & 0,0 & $31.112,1$ & $32.188,3$ & $32.188,3$ & 0,0 & 237,2 & $12.993,2$ \\
7 & 0,0 & $23.424,5$ & $24.890,0$ & $24.890,0$ & 0,0 & 332,8 & $12.993,1$ \\
8 & 0,0 & $28.265,9$ & $29.788,3$ & $29.788,3$ & 0,0 & 268,7 & $12.995,2$ \\
9 & 0,0 & $25.188,7$ & $24.962,8$ & $24.962,8$ & 0,0 & 331,9 & $12.997,0$ \\
10 & 0,0 & $24.007,2$ & $22.900,6$ & $22.900,6$ & 0,0 & 358,9 & $13.005,9$ \\
\hline
\end{tabular}

${ }^{1}$ Inclui os choques de demanda

Nestas circunstâncias, a política de subsídio do governo não é utilizada porque o preço de mercado supera o preço mínimo, ao menos para o valor médio histórico utilizado nesta análise. Se o governo estabelecer um preço mínimo alto em relação ao mercado pode gastar em subsídio mesmo para uma situação como a seqüência 2. O preço mínimo ainda terá influência sobre a área plantada que será maior do que no caso anterior pois o produtor sabe que não receberá menos do que o valor estabelecido pelo governo. O reflexo da ação dos produtores é que a disponibilidade interna é, via de regra, maior neste modelo e os preços de mercado são menores (embora em pequena 
proporção) e o consumo é maior. Os resultados deste modelo são apresentados na Tabela 16.

Tabela 16. Valores das variáveis endógenas, em mil toneladas, para o modelo de economia fechada com intervenção através de PEP, para a sequiência 2.

\begin{tabular}{|c|c|c|c|c|c|c|c|c|}
\hline Ano & $\begin{array}{c}\text { Estoque } \\
\text { Inicial } \\
\left(I_{t-1}\right)\end{array}$ & $\begin{array}{c}\text { Produção } \\
\left(H_{t}\right)\end{array}$ & $\begin{array}{c}\text { Disponi- } \\
\text { bilidade }^{1} \\
\left(S_{t}\right)\end{array}$ & $\begin{array}{c}\text { Consumo } \\
\left(D_{t}\right)\end{array}$ & $\begin{array}{c}\text { Estoque } \\
\text { Final } \\
\left(I_{t}\right)\end{array}$ & $\begin{array}{c}P_{\mathrm{t}} \\
(\mathrm{R} \$ / \mathrm{t})\end{array}$ & $\begin{array}{c}\theta_{t} \\
(\mathrm{R} \$ / \mathrm{t})\end{array}$ & $\begin{array}{c}A_{t} \\
\text { (Mil ha) }\end{array}$ \\
\hline 0 & $5.000,0$ & $35.000,0$ & $40.000,0$ & $36.923,8$ & $3.076,2$ & 175,19 & 42,81 & $12.913,8$ \\
\hline 1 & $3.076,2$ & $21.936,8$ & $25.280,5$ & $25.280,5$ & 0,0 & 327,72 & 0,00 & 12.994, \\
\hline 2 & 0,0 & $33.462,9$ & $32.947,2$ & $32.947,2$ & 0,0 & 227,28 & 0,00 & $12.994,7$ \\
\hline 3 & 0,0 & $27.503,2$ & $26.918,3$ & $26.918,3$ & 0,0 & 306,27 & 0,00 & $13.113,6$ \\
\hline 4 & 0,0 & $28.187,2$ & $27.967,3$ & $27.967,3$ & 0,0 & 292,52 & 0,00 & 12.994, \\
\hline 5 & 0,0 & $34.128,4$ & $33.803,4$ & $33.803,4$ & 0,0 & 216,07 & 1,93 & $12.994,7$ \\
\hline 6 & 0,0 & $31.116,1$ & $32.192,3$ & $32.192,3$ & 0,0 & 237,18 & 0,00 & $12.996,2$ \\
\hline 7 & 0,0 & $23.430,0$ & $24.895,5$ & $24.895,5$ & 0,0 & 332,77 & 0,00 & 12.995 \\
\hline 8 & 0,0 & $28.270,9$ & $29.793,3$ & $29.793,3$ & 0,0 & 268,60 & 0,00 & $13.015,8$ \\
\hline 9 & 0,0 & $25.228,6$ & $25.002,6$ & $25.002,6$ & 0,0 & 331,36 & 0,00 & $13.032,4$ \\
\hline 10 & 0,0 & $24.072,6$ & $22.965,9$ & $22.965,9$ & 0,0 & 358,05 & 0,00 & 13.114, \\
\hline
\end{tabular}

${ }^{1}$ Inclui os choques de demanda

Os valores resultantes da seqüência 2 para o mercado aberto sem intervenção estão na Tabela 17. A principal diferença, naturalmente, é que a escassez é reduzida através de compras externas. O limite inferior do consumo interno é dado pelo volume de produto que eleva o preço interno até a paridade de importação. Os resultados mostram que haverá importação em metade do período. Observe que, ao contrário das exportações, o país importa volumes pequenos para completar o abastecimento interno 
como no ano três. Os preços são, obviamente, mais baixos do que na situação anterior o que beneficiaria os consumidores internos.

Tabela 17. Valores das variáveis endógenas, em mil toneladas, para o modelo de economia aberta sem intervenção, para a seqüência 2.

\begin{tabular}{|c|c|c|c|c|c|c|c|c|}
\hline Ano & $\begin{array}{c}\text { Estoque } \\
\text { Inicial } \\
\left(I_{t-1}\right)\end{array}$ & $\begin{array}{c}\text { Produção } \\
\left(H_{t}\right)\end{array}$ & $\begin{array}{l}\text { Impor- } \\
\text { tação } \\
\left(M_{t}\right)\end{array}$ & $\begin{array}{c}\text { Disponi- } \\
\text { bilidade }^{1} \\
\qquad\left(S_{t}\right)\end{array}$ & $\begin{array}{l}\text { Consumo } \\
\qquad\left(D_{t}\right)\end{array}$ & $\begin{array}{c}\text { Expor- } \\
\text { tação } \\
\left(M_{t}\right)\end{array}$ & $\begin{array}{c}\text { Estoque } \\
\text { Final } \\
\left(I_{t}\right)\end{array}$ & $P_{\mathrm{t}}$ \\
\hline & $5.000,0$ & $35.000,0$ & 0,0 & $40.000,0$ & $35.793,3$ & $3.028,6$ & $1.178,2$ & $190,0012.967,2$ \\
\hline 1 & $1.178,2$ & $22.027,8$ & $3.923,3$ & $27.396,7$ & $27.396,7$ & 0,0 & 0,0 & $300,0012.984,5$ \\
\hline 2 & 0,0 & $33.436,6$ & 0,0 & $32.921,0$ & $32.921,0$ & 0,0 & 0,0 & $227,6312.984,4$ \\
\hline 3 & 0,0 & $27.481,4$ & 500,3 & $27.396,7$ & $27.396,7$ & 0,0 & 0,0 & $300,0012.984,5$ \\
\hline 4 & 0,0 & $27.909,6$ & 0,0 & $27.689,8$ & $27.689,8$ & 0,0 & 0,0 & $296,1612.984,5$ \\
\hline 5 & 0,0 & $34.101,6$ & 0,0 & $33.776,7$ & $33.776,7$ & 0,0 & 0,0 & $216,4212.984,5$ \\
\hline 6 & 0,0 & $31.091,6$ & 0,0 & $32.167,8$ & $32.167,8$ & 0,0 & 0,0 & $237,5012.984,5$ \\
\hline 7 & 0,0 & $23.408,8$ & $2.522,4$ & $27.396,7$ & $27.396,7$ & 0,0 & 0,0 & $300,0012.984,4$ \\
\hline 8 & 0,0 & $28.246,8$ & 0,0 & $29.769,2$ & $29.769,2$ & 0,0 & 0,0 & $268,9212.984,4$ \\
\hline 9 & 0,0 & $25.167,6$ & $2.455,0$ & $27.396,7$ & $27.396,7$ & 0,0 & 0,0 & $300,0012.984,4$ \\
\hline 10 & 0,0 & $23.983,8$ & $4.519,6$ & $27.396,7$ & $27.396,7$ & 0,0 & 0,0 & $300,0012.984,4$ \\
\hline
\end{tabular}

${ }^{1}$ Inclui os choques de demanda

Para o mercado aberto com intervenção através de PEP, a sequiência de choques negativos de oferta e/ou positivos de oferta leva aos valores contidos na Tabela 18. Observe que, exceto na primeira importação que ocorre no ano 1 , as compras externas são menores no modelo com subsídio ao produtor. Quando não há importação, o consumo também é maior e os preços são mais baixos. As razões são as mesmas discutidas para o mercado fechado com intervenção. 
Tabela 18. Valores das variáveis endógenas, em mil toneladas, para o modelo de economia aberta com intervenção através de PEP, para a seqüência 2.

\begin{tabular}{|c|c|c|c|c|c|c|c|c|c|}
\hline Ano & $\begin{array}{c}\text { Estoque } \\
\text { Inicial } \\
\left(I_{t-1}\right)\end{array}$ & $\begin{array}{c}\text { Produção } \\
\qquad\left(H_{t}\right)\end{array}$ & $\begin{array}{l}\text { Impor- } \\
\text { tação } \\
\left(M_{t}\right)\end{array}$ & $\begin{array}{c}\text { Disponi- } \\
\text { bilidade }^{1} \\
\left(S_{t}\right)\end{array}$ & $\begin{array}{l}\text { Consumo } \\
\left(D_{t}\right)\end{array}$ & $\begin{array}{c}\text { Expor- } \\
\text { tação } \\
\left(M_{t}\right)\end{array}$ & $\begin{array}{c}\text { Estoque } \\
\text { Final } \\
\left(I_{t}\right)\end{array}$ & $\begin{array}{cc}P_{\mathrm{t}} & \theta_{t} \\
(\mathrm{R} \$ / \mathrm{t}) & (\mathrm{R} \$ / \mathrm{t})\end{array}$ & $A_{t}$ \\
\hline 0 & $5.000,0$ & $35.000,0$ & 0,0 & $40.000,0$ & $35.793,3$ & $3.028,6$ & $1.178,2$ & $190,0028,00$ & $12.965,2$ \\
\hline 1 & $1.178,2$ & $22.020,7$ & $3.930,4$ & $27.396,7$ & $27.396,7$ & 0,0 & 0,0 & $300,00-$ & $12.985,8$ \\
\hline 2 & 0,0 & $33.440,0$ & 0,0 & $32.924,3$ & $32.924,3$ & 0,0 & 0,0 & $227,58-$ & $12.987,8$ \\
\hline 3 & 0,0 & $27.488,8$ & 492,9 & $27.396,7$ & $27.396,7$ & 0,0 & 0,0 & $300,00-$ & $12.985,8$ \\
\hline 4 & 0,0 & $27.912,4$ & 0,0 & $27.692,6$ & $27.692,6$ & 0,0 & 0,0 & $296,12-$ & $12.985,8$ \\
\hline 5 & 0,0 & $34.105,0$ & 0,0 & $33.780,1$ & $33.780,1$ & 0,0 & 0,0 & $216,371,63$ & $12.986,3$ \\
\hline 6 & 0,0 & $31.095,9$ & 0,0 & $32.172,1$ & $32.172,1$ & 0,0 & 0,0 & $237,44-$ & $12.985,9$ \\
\hline 7 & 0,0 & $23.411,3$ & $2.519,9$ & $27.396,7$ & $27.396,7$ & 0,0 & 0,0 & $300,00-$ & $12.987,8$ \\
\hline 8 & 0,0 & $28.254,4$ & 0,0 & $29.776,8$ & $29.776,8$ & 0,0 & 0,0 & $268,82-$ & $12.987,8$ \\
\hline 9 & 0,0 & $25.174,4$ & $2.448,2$ & $27.396,7$ & $27.396,7$ & 0,0 & 0,0 & $300,00-$ & $12.987,8$ \\
\hline 10 & 0,0 & $23.990,2$ & $4.513,1$ & $27.396,7$ & $27.396,7$ & 0,0 & 0,0 & $300,00-$ & $12.987,8$ \\
\hline
\end{tabular}

${ }^{1}$ Inclui os choques de demanda

A exemplo das figuras apresentadas para a seqüência 1, são apresentadas algumas figuras equivalentes para a sequência 2. O índice 100 continua definido como o valor da variável endógena no ano zero para o modelo de mercado fechado sem intervenção. A disponibilidade total (interna mais importações) está na Figura 31 que é praticamente igual ao comportamento do consumo, exceto no ano zero quando parte é estocada. O preço tem comportamento exatamente inverso ao da disponibilidade e consumo e pode ser visualizado na Figura 32. É claro que no mercado aberto os valores são menores nos anos em que há importação. 


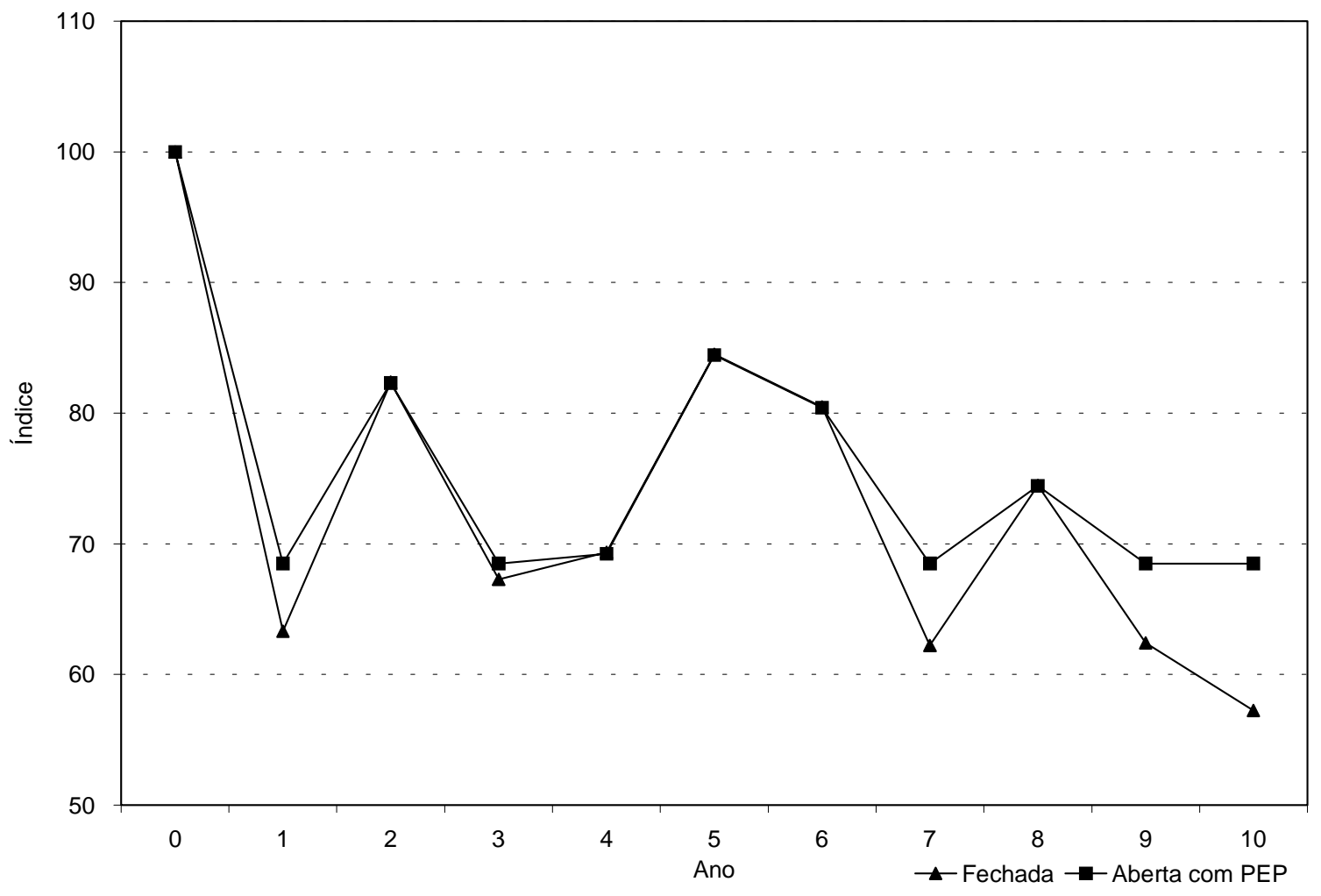

Figura 31 - Índice da disponibilidade total de milho $\left(S_{t}\right)$, para os modelos de economia fechada sem intervenção e aberta com intervenção via PEP, seqüência 2.

Como não há formação de estoques nas condições representadas pela sequencia 2, a função do preço esperado se transforma numa linha reta para ambos os modelos. A diferença está no valor desta expectativa, como pode ser deduzido a partir das Figuras 10 e 19 na seção 5.1. Para o mercado fechado sem intervenção o preço esperado sem estoques é de $\mathrm{R} \$ 228,64 /$ tonelada e de $\mathrm{R} \$ 224,15$ para o mercado aberto. É por isto que a área plantada no mercado fechado é maior do que para o mercado aberto. 


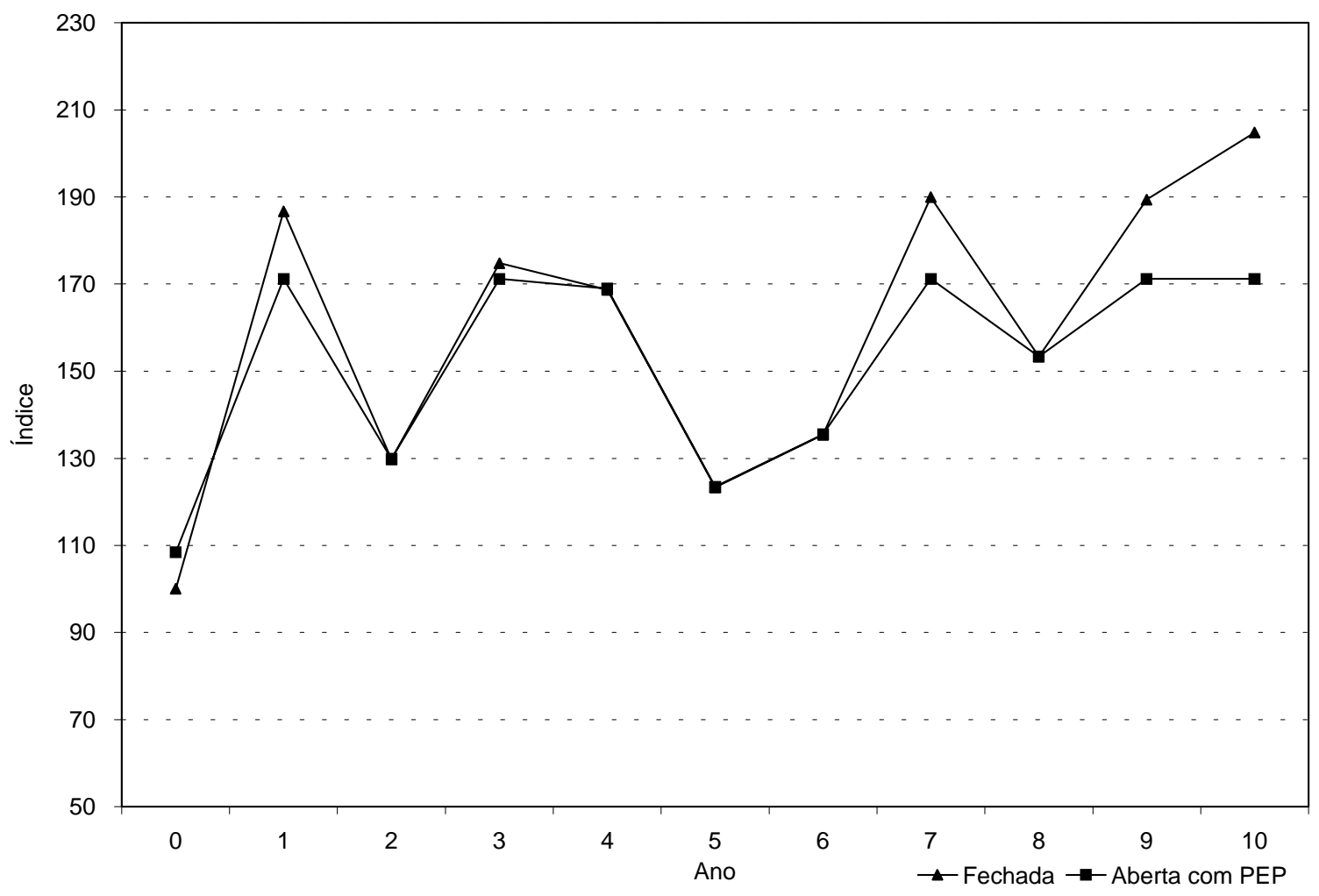

Figura 32 - Índice do preço anual de milho $\left(P_{t}\right)$, para os modelos de economia fechada sem intervenção e aberta com intervenção via PEP, seqüência 2.

O mérito do estudo do mercado de um produto agrícola armazenável através de um modelo armazenamento com expectativa racional é compreender o papel dos estoques nestes mercados e permitir simulações de diversos cenários. Estes modelos podem ser utilizados de diversas maneiras, inclusive, por exemplo, para estudos prévios da determinação do preço mínimo do produto. A diferença deste estudo com relação aos trabalhos anteriores como Lima \& Barros (1996) e outros é considerar o caráter dinâmico do armazenamento e expectativas racionais em relação ao futuro.

Algumas das limitações do estudo foram sendo apontadas ao longo das análises tais como os preços externos fixos. Preços externos variáveis podem ser 
incluídos, por exemplo, como em Makki et al., (1996), considerando o país como importante no mercado internacional. Pesquisas futuras neste tipo de análise para o mercado de milho devem avançar no sentido de dividir o país em regiões e levar em conta o comércio inter-regional. Outra possibilidade interessante é considerar o estoque dentro do ano e intra-anos como em Lowry et al. (1987). A subdivisão do ano safra em meses ou trimestres, por exemplo, permitiria separar a safra de verão da safrinha, ou seja, duas produções dentro do ano agrícola. Apesar do volume relativamente pequeno a safrinha vem ganhando importância nos últimos anos e altera as expectativas dos agentes de mercado.

A subdivisão do ano em períodos menores e a regionalização do mercado brasileiro de milho não foram realizadas neste estudo por diversas razões. A principal é a falta de dados para estimação de funções regionais de oferta de área funções regionais e trimestrais para a demanda para consumo. Para análises mais detalhadas é preciso antes um trabalho de obtenção destas funções que fica, também, como sugestão de pesquisa. 


\section{CONCLUSÕES}

Este estudo se propôs a analisar o armazenamento de milho no Brasil nas condições atuais de mercado aberto levando em conta a influência da Política de Garantia de Preços Mínimos atuando através do mecanismo de Prêmio para Escoamento de Produto (PEP). Para a atingir este objetivo foi empreendido um esforço pioneiro para desenvolver este modelo, adaptando os modelos econômicos de armazenamento mais recentes da literatura mundial, e criando as condições necessárias para representar o mercado brasileiro, não encontradas em outros estudos.

A teoria econômica do papel dos estoques nos mercados de produtos agrícolas sofreu mudanças importantes nas décadas de 80 e 90 que ainda não haviam sido consideradas nos estudos brasileiros. O caráter dinâmico do armazenamento é uma de suas principais características e, até então, não havia recebido a consideração teórica devida. Ao longo deste estudo foi possível perceber quão importante é o papel do estoque nos preços de equilíbrio, na quantidade de produto consumida a cada ano, na tomada de decisão dos produtores rurais quanto ao plantio, na relação dos preços entre dois períodos. Este é o primeiro estudo no Brasil a analisar o armazenamento sob esta nova ótica teórica permitindo, inclusive, avaliar o efeito da abertura do mercado e da intervenção através de subsídio de preço ao produtor.

A natureza econômica dinâmica do armazenamento exige a teoria do controle como base teórica e, como conseqüência, a busca de uma função como solução do modelo, a política ótima ou regra de armazenamento. Como não é possível emprestar produto do futuro para o consumo corrente, ou seja, o armazenamento não pode ser 
negativo, resulta em que a política ótima não é uma função linear. A dependência da produção agrícola em relação ao clima insere um componente estocástico no modelo. $\mathrm{O}$ fato de que a função do preço esperado, um elemento crucial no problema, não ser conhecida a priori insere nova dificuldade ao estudo.

Por ser um problema de controle, estocástico, com restrição na variável resposta (estoque não negativo), o modelo de armazenamento não possui solução algébrica. Por isso, o modelo é estimado através de métodos numéricos, especificamente através da programação dinâmica estocástica. Como a função do preço esperado não é conhecida, é preciso aproximá-la através de outro método numérico, a aproximação de funções através de polinômios.

Cada estudo voltado ao armazenamento nos moldes deste trabalho utiliza diferentes algoritmos para solucionar estes modelos. Não foi encontrado na literatura nenhum algoritmo adequado à solução dos modelos propostos. Assim, os algoritmos apresentados no capítulo quatro foram desenvolvidos para este estudo. Da mesma forma, não foram encontradas rotinas para programas específicos que permitissem estimar os modelos. Investigando a literatura sobre armazenamento, os procedimentos exatos dos autores para solucionar os modelos não são suficientemente claros. A exceção é Wright \& Williams (1991), que serviu de base para a elaboração dos algoritmos para os quatro modelos. Dadas estas circunstâncias, os algoritmos foram executados em planilha eletrônica e, qualquer pesquisador interessado, poderá obter os mesmos resultados do estudo a partir deste recurso simples. Esta é outra contribuição deste estudo. Qualquer modelo semelhante aos utilizados poderá ser estimado pelos mesmos procedimentos.

Os modelos econômicos desenvolvidos neste estudo podem ser utilizados para quaisquer produtos agrícolas armazenáveis com produção anual, tais como arroz, trigo e algodão. Em princípio qualquer política de preços vinculada a estes mercados pode ser incorporada aos modelos permitindo avaliar seus impactos sobre o mercado como um todo. 
Os resultados analíticos dos modelos mostraram que, dados os parâmetros estabelecidos, a situação de economia aberta com subsídio aos produtores através do Prêmio para Escoamento de Produto (PEP) leva a preços menores no mercado brasileiro e gastos do governo com subsídios também menores quando comparados à situação de economia fechada com intervenção através do PEP. Nestas análises, os valores utilizados para o preço mínimo e de paridade de exportação e importação são médias históricas do período 1986 a 2000. O preço mínimo, nestas circunstâncias, é maior do que o preço de paridade de exportação e inferior ao de importação.

A abertura ao comércio exterior tem forte influência sobre o equilíbrio dinâmico do mercado brasileiro de milho, tanto sobre os preços internos quanto na formação de estoques. Com mercado aberto, um país pequeno no mercado internacional, a tem sua formação de estoques delegada ao resto do mundo e o país dependerá das compras externas para compensar os choques de oferta e demanda internos. Os resultados sugerem que, quanto maior o preço mínimo, maior a oferta interna o que pode tornar o país um crescente exportador. Como o PEP é um subsídio de preço ao produtor, sua influência se dá sobre a área plantada, que será maior quanto maior preço mínimo. Quanto mais excedente de produto houver no mercado, maior o volume a ser exportado. Atualmente o Brasil é um pequeno exportador de milho, mas dependendo do valor do preço mínimo e dos preços externos, o país pode passar a exportar volumes mais expressivos. Tal política poderia receber críticas internacionais, em função dos acordos comerciais em andamento.

Um preço mínimo inferior ao preço de paridade de exportação torna a política inócua, pois os preços esperados serão sempre superiores ao preço mínimo. A determinação dos níveis de preços mínimos para os produtos amparados pela Política de Garantia de Preços Mínimos com mercados abertos exige do governo estudos para diferentes cenários. Uma das muitas possibilidades que os modelos desenvolvidos neste estudo permite é incluir uma restrição orçamentária ao governo para a execução da 
política para cada produto. Sob esta restrição é possível estimar os valores de equilíbrio das variáveis endógenas do modelo. Estas e outras análises podem ser feitas buscando os novos equilíbrios para mudanças nos parâmetros dos modelos tais como o custo de armazenamento e a taxa de juros. Os resultados analíticos mostram a consistência teórica dos modelos e abrem um amplo leque de situações em que esta modelagem pode ser utilizada para estimar as respostas do mercado a estas mudanças.

Os próximos passos para o estudo de mercados de produtos agrícolas anuais e armazenáveis no Brasil incluem a regionalização e, dependendo do interesse, da subdivisão do ano agrícola em períodos menores, permitindo a análise do estoque entre anos e intra-anos. 


\section{REFERÊNCIAS BIBLIOGRÁFICAS}

ARGENTINA. Secretaria de Agricultura, Ganadería y Pesca. Séries históricas. http://sagpya.mecon.gov.ar/agricu/series.htm (10 Out. 2000)

BARROS, G.S.A.C.; GUIMARÃES, V.D.A. Análise da eficácia da política de preços para arroz e milho por meio de um modelo econômico de expectativas racionais. Revista de Economia e Sociologia Rural, v.36, n.4, p.113-133, 1998.

BARROS, G.S.A.C.; BERES, N.A.; MALHEIROS, P.C.F. Gastos públicos na agricultura: tendências e prioridades. Estudos de Política Agrícola, n.2, p.7-20, dez.1993.

BRENNAN, M.J. The supply of storage. American Economic Review, v.48, n.1, p.5072, Mar.1958.

COMPANHIA DE FINANCIAMENTO DA PRODUÇÃO. Regras de intervenção. Brasília, 1989. 23p.

COMPANHIA NACIONAL DE ABASTECIMENTO. Indicadores da Agropecuária. Brasília, 1992-2001

COMPANHIA NACIONAL DE ABASTECIMENTO. Cadastro nacional de unidades armazenadoras. Brasília, 1996. 326p. 
COMPANHIA NACIONAL DE ABASTECIMENTO. Regulamento para oferta de prêmio para escoamento de produto - PEP. http://conab.gov.br/comercializacao/regulamentopep.doc (06 Jun. 2000a)

COMPANHIA NACIONAL DE ABASTECIMENTO. Regulamento de venda de contratos de opção de venda de produtos agropecuários. http://conab.gov.br/comercializacao/reg 00197.doc (06 Jun. 2000b)

CRISTIANO, L.J.; FISHER, J.D.M. Algorithms for solving dynamic models with occasionally binding constraints. Journal of Economic Dynamics and Control, v.24, n.8, p.1179-1232, Jul. 2000.

DELGADO, G.C. Uma metodologia para determinação do preço mínimo. Brasília: Comissão de Financiamento da Produção, 1978. 92p. (Coleção Análise e Pesquisa, 3)

ESTADOS UNIDOS. Department of Agriculture. Economics and Statistics System. PS\&D View. http://usda.mannlib.cornell.edu/data-sets/international/93002 (10 Set. 2000).

FUNDAÇÃO INSTITUTO BRASILEIRO DE GEOGRAFIA E ESTATÍSTICA. Pesquisa nacional de orçamentos familiares. http://www.sidra.ibge.gov.br (11 Nov. 2000).

FUNDAÇÃO GETÚLIO VARGAS. Competitividade do sistema agroindustrial do milho. Rio de Janeiro, 1998. 159p.

GARDNER, B. Optimal stockpiling of grain. Lexington: Lexington Books, 1979. 175p.

GARDNER, B.; LÓPEZ, R. Interest-rate subsidies in price stabilization. American Journal of Agricultural Economics, v.78, n.3, p.508-516, 1996. 
GLAUBER, J.; HELMBERGER, P.; MIRANDA, M. Four approaches to commodity market stabilization: a comparative analysis. American Journal of Agricultural Economics, v.71, n.2, p.326-337, 1989.

GUIMARÃES, V.D.A. Comercialização e transmissão de preços de carne de frango no Estado de São Paulo. Piracicaba, 1990. 119p. Dissertação (MS) - Escola Superior de Agricultura “Luiz de Queiroz”, Universidade de São Paulo.

GUSTAFSON, R.L. Carryover levels for grain: a method for determining amounts that are optimal under specified conditions. Washington: USDA, 1958. 92p. (Technical Bulletin, 1178)

HELMBERGER, P.; WEAVER, G. Welfare implications of commodity storage under uncertainty. American Journal of Agricultural Economics, v.54, n.4, p.63-96, 1977.

INDICADORES DA AGROPECUÁRIA. Brasília: Companhia Nacional de Abastecimento - CONAB. / Vários números /

JUDD, K.L. Computational economics and economic theory: substitutes or complements? Journal of Economic Dynamics and Control, v.21, n.6, p.907-942, Jun 1997.

JUDD, K.L. Numerical methods in economics. Cambridge: The MIT Press, 1999. 633p.

KALDOR, N. Speculation and economic stability. Review of Economic Studies, v.7, n.1, p.1-27, Oct.1939.

KENNEDY, J.O.S. Dynamic programming: applications to agriculture and natural resources. London: Elsevier Applied Science, 1986. 341p. 
LENCE, S.H.; HAYES, D.J. U.S. farm policy and the variability of commodity prices and farm revenues. Ames: Iowa State University, 2000. 36p. (Working Paper, 00-WP 239)

LIMA, S.M.A; BARROS, G.S.A.C. Eficácia da política de preços mínimos nos anos 80 e 90: o caso do milho no Brasil. Revista Brasileira de Economia, v.50, n.2, p.161-178, 1996.

LOWRY, M.; GLAUBER, J.; MIRANDA, M.; HELMBERGER, P. Pricing and storage of field crops: a quarterly model applied to soybeans. American Journal of Agricultural Economics, v.69, n.4, p.740-749, Nov.1987.

MAKKI, S.S.; TWEETEN, L.G.; MIRANDA, M.J. Wheat storage and trade in an efficient global market. American Journal of Agricultural Economics, v.78, n.4, p.879-890, Nov.1996.

MASSEL, B.F. Price stabilization and welfare. Quarterly Journal of Economics, v.83, n.2, p.284-298, 1969.

MCNEW, K.; GARDNER, B. Income taxes, price variability and storage. American Journal of Agricultural Economics, v.81, n.3, p.544-552, 1999.

MELLO, F.H. A liberalização comercial e a agricultura familiar no Brasil. São Paulo: USP, 2000. 62p.

MIRANDA, M.J.; FACKLER, P.L. Applied computational economics and finance. http://www4.ncsu.edu/ pfackler/compecon/compecon.pdf (12 Mai. 2001). 
MIRANDA, M.J.; GLAUBER, J.W. Estimation of dynamic nonlinear rational expectations models for primary commodity markets with private and government stockholding. Review of Economics and Statistics, v.75, n.3, p.463-470, Aug.1993.

MIRANDA, M.J.; HELMBERGER, P.B. The effects of commodity price stabilization programs. American Economic Review, v.78, n.1, p.46-57, Mar.1988.

MUTH, J.F. Rational expectations and the theory of price movements. Econometrica, v.29, n.2, p.315-335, Apr.1961.

NEWBERY, D.M.G; STIGLITZ, J.E . The theory of commodity price stabilization rules: welfare impacts and supply responses. Economic Journal, v.89, p.799-817. Dec. 1979.

OI, W.Y. The desirability of price instability under perfect competition. Econometrica, v.29, n.2, p.58-62, Apr. 1961.

OLIVEIRA, J.C.; ALBUQUERQUE, C.P. Avaliação da política de preços mínimos. Brasília: Comissão de Financiamento da Produção, 1977. 27p. (Coleção Análise e Pesquisa, 2)

PARANÁ. Secretaria de Agricultura e Abastecimento. Departamento de Economia Rural. Acompanhamento conjuntural. Curitiba: SEAB, 1982-2001.

REUTLINGER, S. A simulation model for evaluating worldwide buffer stocks of wheat. American Journal of Agricultural Economics, v.58, n.1, p.1-12, Feb.1976.

SILBERBERG, E. The structure of economics: a mathematical analysis. 2.ed. New York: McGraw-Hill, 1990. 686p. 
TOWNSEND, R.M. The eventual failure of price fixing schemes. Journal of Economic Theory, v.14, p.190-199, 1977.

TURNOVSKY, S.J. Price expectations and the welfare grains from price stabilization. American Journal of Agricultural Economics, v.56, n.4, p.706-716, Nov.1974.

WAUGH, F.V. Does the consumer gain from price instability? Quarterly Journal of Economics, v.58, n.2, p.602-614, Aug, 1944.

WORKING, H. Theory of the inverse carrying charge in futures markets. Journal of Farm Economics, v.30, n.1, p.1-28, Feb.1948.

WRIGHT, B.D.; WILLIAMS, J.C. The economic role of commodity storage. Economic Journal, v.92, n.367, p.596-616, Sep.1982.

WRIGHT, B.R.; WILLIAMS, J.C. The welfare effects of the introduction of storage. Quarterly Journal of Economics, v.99, n.1, p.169-182, Feb.1984.

WRIGHT, B.R.; WILLIAMS, J.C. Storage and commodity markets. New York: Cambridge University Press, 1991. 502p. 